\title{
Whole Fruits and Fruit Fiber Emerging Health Effects
}

\author{
Mark L. Dreher \\ Nutrition Science Solutions, LLC, Wimberley, 78676 TX, USA; mdreher@nutriscisolutions.com or nss3@sbcglobal.net; \\ Tel.: +1-512-847-9182
}

Received: 24 October 2018; Accepted: 22 November 2018; Published: 28 November 2018

\begin{abstract}
Less than $10 \%$ of most Western populations consume adequate levels of whole fruits and dietary fiber with typical intake being about half of the recommended levels. Evidence of the beneficial health effects of consuming adequate levels of whole fruits has been steadily growing, especially regarding their bioactive fiber prebiotic effects and role in improved weight control, wellness and healthy aging. The primary aim of this narrative review article is to examine the increasing number of health benefits which are associated with the adequate intake of whole fruits, especially fruit fiber, throughout the human lifecycle. These potential health benefits include: protecting colonic gastrointestinal health (e.g., constipation, irritable bowel syndrome, inflammatory bowel diseases, and diverticular disease); promoting long-term weight management; reducing risk of cardiovascular disease, type 2 diabetes and metabolic syndrome; defending against colorectal and lung cancers; improving odds of successful aging; reducing the severity of asthma and chronic obstructive pulmonary disease; enhancing psychological well-being and lowering the risk of depression; contributing to higher bone mineral density in children and adults; reducing risk of seborrheic dermatitis; and helping to attenuate autism spectrum disorder severity. Low whole fruit intake represents a potentially more serious global population health threat than previously recognized, especially in light of the emerging research on whole fruit and fruit fiber health benefits.
\end{abstract}

Keywords: prebiotic effects; gastrointestinal health; weight management; cardiovascular disease; diabetes; metabolic syndrome; successful aging; cancer; psychological well-being; depression; asthma; bone mineral density

\section{Introduction}

The beneficial health effects of consuming healthy dietary patterns rich in dietary fiber from whole plant foods include: improving gut health; lowering elevated LDL-cholesterol; reducing the risk of excessive weight gain and obesity; decreasing cardiovascular disease (CVD), coronary heart disease (CHD) and mortality risks; reducing risks of several cancers, stroke and type 2 diabetes; and improving the odds for successful aging [1-5]. Whole fruits (e.g., fresh, frozen, canned or dried) are recognized for their fiber content, very low to moderate energy density, and as being important sources of healthy nutrients (e.g., potassium and vitamin C) and phytochemicals (e.g., polyphenols and carotenoids), which work synergistically to support a wide range of health benefits [1,2,6-9]. Although most of the fiber from whole fruit is removed during fruit juice processing, $100 \%$ fruit juices retain similar levels of other healthy vitamins, minerals and phytochemicals [10]. About $90 \%$ of the US (and other Western) populations do not eat the recommended daily intake of fruit (e.g., 1 to $11 / 2$ cups for children 2-8 years, $11 / 2$ cups for adolescent girls and boys, $11 / 2$ to 2 cups for women, and 2 cups for men) [11]. The typical daily fruit intake is about half the recommended level with juice consumption making up one-third of this level for adults and one-half for children [11]. Consequently, fruit fiber is a relatively small component of the total fiber consumed in populations eating a Western dietary pattern.

The 2015-2020 Dietary Guidelines for Americans named fiber as a major shortfall nutrient of important public health concern [1,12]. Fiber is defined as carbohydrates from plant cell walls, 
resistant starch and oligosaccharides that are resistant to gastric acidity, hydrolysis by mammalian enzymes, and absorption in the upper gastrointestinal tract. The human gastrointestinal tract, and cardiometabolic and immune systems evolved on high fiber plant-based diets ( $\geq 50 \mathrm{~g}$ total fiber/day), including the consumption of wild berries and other native fiber-rich edible plants by hunter-gathers, and later grains, fruits and vegetables from traditional farming, which provided fiber rich diets until the mass globalization of Western dietary patterns in the 20th and 21st centuries. The low fiber Western diet has contributed to increased risk of weight gain, inflammation, chronic diseases and other health concerns in large part by increasing the risk of colonic microbiota dysbiosis associated with unhealthy immunity, cardiometabolic and energy regulatory processes [13-17]. With the current high prevalence of the Western diet, only about $3 \%$ of men and $6 \%$ of women habitually consume $\geq 14 \mathrm{~g}$ fiber $/ 1000 \mathrm{kcal}$, the threshold level considered adequate for optimal health [18-24]. In most Western countries, the typical fiber intake is about half the adequate level. Specific adequate total daily fiber intake varying by age and gender is summarized in Figure 1 [18]. Fiber-rich, plant-based dietary patterns are a major contributor to prebiotic health effects, which stimulate the growth of beneficial intestinal bacterial species to promote and maintain a healthy colonic microbiota ecosystem (microbiome) in large part from fermentation of fiber to short chain fatty acids (SCFAs) [1-4,9,14-17,22-35].

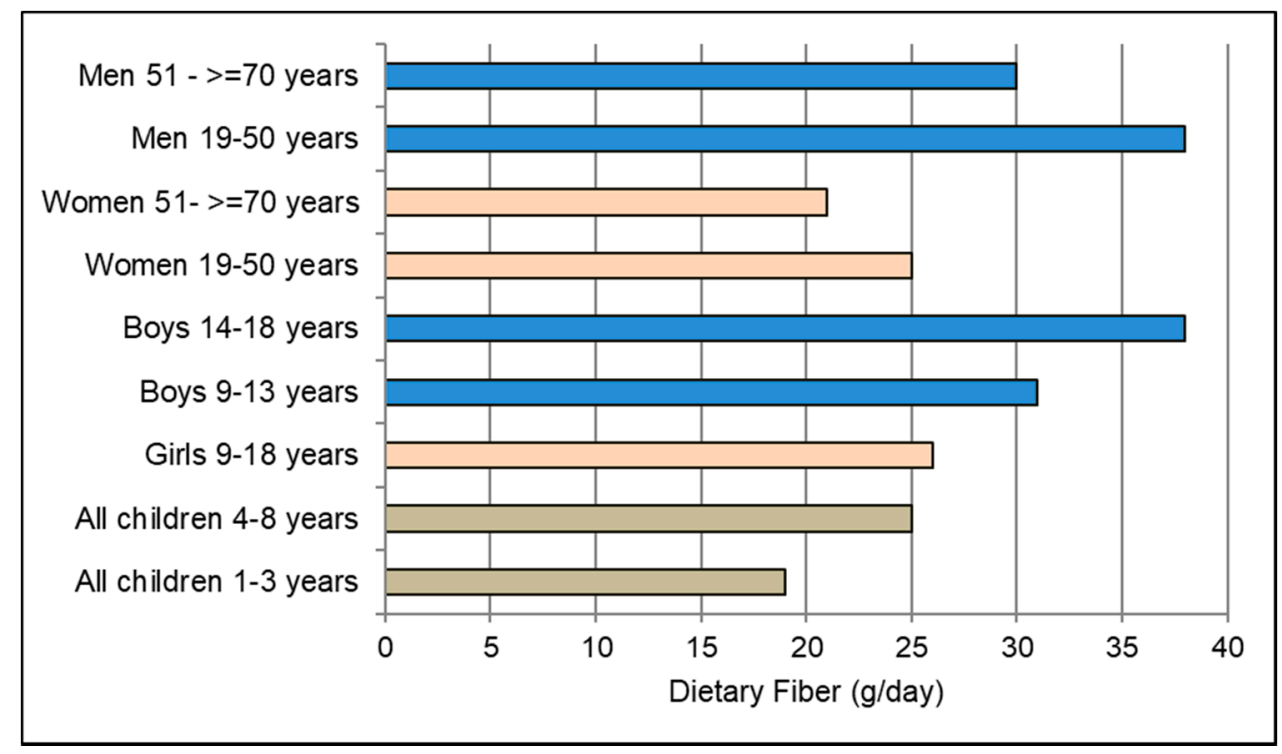

Figure 1. Recommended daily dietary fiber intake by age and gender [18].

The primary aim of this narrative review article is to examine emerging prebiotic and other health effects associated the intake of whole fruits, especially fruit fiber, throughout the human lifecycle.

\section{Fruit as a Prebiotic Source}

\subsection{Fruit Fiber Components and Fermentability}

A comprehensive table of whole fruit total fiber and sub-components, sugar, and energy content per serving is provided in Table 1. As fruit ripens after harvest, the 3-dimensional hydrated cell wall fiber components pectin, hemicellulose and cellulose become increasingly disassembled, allowing for more microbial access and enhancing susceptibility to fermentation [26-28,36,37]. The process of eating, and then digestion in the upper gastrointestinal tract further breaks down the whole fruit into smaller particles and damages the fruit cell wall surfaces to enable greater colonic bacterial enzymatic breakdown and fermentation. Starchy fruits (e.g., bananas and plantains) provide fiber from both cell walls and resistant starch stored within the cells [32,38]. Generally, it has been assumed that soluble fibers are fermented more rapidly and completely compared with insoluble fibers, but this view is 
changing, especially concerning ripe fresh fruits, with cell wall "insoluble fibers" in a hybrid hydrated and partially disassembled state with increased susceptibility to fermentation [22,26]. Also, it is hard to rely on insoluble and soluble quantifications as current standardized methods have many limitations in accurately separating them into individual fractions. Whole fruit can provide a major source of fermentable fiber to support colon prebiotic activity, which can contribute to a wide range of potential human health benefits with sustained consumption at recommended levels.

Table 1. Specific whole fruit fiber, available carbohydrates and energy content $[1,2,6-9]$.

\begin{tabular}{|c|c|c|c|c|c|c|c|c|}
\hline \multirow[b]{2}{*}{ Fruit Source } & \multirow{2}{*}{ Serving Size * } & \multicolumn{4}{|c|}{ Estimated Fiber Components } & \multirow{2}{*}{$\begin{array}{c}\text { Sugar } \\
\text { (Starch) } \\
(100-g)\end{array}$} & \multirow{2}{*}{$\begin{array}{l}\text { Energy } \\
\text { Density } \\
\text { (kcal/g) }\end{array}$} & \multirow{2}{*}{$\begin{array}{c}\begin{array}{c}\text { Energy } \\
\text { (kcal) }\end{array} \\
100-\mathrm{g}\end{array}$} \\
\hline & & $\begin{array}{c}\text { Total } \\
(100-g)\end{array}$ & $\begin{array}{c}\text { Insoluble } \\
(100-\mathrm{g})\end{array}$ & $\begin{array}{c}\text { Soluble } \\
(100-g)\end{array}$ & $\begin{array}{l}\text { Pectin ** } \\
(100-g)\end{array}$ & & & \\
\hline \multicolumn{9}{|c|}{ Fresh Fruit } \\
\hline Apples & $1(182 \mathrm{~g})$ & 2.4 & 1.7 & 0.5 & 0.8 & 10 & 0.5 & 52 \\
\hline Avocados & $1 / 3(50 \mathrm{~g})$ & 6.8 & 4.4 & 2.4 & 2.4 & $<1.0$ & 1.6 & 160 \\
\hline Bananas & $1(118 \mathrm{~g})$ & 2.6 & 1.8 & 0.8 & 0.6 & $12(5)$ & 0.9 & 89 \\
\hline Blackberries & 1 cup $(144 \mathrm{~g})$ & 5.3 & 4.7 & 0.6 & 1.4 & 4.9 & 0.4 & 43 \\
\hline Blueberries & 1 cup $(148 \mathrm{~g})$ & 2.8 & 2.4 & 0.3 & 0.8 & 10 & 0.6 & 57 \\
\hline Cherries & 1 cup(138 g) & 2.2 & 1.6 & 0.6 & 0.7 & 13 & 0.6 & 63 \\
\hline Figs & $1(100 \mathrm{~g})$ & 3.0 & 2.4 & 0.6 & 1.0 & 16 & 0.7 & 74 \\
\hline Grapefruits & 1 cup $(154 \mathrm{~g})$ & 1.6 & 1.1 & 0.5 & 0.6 & 7.0 & 0.4 & 42 \\
\hline Guavas & $1 \mathrm{cup}(165 \mathrm{~g})$ & 5.4 & 4.2 & 1.8 & 1.5 & 9.0 & 0.7 & 68 \\
\hline Kiwis & $2(138 \mathrm{~g})$ & 3.0 & 2.2 & 0.9 & 0.7 & 9.0 & 0.6 & 61 \\
\hline Mangoes & 1 cup $(165 \mathrm{~g})$ & 1.6 & 1.0 & 0.6 & 0.5 & 14 & 0.6 & 60 \\
\hline Oranges & $1(131 \mathrm{~g})$ & 2.4 & 1.4 & 1.0 & 0.8 & 9.1 & 0.5 & 47 \\
\hline Papayas & 1 cup(145 g) & 1.7 & 1.4 & 0.3 & 0.5 & 7.6 & 0.4 & 43 \\
\hline Pears & $1(166 \mathrm{~g})$ & 3.1 & 2.2 & 0.9 & 1.0 & 10 & 0.6 & 60 \\
\hline Plantains & $1 / 2(134 \mathrm{~g})$ & 2.2 & 1.5 & 0.7 & 0.4 & $2.2(30)$ & 1.5 & 149 \\
\hline Pomegranate arils & 1 cup $(122 \mathrm{~g})$ & 5.7 & 4.1 & 1.6 & 2.0 & 12 & 0.8 & 81 \\
\hline Raspberries & $1 \operatorname{cup}(123 \mathrm{~g})$ & 6.5 & 5.3 & 1.2 & 1.6 & 4.4 & 0.5 & 52 \\
\hline Strawberries & 1 cup $(152 \mathrm{~g})$ & 2.0 & 1.5 & 0.5 & 0.7 & 4.7 & 0.3 & 33 \\
\hline Apricots & $2(70 \mathrm{~g})$ & 2.0 & 1.0 & 1.0 & 0.7 & 9.1 & 0.5 & 49 \\
\hline Cantaloupes & $1 \operatorname{cup}(177 \mathrm{~g})$ & 0.9 & 0.6 & 0.3 & 0.3 & 7.9 & 0.3 & 34 \\
\hline Green grapes & 1 cup $(92 \mathrm{~g})$ & 0.9 & 0.6 & 0.3 & 0.2 & 17 & 0.7 & 69 \\
\hline Peaches & $1(150 \mathrm{~g})$ & 1.5 & 0.9 & 0.6 & 0.5 & 9.0 & 0.4 & 39 \\
\hline Pineapples & $1 \operatorname{cup}(165 \mathrm{~g})$ & 1.4 & 1.1 & 0.3 & 0.5 & 10 & 0.5 & 50 \\
\hline Plums & $2(132 \mathrm{~g})$ & 1.4 & 0.9 & 0.5 & 0.4 & 11 & 0.5 & 45 \\
\hline Watermelons & 1 wedge (286 g) & 0.4 & 0.3 & 0.1 & 0.1 & 6.3 & 0.3 & 29 \\
\hline \multicolumn{9}{|c|}{ Dried Fruit } \\
\hline Apricots & $6(40 \mathrm{~g})$ & 10 & 7.5 & 2.5 & 3.0 & 37 & 2.6 & 258 \\
\hline Cranberries & $1 / 4 \operatorname{cup}(40 \mathrm{~g})$ & 7.5 & 5.0 & 2.5 & 2.5 & 72 & 3.3 & 325 \\
\hline Dates, pitted & $5-6(40 \mathrm{~g})$ & 7.5 & 6.0 & 1.5 & 2.5 & 72 & 3.0 & 300 \\
\hline Dried Figs & $1 / 3$ cup (40 g) & 12 & 8.8 & 37 & 4.3 & 50 & 2.8 & 275 \\
\hline Prunes & $7(40 \mathrm{~g})$ & 7.5 & 5.0 & 2.5 & 2.5 & 37 & 2.5 & 250 \\
\hline Raisins & $1 / 4 \mathrm{cu}(40 \mathrm{~g})$ & 5.0 & 3.7 & 1.2 & 1.7 & 73 & 3.0 & 300 \\
\hline
\end{tabular}

* Based on commonly consumed fruit servings from USDA Food Composition Databases [7] ** Fruit pectin $=$ mean $35 \%$ (range $20-40 \%$ ) of total fiber [9].

\section{2. "In Vitro" Human Colonic Microbiota Model System Studies}

\subsubsection{Pectin}

The most extensively studied fruit fiber prebiotic component is pectin, which comprises on average $35 \%$ of fruit fiber cell wall content $[9,37]$. A Korean in vitro human colonic microbiota model system study (3 male donors with diverse microbiota profiles) confirmed the effectiveness of 
pectin in promoting robust prebiotic activity in all subjects [39]. Although donors had differences in baseline colonic microbiota composition, there were similar increases in healthy bacteria after pectin fermentation including species belonging to butyrate producing Clostridium cluster XIV (e.g., Lachnospira), and Sutterella. After pectin intake, microbiota production of SCFAs, acetate and butyrate levels increased $6 \mathrm{~h}$ post intake. Acetate continuously increased up to $18 \mathrm{~h}$, then rapidly decreased by $36 \mathrm{~h}$. Butyrate steadily increased approximately $28 \%$ by $48 \mathrm{~h}$. Propionate slowly increased after $12 \mathrm{~h}$ until about $48 \mathrm{~h}$ at a much slower rate than acetate or butyrate. Increased butyrate levels are used as the main energy source by colonocytes to maintain the colonic protective barrier and in lowering colonic luminal $\mathrm{pH}$ to inhibit pathogenic bacteria. A comparison between apple pectin and inulin using a human colonic microbial anaerobic continuous-flow fermenter found that they were both effective in promoting prebiotic activity with anti-inflammatory effects, although apple pectin was three times more effective in promoting Bacteroides and overall microflora diversity than inulin, presumably reflecting the differing complexity of the two prebiotics [40]. A recent study using an in vitro Simulator of the Human Intestinal Microbial Ecosystem (SHIME ${ }^{\circledR}$ ) suggests that citrus pectin stimulated the production of butyric acid in the simulated transverse and descending colon, as well as the growth of genera Lactobacillus, Megamonas, and Lachnospiracea with related anti-inflammatory effects, and a reduction of ammonium ions [41]. A 2018 in vitro study also suggests that pectins have the potential to improve the survival of probiotic bacteria such as Lactobacillus in the stomach and small intestine [42]. Overall, these studies find that fruit fiber, especially pectin, can help re-balance the colonic microbiota towards a higher anti-inflammatory profile by: (1) increasing the Bacteroidetes/Firmicutes ratio, and increasing the abundance of Bifidobacterium and Clostridium cluster XIV, resulting in enhanced colonic mucosal barrier integrity and function, increased mucosal immunity, increased butyrate production, and a decrease in enteric pathogens; (2) promoting Eubacterium eligens, which upregulates pectinolytic enzymes; and (3) supporting certain Faecalibacterium prausnitzii strains in utilizing the fermentation of pectin to exert anti-inflammatory effects [31-33,43-48]. Pectin is a major fruit prebiotic that has been extensively studied and shown to promote a healthy, anti-inflammatory colonic microbiota ecosystem with greater microflora diversity than inulin.

\subsubsection{Fruits}

Several in vitro human fecal microbiota model fermentation systems studies support the prebiotic effects of whole fruits. A study which evaluated apples with an in vitro batch culture colonic model system ( $\mathrm{pH} 5.5-6.0 ; 37^{\circ} \mathrm{C}$; inoculated with feces from three healthy donors; 3 varieties) found that all the apple varieties exhibited beneficial prebiotic activity by improving colonic microbiota bacterial diversity, and increasing Actinobacteria relative abundance and total SCFAs levels $(p<0.05)$ [49]. The Renetta Canada apple variety, rich in fiber and polyphenols in particular had positive consequences for human health by increasing Bifidobacteria, F. prausnitzii, butyrate levels and polyphenol microbial metabolites $(p<0.05)$. Raisins assessed with a simulated in vitro digestive system with dynamic mastication, gastric, duodenal and colonic human models showed that raisins significantly increased the proportion of Bifidobacteria and Lactobacilli, decreased numbers of Firmicutes, and approximately doubled the fecal concentration of propionate and butyrate compared to controls [50]. Commonly consumed whole fruits can promote a healthy microbiota ecosystem by the actions of their fiber and polyphenolics.

\subsection{Human Trials}

A growing number of human trials support the prebiotic effects of whole fruit and fruit fiber in promoting a healthy microbiome. A 2016 dose-response Randomized Controlled Trial (RCT) (122 subjects; 2, 4 and 6 fruit and vegetable servings vs. a habitual control diet) found that the fiber content of fruits and vegetables was more important than the polyphenol content in promoting healthier fecal microflora (e.g., Bacteroide/Prevotella ratio and Bifidobacteria) [35]. A longitudinal study (22 children; age 4 to 8 years) showed that the number of fruit servings/day was positively correlated 
with the relative abundance of colonic bacteria Bacteroides and Bacteroidetes in the children studied (Figure 2), suggesting that higher fruit fiber intake is associated with a healthier microbiome for better childhood immune function compared to the typical low fruit intake by children in the US [51]. A growing number of human studies on specific fruit sources show varying levels of prebiotic effects depending on the fruit source and daily amount consumed when compared to control low fiber diets or food. For apples, an open trial ( 8 healthy men; 2 apples/day added to usual diet vs. baseline) showed that apples significantly increased the proportion of Bifidobacteria in feces on day $7(p<0.05)$ and day $14(p<0.01)$, decreased fecal C. perfringens, Enterobacteriaceae and Pseudomonas with a trend toward higher levels of fecal SCFAs [52]. For prunes, a dose-response parallel RCT (120 constipated adults; low fiber diets) found that $\geq 80 \mathrm{~g}$ prunes [ $6 \mathrm{~g}$ fiber]/d significantly increased Bifidobacteria and stool weight and frequency with trends for higher SCFAs levels and lower stool $\mathrm{pH}$ [53]. For bananas, four RCTs in adults and children found that bananas and banana flakes were significantly more effective in reducing chronic pathogenic bacterial diarrhea severity (e.g., severe Shigellosis dysentery, Clostridium difficile) compared to control food, rice-based diets or standard medical treatment [54-57]. For plantains, a RCT (80 infants and children with persistent pathogenic bacterial diarrhea) showed that cooked plantains significantly shortened average duration of diarrhea by $18 \mathrm{~h}$ compared to yogurt [58]. For kiwi fruit, an open trial (6 young Chinese women) found that 2 kiwi fruit equivalents / day enhanced growth of lactic acid bacteria and decreased levels of pathogenic bacteria within $24 \mathrm{~h}$ compared to diets restricted in fruit and yogurt [59]. For dates, a crossover RCT ( 22 healthy men and women; 7 dates or $50 \mathrm{~g}$ vs. refined carbohydrate control) demonstrated that a single serving of dates produced a non-significant increase of healthy microbiota bacterial groups and SCFAs, but beneficial changes were shown for stool frequency, ammonia concentrations and genotoxicity of fecal water [60]. Generally, at least 2 daily whole fruit servings, especially fruits with $\geq 2.5 \mathrm{~g}$ fiber/serving are required to stimulate significant colonic prebiotic activity (higher SCFAs, production, increased levels of Bifidobacteria, reduced levels of pathogenic bacteria and protection against persistent bacterial diarrhea in children and adults) compared to $\leq 1$ whole fruit serving/day common in Western diets $[1,2,11,12]$.

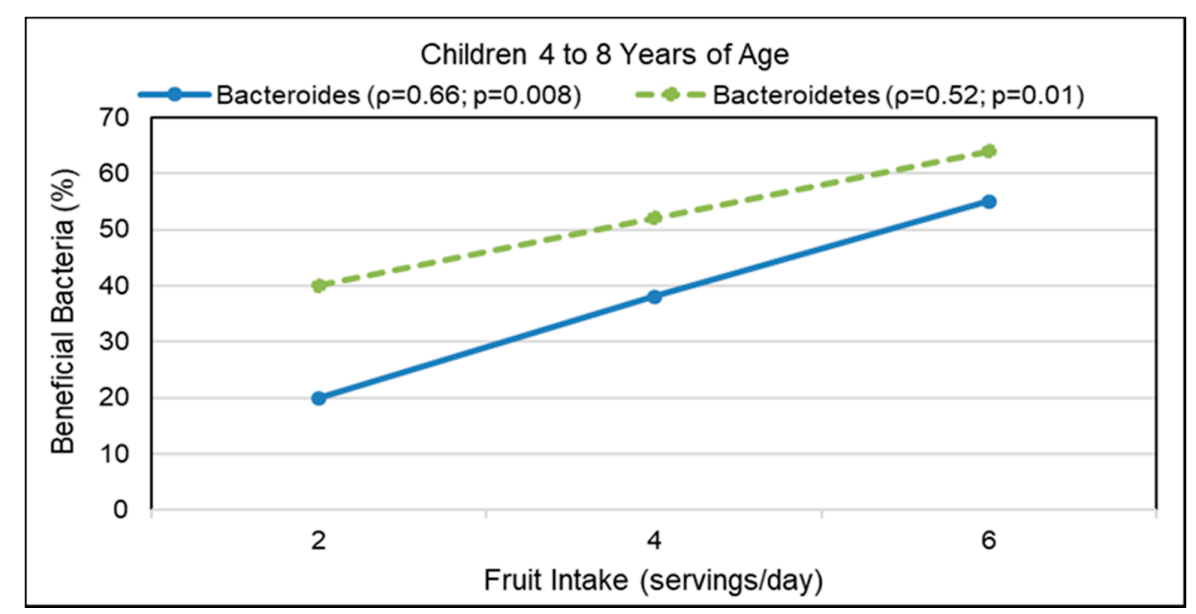

Figure 2. Correlations between daily servings of fruit intake and the microbiota abundance of beneficial Bacteroides and Bacteroidetes in children [51].

\section{Emerging Health Benefits Associated with Whole Fruits and Fruit Fiber}

\subsection{Gastrointestinal Tract}

Acute or chronic colonic gastrointestinal health issues affect the well-being of all humans with variations depending on age, genetic propensity, food borne pathogenic infections, diet and water quality, level of fluid intake, physical activity, medications, stress coping ability and other factors. 


\subsubsection{Constipation}

The prevalence of constipation worldwide is approximately $16 \%$ in all adults and $33.5 \%$ in adults over 60 years [61]. The risk of constipation is affected by genetic predisposition, socioeconomic status, low fiber intake, inadequate fluid intake, lack of mobility, hormone imbalance, and side effects of medications. A RCT ( 80 Chinese adults with slow-transit constipation) found that pectin significantly reduced mean constipation score and increased the population of colonic healthy microflora [62]. A crossover RCT showed that increased intake of whole fruits and vegetables significantly reduced fecal transit time by $14 \mathrm{~h}$, increased the number of daily bowel movements by 0.4 , and daily wet fecal weight by $118 \mathrm{~g}$ compared to 100\% fruit and vegetable juices [63]. The Bristol Stool Scale may be useful as a quick indicator of microbiota health quality since the stool quality shape rating and increased fecal mass (about $50 \%$ bacteria) are crude indicators of microbiome health [22]. The viscous, low to moderate fermentable soluble fiber in whole fruits can effectively relieve constipation symptoms. For mangos, a parallel RCT showed that $300 \mathrm{~g}$ (2 servings)/day of fresh mangos, approximately $5 \mathrm{~g}$ of mango fiber, significantly reduced total constipation score (including frequency of bowel movements, difficulty/straining to evacuate, pain on evacuation, abdominal pain, daily evacuation attempts, and duration of constipation) by $60 \%$ in chronically constipated adults compared to baseline [64]. For prunes, a systematic review (4 RCTs) and a RCT found that in constipated subjects, 2 daily servings of prunes were as effective as 2 daily servings of psyllium for increasing stool frequency and improving stool consistency $[65,66]$. For kiwi fruit, twice daily intake improved laxation, softened stools, and relieved chronic constipation with the active component being a highly viscous soluble fiber with modest fermentability $[67,68]$. The daily intake of 2 servings of fiber rich fruits can promote regularity and help to protect against constipation.

\subsubsection{Irritable Bowel Syndrome}

Irritable bowel syndrome (IBS), characterized by altered bowel motility, abdominal pain, flatulence, and abnormal immune function, is the most common chronic functional gastrointestinal disorder. It affects about $10-15 \%$ of the global population and is most prevalent in people $<45$ years [69]. A cohort study observed that IBS patients have significantly lower microbial diversity, butyrate-producing bacteria and Methanobacteria compared to healthy controls. This is associated with colonic dysbiosis, reduced intestinal barrier function and impaired colonic hydrogen disposal linked to an excess of abdominal gas [70]. Although short chain highly fermentable prebiotic supplements should be restricted to avoid the risk of a rapid increase in gas, bloating/distension, and abdominal pain/discomfort, the consumption of long-chain or complex, soluble and more slowly fermentable, butyrate producing fibers, such as fruit pectin may have a role in helping to control IBS symptoms [71,72]. A Chinese RCT (IBS diarrhea) found that pectin significantly increased Bifidobacteria, decreased total Clostridium sp $(p<0.05)$, reduced IBS symptoms, normalized cytokine levels, and improved Bristol stool scale score and quality of life assessments [73]. Another RCT (IBS-constipation) showed that 2 kiwi fruit/day significantly shortened colon transit time, increased defecation frequency and improved overall bowel function [74]. Two servings/day of low FODMAP (fermentable oligosaccharides, disaccharides, monosaccharides and polyols) fresh fruit including: bananas, blueberries, oranges, durians, grapefruits, grapes, honeydew melons, avocados, kiwifruit, lemons, limes, mandarin oranges, passion fruit, raspberries, and strawberries, have been proposed as a potential dietary option for IBS management, allowing 2-3 $\mathrm{h}$ between each fruit serving to avoid over loading the gastrointestinal system and to confirm the effectiveness of any specific fruit [75]. The daily intake of 2-3 servings/day of low FODMAP fruits or 5-10 g/day fruit fiber may help to reduce IBS risk and prevent flare-up in IBS patients.

\subsubsection{Inflammatory Bowel Diseases}

Inflammatory bowel disease (IBD) is a chronic inflammatory condition including Crohn's disease (CD) and ulcerative colitis (UC) with active clinical symptoms including diarrhea and/or constipation, 
stool containing mucus and/or blood and varying degrees of abdominal cramping followed by periods of remission [76]. Although healthy diets including high fiber and low FODMAP fruits and vegetables have been recommended to reduce IBD pathogenesis and prolong maintenance of clinical remission, more well-designed studies on the effects of diet are needed to help dietitians to provide better evidence-based nutritional guidance to IBD patients. IBD risk may be associated with low fiber diets, which are related to a dysfunctional microbiome and reduced microbiota fecal concentrations of butyrate. The adequate intake of prebiotic fiber can increase colonic butyrate to levels needed to maintain the mucosal barrier function to protect against IBD inflammatory pathogenesis [77].

\section{Crohn's Disease (CD)}

$\mathrm{CD}$ is a transmural inflammatory condition that can affect both the large and small intestine, and may be associated with bowel obstruction, strictures, and/or abscesses [76]. There are two identified peaks for occurrence of CD: (1) age range of teens to 35 years and (2) 60-80 years [78]. A meta-analysis (10 case-control studies) [79], a systematic review (5 cohort or case-control studies) [80], and The Nurses' Health Study [81] found that increased fruit intake reduced CD risk in these populations by approximately $40 \%$. Conversely, increased vegetable and whole grain consumption was not significantly associated with lower CD risk [79-81]. A 2007 Canadian case-controlled study in children found significant reduction in CD risk for higher fruit and total fiber intake (Figure 3), suggesting that increased fruit fiber may have a role in reducing CD risk [82]. A 2015 meta-analysis (7 cohort and case-control studies) observed a linear dose-response decrease in CD risk by $13 \%$ for each $10 \mathrm{~g} /$ day total fiber increment $(p<0.05)$, which is equivalent to 2 to 3 whole fruit servings/day [83]. A-2016 internet cohort study (1619 adults with CD remission) observed that participants who reported that they did not avoid fiber rich foods such as whole fruits were $40 \%$ less likely to have a CD flare-up than those who avoided high fiber foods [84]. However, a 2018 European prospective multi-center cohort (EPIC-IBD) study did not observe any statistically significant associations between total fiber or fiber from fruit, vegetables or cereals with reduced CD risk [85]. Although the adequate intake of whole fruit and fruit fiber may help to reduce $C D$ risk and prolong $C D$ remission periods, studies on the specific effects of fruit fiber on CD risk are limited.

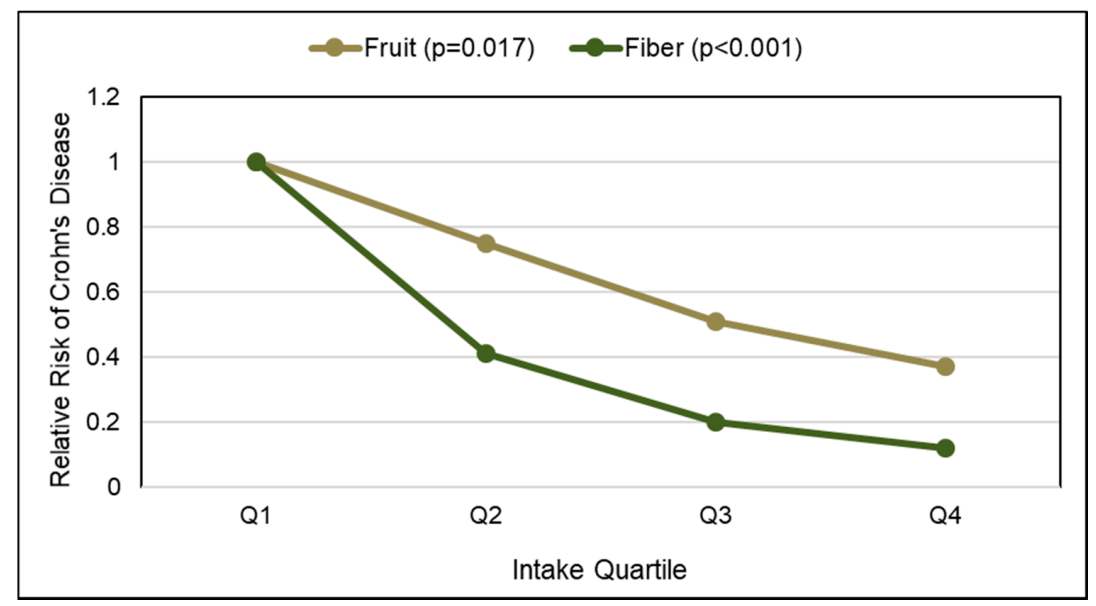

Figure 3. Risks of Crohn's disease in children for fruit and total fiber intake [82].

Ulcerative Colitis (UC)

UC is a non-transmural inflammatory condition which only affects the colon mucosa and superficial submucosa in adults [76]. A meta-analysis (9 case-control studies) observed that higher consumption of fruits and vegetables was associated with an approximately $30 \%$ reduction in UC risk [79]. A systematic review (8 cohort and case-control studies) observed that fruit intake was not significantly associated with lower UC risk but high vegetable intake was associated with decreased 
risk of UC [80]. A 2018 EPIC-IBD study did not observe any statistically significant associations between total fiber or fiber from fruit, vegetables or cereals with reduced UC risk [85]. There is limited and inconsistent evidence supporting beneficial effects of fruit and fruit fiber in reducing UC risk or prolonging UC remission.

\subsubsection{Diverticular Disease}

Colonic diverticulosis, characterized by herniation or out-pouching of the colon known as diverticula, is progressively more prevalent with aging, occurring in about $30 \%$ of people at age 60 years and $70 \%$ of people $\geq 80$ years [86]. However, only $10-25 \%$ of individuals with diverticulosis develop symptoms such as abdominal pain and changes in bowel habit and $4 \%$ have a lifetime risk of developing serious life-threatening complications with high medical and hospitalization costs. Risk factors associated with diverticular disease include obesity, and diets low in fiber and high in red meat [87]. A cross-sectional study observed that patients with diverticular disease had colonic microbiota dysbiosis including increased colonic inflammation associated with increased presence of macrophages [88]. The Swedish Mammography Cohort and the Cohort of Swedish Men (approx. 89,000 middle-age and elderly women and men) observed that those with the highest intake of fruit and vegetable fibers had an approximately 30\% decreased risk of hospitalization compared to those with the lowest intake but cereal fiber did not affect risk [89]. The UK Million Women Study (approximately 700,000 women) observed that diverticular disease risk was significantly reduced per $5 \mathrm{~g}$ of fruit fiber by $19 \%$ and $5 \mathrm{~g}$ of cereal fiber by 16\% compared to no risk reduction effects for either vegetable or potato fiber [90]. A review of diet and diverticular disease suggests that increased fruit fiber intake reduced diverticular disease risk by 38\% [91]. An EPIC UK/Oxford cohort (47,033 adults) observed that higher total fiber intake ( $\geq 26 \mathrm{~g} /$ day vs. $<14 \mathrm{~g} /$ day) was associated with a significantly reduced risk of diverticular disease by $41 \%$ and vegetarian diets were significantly associated with a 31\% lower risk of diverticular disease compared to diets with high meat intake [92]. A 2018 systematic review concluded that the intake of adequate fiber after an acute episode of symptomatic uncomplicated diverticular disease can reduce the risk of future flare-ups [93]. Adequate fruit and fiber intake appear to be effective in reducing diverticular disease risk and flare-ups or complications including hospitalizations.

\subsection{Weight Control}

The growing worldwide overweight and obesity pandemic is among the greatest public health challenges of our time affecting approximately 2 billion plus people worldwide. Its causes are multifactorial involving unhealthy lifestyle factors including the consumption of energy dense and low fiber Western diets combined with sedentary lower energy expenditure, genetic, environmental, and emotional factors.

\subsubsection{Observational Studies}

Fruit

A number of prospective cohort studies have observed associations between diets containing fruits and vegetables and weight control, weight loss, and risk of obesity. A 2015 systematic review and meta-analysis of prospective cohort studies (17 studies; 563,277 participants) showed that fruit intake was associated with modest reductions in body weight and waist circumference and a reduced risk of obese adiposity by 17\% [94]. A 2016 review article concluded that the consumption of increased levels of whole fruit was uniquely protective against weight gain and obesity [95]. Pooled data from 3 US prospective studies including the Nurses' Health Studies and Health Professionals Follow-up Study (133,468 men and women; baseline normal BMI; 4-year cycles) observed lower weight for intake of total non-juice fruit by $0.53 \mathrm{lb} /$ serving and total vegetables by $0.25 \mathrm{lb} /$ serving [96]. The observed weight change effects for a daily serving of specific fruits and vegetables are summarized in Figure 4. 
Fiber-rich, very low energy dense blueberries, apples and pears, cauliflower, string beans, peppers and broccoli were among the most effective in the support of weight loss whereas a daily serving of starchy vegetables such as peas, potatoes, and corn were associated with weight gain. The Australian Longitudinal Study on Women's Health (4287 women; 6 years) observed that women consuming a mean of $117 \mathrm{~g}$ fruits and vegetables/day gained $1.1 \mathrm{~kg}$ less weight than those consuming a mean of $35 \mathrm{~g} /$ day $(p=0.002)$ [97]. The Women's Health Study (18,146 women; mean 15.9 years) observed that high fruit, but not vegetable intake was inversely associated with the risk of becoming overweight or obese [98]. Overall, this study found no significant associations for fruit and fiber intake with weight gain, whereas higher vegetable intake was associated with greater weight gain. Among women with a body mass index (BMI) $<23 \mathrm{~kg} / \mathrm{m}^{2}$ increased fruit intake was associated with a $13 \%$ lower risk of becoming overweight or obese in older age $(p=0.01)$. A 2018 cohort study (4357 middle age participants; 5 years) observed that increased fruit and vegetable intake was associated with a significant decrease in body weight and BMI among Chinese men and similar but not significant change in body weight and BMI among women [99]. A large-scale Canadian population-based survey (26,340 individuals) observed that compared to individuals with $<1$ fruit serving/day those with $>2$ fruit servings/day had a 10\% lower risk for obesity and 12\% lower risk of abdominal obesity (all $p$ for trend <0.05) [100]. The National Health and Nutrition Examination Survey (NHANES) observed that increasing the number of servings of whole fruits and non-starchy vegetables relative to total daily food intake was inversely associated with BMI, waist circumference, and fasting insulin [101]. In the Women's Health Initiative (49,106 postmenopausal, 3 years) each serving of 100\% fruit juice/day was associated with a mean 3-year weight gain of $0.4 \mathrm{lbs}$, partly due to the loss of fiber during processing [102]. For better weight control or modest weight loss overtime, diets containing higher non-juice whole fruits were more effective than fruit juice or vegetables, especially starchy vegetables.

\section{Fiber-Rich Diets}

Although there are no observational studies which specifically examined associations between higher fruit fiber intake and weight control, waist circumference and visceral fat, there are a number of observational studies for total fiber, which can mirror the expected effects from increased fruit fiber intake, especially from fiber rich fresh fruit because of their low energy density. A systematic review of 14 prospective cohort, case-control and randomized trials found that fiber-rich foods, especially low in energy density, protect against long-term increased weight and waist circumference gain [103]. The Nurses' Health Study (74,091 US female nurses; 12 years) observed that women with the highest intake of fiber gained an average of $1.5 \mathrm{~kg}$ less than those with the lowest intake of fiber ( $p$-trend $<0.0001$ ) independent of body weight at baseline and age, and they had a $49 \%$ lower risk of major weight gain [104]. In particular, greater increases in fiber intake were associated with less BMI and weight gain every 2 to 4 years (Figure 5). A study in 252 women (20-months) observed that each $1 \mathrm{~g} / 1000 \mathrm{kcal}$ increase in total fiber significantly reduced body weight by $0.25 \mathrm{~kg}$ and body fat by $0.25 \%$, by reducing total metabolizable energy intake [105]. Total fiber intake was inversely associated with obesity, metabolic syndrome and elevated CRP risk among US adults in the NHANES 1999-2010 analysis [106]. An EPIC study (48,631 men and women; 5.5 years) observed that an increased level of fiber intake predicted significantly lowered visceral fat, as measured by waist circumference for a given $\mathrm{BMI}\left(\mathrm{WC}_{\mathrm{BMI}}\right)$, in women [107]. In this study each $10 \mathrm{~g}$ increase in fiber intake was associated with a lower $\mathrm{WC}_{\mathrm{BMI}}$ in women by $0.06 \mathrm{~cm}$ and in men by $0.01 \mathrm{~cm}$. The Insulin Resistance and Atherosclerosis Family Study (339 African American adults and 775 Hispanic American adults; 5-years) observed that each $10 \mathrm{~g}$ increase in soluble fiber decreased the accumulation of visceral fat tissue by $3.7 \%$ $(p=0.01)$ [108]. An intervention trial of Malaysian housewives (255 women; reduced calorie diet to 1200-1500 kcal/day; 6 months) showed that each gram reduction of fiber $/ 1000 \mathrm{kcal}$ intake prevented body fat loss by $243 \mathrm{~g} /$ day $(p=0.035)$ [109]. Fruit is an important contributor to help people consume dietary patterns with adequate fiber ( $\geq 14 \mathrm{~g} / 1000 \mathrm{kcals}$; Table 1$)$ which tends to result in leaner phenotypes compared to those consuming low fiber Western diets ( $\leq 10 \mathrm{~g} / 1000 \mathrm{kcal})[1,2,11,12,18-21]$. 


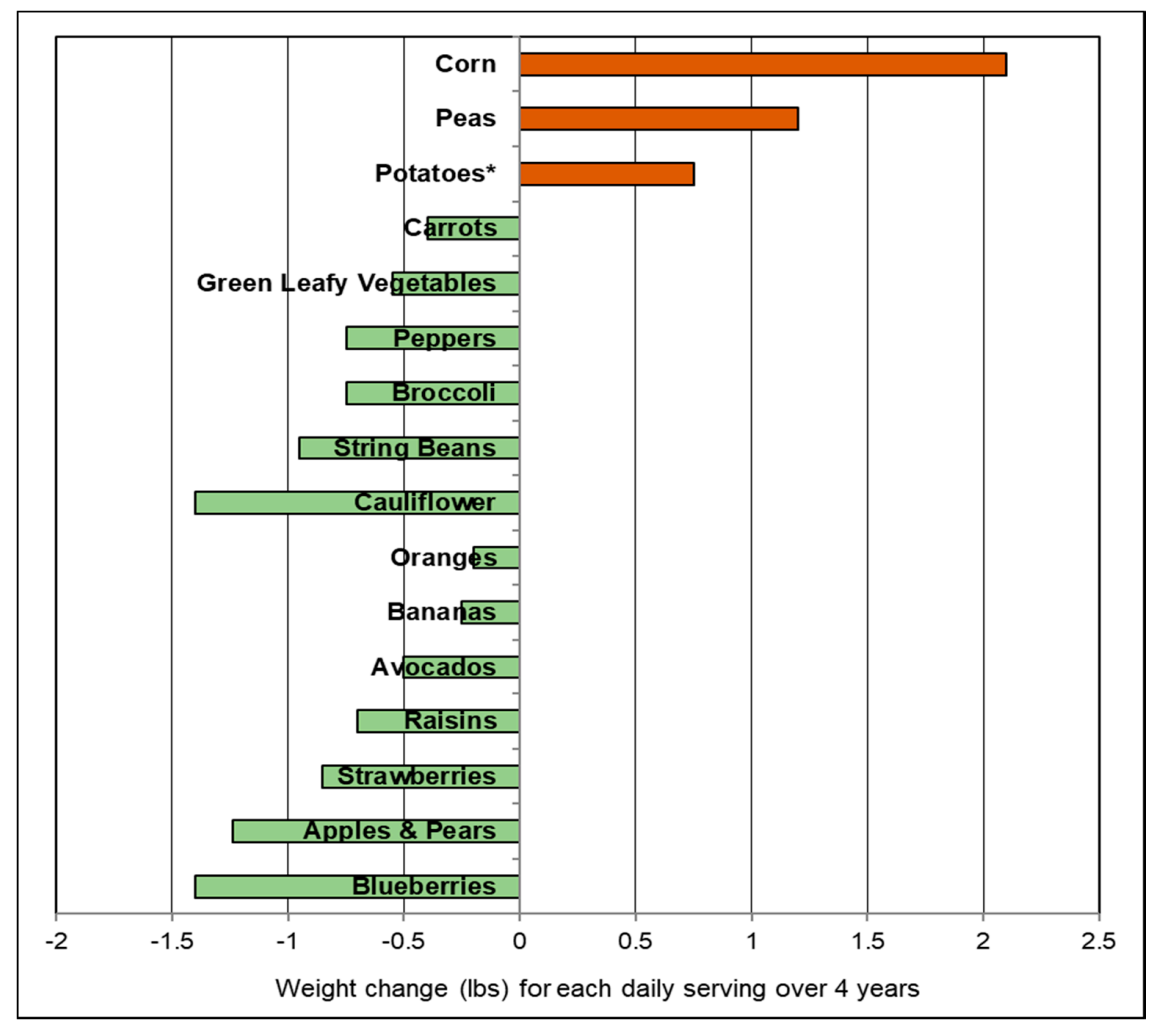

Figure 4. Associations between a daily serving of specific non-juice fruits and vegetables and weight change in US men and women over 4 years from the Nurses' Health Studies and Health Professionals Follow-up Study (pooled data; multivariate adjusted; *excludes French fries and potato chips) [96].

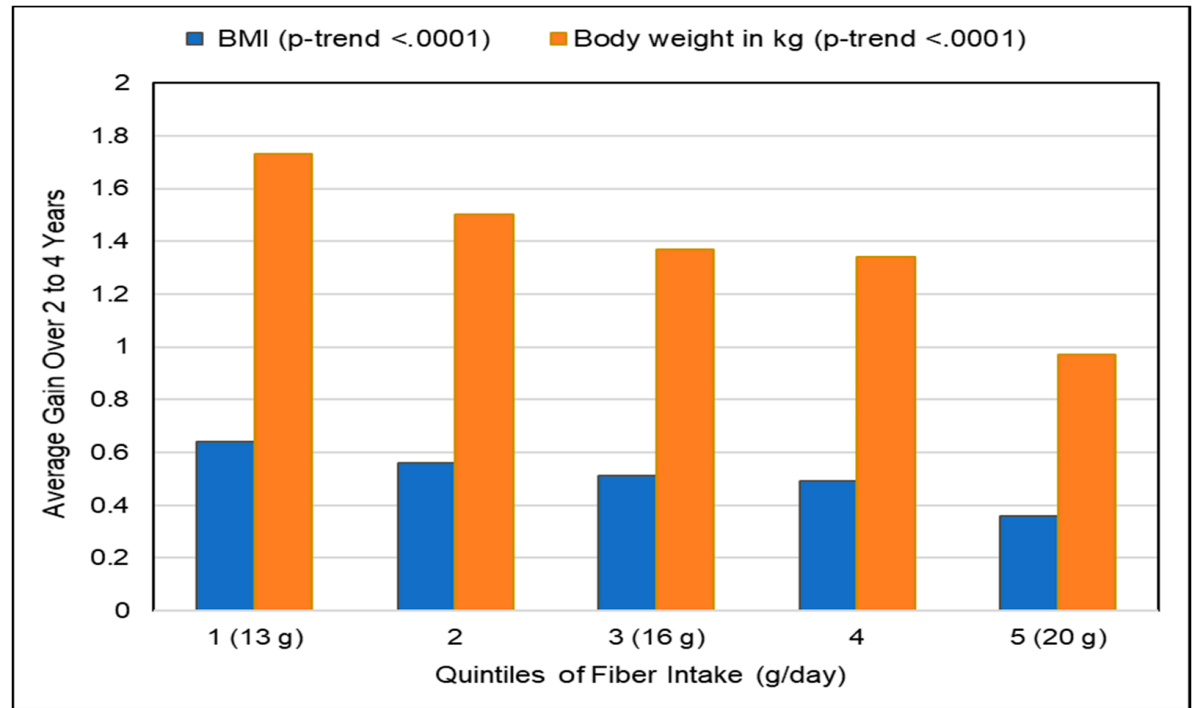

Figure 5. Change in body mass index (BMI) and weight associated with level of fiber intake from The Nurses' Health Study (74,091 women; age 50 years; 12 years) [104].

\subsubsection{Randomized Controlled Trials (RCTs)}

\section{Fruits and Vegetables}

A number of RCTs have evaluated the effects of increased intake of fruits and vegetables on body weight. A 2014 systematic review and meta-analysis (7 RCTs; 1103 subjects; $\geq 8$ weeks) found that total fruits and vegetables including 100\% juices in the inclusion criteria show no discernable effects 
on weight loss [110]. Another 2014 systematic review and meta-analysis excluding 100\% juice (8 RCTs; 1026 participants; mean 15 weeks duration) showed that mean increased intake of non-juice total fruits and vegetables by $133 \mathrm{~g} /$ day reduced body weight by $0.54 \mathrm{~kg}(p<0.01)$, independent of changes in energy intake [111]. The Diabetes Prevention Program multicenter RCT (2624 subjects at risk for diabetes; 1 year) found that weight loss was positively associated with increases in daily servings of non-citrus fruit, and dark green and bright yellow vegetables [112]. A parallel multicenter RCT based on the DASH diet (sub-study of 828 successful weight loss participants) showed that increased intake of total fruits and vegetables was associated with weight loss of $0.3 \mathrm{~kg}$ per daily serving during the initial 6-months of the study and continued at a lower rate of $0.04 \mathrm{~kg}$ per 6-months for the next 30 months [113]. For apples and pears, a parallel RCT (49 women; isocaloric 3 small apples or pears [0.64 kcal $/ \mathrm{g}$ ] or 3 oat cookies [3.7 kcal $/ \mathrm{g}$ ] added to the usual diet; 10 weeks) showed that apples and pears significantly reduced weight by $0.8-0.9 \mathrm{~kg}(p<0.001)$, whereas the cookies increased weight by $0.2 \mathrm{~kg}(p=0.35)$ [114]. For avocados, a parallel RCT (51 healthy adults; hypocaloric diet; 12-weeks) found that one Hass avocado [9.2 g fiber]/day or an equally hypocaloric diet without avocados were both equally effective in lowering body weight and BMI by about 3\% [115]. Diets containing increased servings of non-juice fruits and vegetables can promote modest weight loss and improved weight loss maintenance.

\section{Fiber-Rich Diets}

Although there are no RCTs that specifically examined the effects of higher fruit fiber intake and weight control, waist circumference and visceral fat, there are six-high quality RCTs on fiber-rich diets, which are reflective of the expected effects from increased fruit fiber intake on weight control. The Diabetes Prevention Program multicenter RCT reported that an intensive lifestyle intervention group had a 1-year weight loss of $1.45 \mathrm{~kg}$ per $5 \mathrm{~g}$ fiber intake $(p=0.0001)$, independent of changes in energy intake [112]. A parallel RCT (240 obese metabolic syndrome subjects; 1 year) found that a high fiber diet (goal to consume $>30 \mathrm{~g}$ fiber / day) was as effective as a reduced energy multicomponent AHA weight loss program after one year [116]. An Australian RCT (72 obese subjects; 12-week duration) showed those consuming $31 \mathrm{~g}$ fiber significantly reduced body weight, BMI and \% body fat compared to a 20-g fiber/day control [117]. A parallel RCT (113 adults; BMI > 25; randomized into a low-fat vegan diet group at $29 \mathrm{~g}$ fiber/day vs. Western habitual diet at $15 \mathrm{~g}$ fiber/day; $22 \mathrm{weeks}$ ) found that the higher fiber diet group lost significantly more weight by $5.2 \mathrm{~kg}$ and waist circumference by $5.5 \mathrm{~cm}$ compared to the lower fiber Western diet control group $(p<0.0001)$ [118]. Weight loss of $5 \%$ of body weight was more frequently found for subjects in the high fiber group by $49 \%$ vs. control group by $11 \%(p<0.0001)$. The Finnish Diabetes Prevention Study (522 prediabetic subjects; 4-year duration) showed adequate fiber intake significantly reduced body weight by $2.6 \mathrm{~kg}$ ( $p$-trend $=0.001)$ and waist circumference by $1.3 \mathrm{~cm}$ ( $p$-trend $=0.033$ ) [119]. In this study, the adjusted 3-year weight reduction among those whose diets were both low in fat and high in fiber averaged $2.4 \mathrm{~kg}$ more than subjects on a high fat and low fiber diet (Figure 6). A parallel RCT found that centrally obese post-menopausal women who were more dietary adherent to an energy restricted diet lost up to $23 \%$ more visceral fat than less adherent subjects, which was correlated with their higher intake of fiber $(p<0.001)$ [120]. These RCTs support that consumption of fiber-rich diets ( $>28 \mathrm{~g}$ fiber/day) can lead to weight loss and improved body composition compared to a low fiber Western diet ( $\leq$ approx. $20 \mathrm{~g}$ fiber/day). 


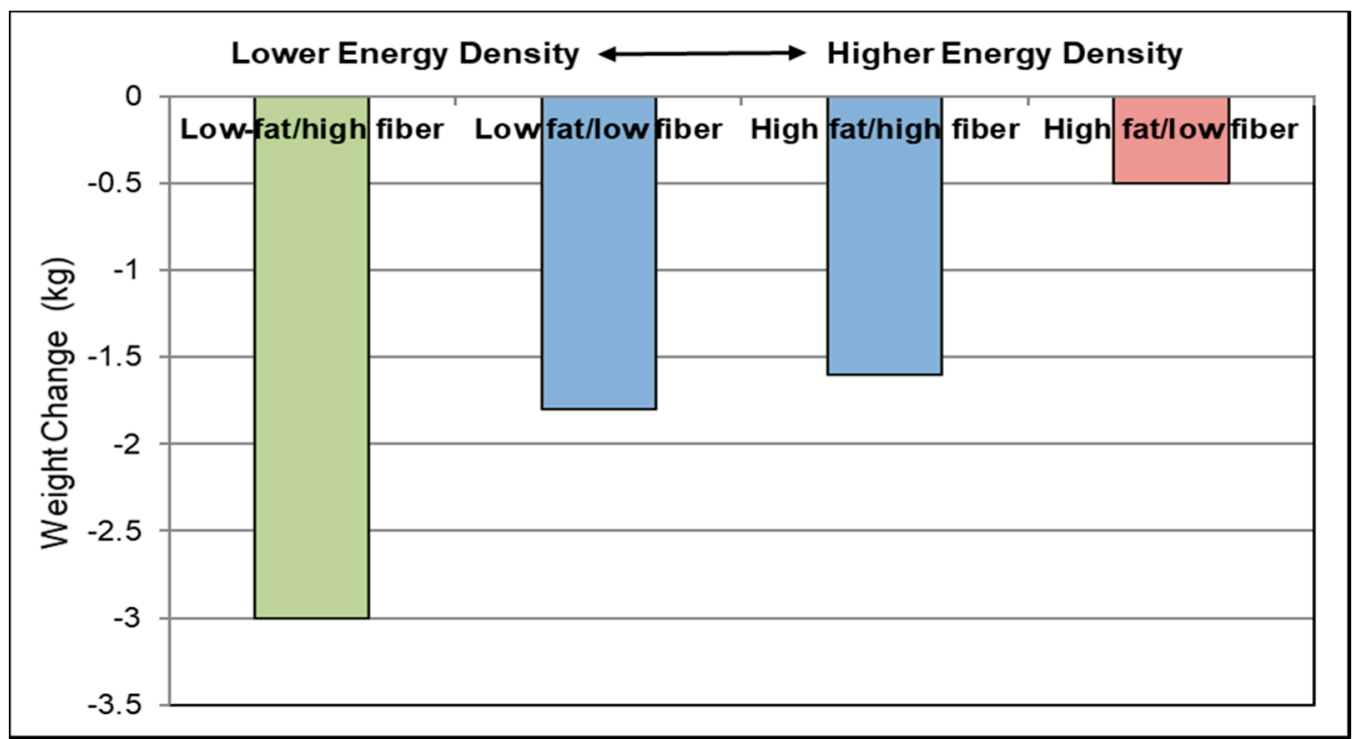

Figure 6. Effect of dietary energy density associated with various levels of fat and fiber intake on body weight in overweight and obese pre-diabetic adults over 3 years in an intensive dietary and exercise program (fiber range 10.9 to $15.6 \mathrm{~g} / 1000 \mathrm{kcal}$ and fat range from $<30$ to $>36.9 \%$ energy) [119].

\subsubsection{Mechanisms}

\section{Colonic Microbiota}

A 2018 review article concluded that higher fiber diets tend to be associated with a healthier microbiome (e.g., microflora richness and biodiversity, and higher SCFAs production), which are associated with a lower risk of obesity [121]. Acetate is considered moderately obesogenic, whereas butyrate and propionate are mainly anti-obesogenic. At the macro-colonic microbiota microflora level, individuals with a lean phenotype tend to have a higher Bacteroidetes to Firmicutes ratio than those with an obese phenotype. A cross-sectional study ( 68 healthy adults, with a BMI range of 23 to $34 \mathrm{~kg} / \mathrm{m}^{2}$ ) observed that lower intake of both fresh whole and dried fruits is associated with higher BMI and had a trend toward reduced levels of the Bacteroides group in obese subjects [122]. The combination of fruit fiber such as pectin and polyphenol components can influence the colonic microbiota ecosystem to increase the number of bacterial phyla Bacteroidetes and Actinobacteria, which are predominant in lean individuals and decrease the prevalence of Firmicutes and Proteobacteria, which are dominant in obese individuals $[98,123]$. Several RCTs have evaluated the effects of fiber intake on microbiota health and weight control. A Danish RCT (62 subjects; $66 \%$ women; mean age 44 years; ad libitum New Nordic diet high in fiber or an average Danish diet lower in fiber; 26 weeks) found an association between the ratio of Prevotella (associated with plant-based diets rich in fiber) to Bacteroides (P/B) and the effectiveness of fiber-rich diets on weight loss [124]. Subjects consuming a high fiber diet with a high microbiota $\mathrm{P} / \mathrm{B}$ ratio lost more weight by $2.3 \mathrm{~kg}$ compared to subjects with a high fiber diet and a low $\mathrm{P} / \mathrm{B}$ ratio $(p=0.041)$. The difference in weight loss responsiveness due to $\mathrm{P} / \mathrm{B}$ ratio may be partially associated with propionate produced by the microbiota. Experimental studies suggest that propionate helps to regulate energy homeostasis by suppressing adipogenesis and inhibiting the excessive formation of adipocytes throughout the body via the inhibition of free fatty acid receptor 2 to block fat accumulation by inhibiting lipid droplet formation and differentiation in the adipose tissue [125]. A crossover RCT (20 non-obese men) suggests that prebiotic fiber stimulated colonic propionate production and appears to have had a role in decreasing the subjective desire for high-energy food leading to reduced energy intake during an ad libitum meal by attenuating reward-based eating behavior pathways, independent of changes in plasma PYY and GLP-1 [126]. Also, experimental studies suggest that butyrate may affect energy metabolism indirectly, acting through the gut-brain axis by crossing the blood-brain 
barrier and activating the vagus nerve and hypothalamus to affect appetite and energy intake [127]. Although more research is needed to better link the various types and sources of fiber with the specific microflora and particular SCFA production that best protects against obesity, a sustained diet high in fiber appears to be associated with a lean phenotype.

\section{Energy Density (ED)}

The consumption of low ED foods, especially volumetric foods such as soups or fresh fruits, prior to or as part of a meal can enhance satiety, or reduce hunger and total energy intake during the meal or throughout the day. This is linked to a complex mixture of cognitive, sensory, gastrointestinal, hormonal and neural processes [128,129]. In the natural state most fresh and minimally processed fruits are high in bulk volume and low in ED, ranging from 0.3 to $1.6 \mathrm{kcal} / \mathrm{g}$ (Table 1), because of high water $(0 \mathrm{kcal} / \mathrm{g})$ and fiber $(1-2 \mathrm{kcals} / \mathrm{g})$ content. A recent study showed that humans tend to have a relatively low energy regulatory sensitivity to foods or meals with an ED $>1.75 \mathrm{kcal} / \mathrm{g}$, which can lead to a positive energy balance associated with increased risk of weight gain [130]. For fruits, fresh fruits average $0.6 \mathrm{kcals} / \mathrm{g}$ and dried fruits average $2.9 \mathrm{kcal} / \mathrm{g}$ as calculated from Table 1 , less than many $\geq 5 \mathrm{kcal} / \mathrm{g}$ confectionery, chip or bakery snacks. According to an analysis of the third National Health and Nutrition Survey (NHANES III), the mean ED of the US diet is estimated to be $1.9 \mathrm{kcal} / \mathrm{g}$, which is consistent with the Western diet, low in fruit and vegetable intake and resulting in higher than normal BMIs [131]. A NHANES cross-sectional study from 2005-2008 (9551 adults) observed that higher proportions of energy intake and food weight from low-ED foods like fresh fruits were associated with significantly lower BMI and waist circumference [132]. For example, the substitution of $\geq 2$ servings fresh fruit for higher ED snacks or desserts typical in Western diets can help to reduce total dietary ED to $<1.75 \mathrm{kcal} / \mathrm{g}$ needed to better support weight control or promote modest weight loss. Providing fresh fruit early in a child's life is one of the best healthful eating behaviors that is predictive of lower energy intake later in life [133]. A cross-sectional study of weight loss maintainers who lost $>10 \%$ of their body weight and maintained that loss for $\geq 5$ years reported that they consumed diets

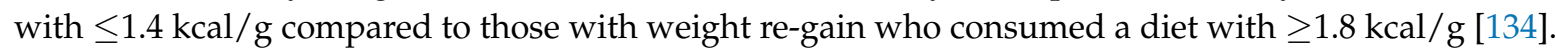
The consumption of 2 or more daily servings of fresh fruits as a replacement for higher ED foods such as low fiber, energy rich snacks can help to reduce the total diet energy density level below $1.75 \mathrm{kcal} / \mathrm{g}$ to better support weight control and modest weight loss.

\section{Satiety and Energy Intake}

Fruit Fiber. Several RCTs have examined the effects of fruit fiber on satiety and energy intake. A systematic review of RCTs on satiety, acute energy intake, total energy intake and body weight found that more viscous or gelling fibers (e.g., pectins, $\beta$-glucans and guar gum) reduced appetite more often than less viscous fibers (59\% vs. 14\%) and lowered acute energy intake (69\% vs. 30\%) [135]. For pectin, RCTs show that $\geq 5 \mathrm{~g}$ of fruit pectin added to orange juice significantly increased satiety and reduced ice cream intake $4 \mathrm{~h}$ later $(p<0.001)$ [136], and 10 g pectin modestly but significantly lowered hunger, increased fullness, and reduced energy intake by $5.6 \%(p=0.012)$ compared with the $10 \mathrm{~g}$ gelatin and starch control [137]. For orange pomace, a double-blind, crossover RCT found that adding $5.5 \mathrm{~g}$ of orange pomace fiber to low fiber orange juice or orange flavor beverage significantly increased satiety vs. a low fiber control juice $(p<0.0001)$ [138]. For banana flour, an RCT showed that adding $8 \mathrm{~g}$ unripe banana flour ( $5 \mathrm{~g}$ resistant starch) to soup significantly reduced hunger and increased satiety parameters resulting in a $14 \%$ reduction in energy intake compared to the placebo soup [139]. The intake of greater than $5 \mathrm{~g}$ of fruit fiber from cell wall components or resistant starch can help to increase satiety, and reduce hunger and energy intake in a subsequent meal.

Fruit. A number of RCTs have evaluated the effects of consuming fresh or dried fruits on satiety, hunger and energy intake. Whole fruit consumption results in greater upper intestinal bulk fiber volume, which can delay the absorption of nutrients long enough to deliver a portion of them to the 
distal ileum. This stimulates the release of a cascade of metabolic ileal brake responses associated with the release of satiety hormones (e.g., glucagon-like peptide-1 [GLP-1] and peptide YY), which slow gastric emptying and small bowel transit to reduce acute appetite and energy intake [140,141]. For apples or pears, women adding 3 small apples or pears to the usual diet reduced daily energy intake by 20-25 kcals/day compared to a $1 \mathrm{kcal}$ increase for 3 oatmeal cookies [114] and young adults consuming a whole apple 15 min before a meal significantly lowered energy intake by $15 \%$ $(p<0.0001)$ [142] whereas apple sauce reduced energy intake by about $7 \%$ and apple juice had no effect. For mixed berries, adults consuming $65 \mathrm{kcal}$ snacks of mixed berries [3.6 g fiber] $60 \mathrm{~min}$ before an emphad-libitum pasta dinner reduced energy intake by $20 \%$ more than after an isocaloric sweet confectionery snack (Figure 7) [143]. For fruit snacks, children snacking on grapes and raisins consumed half the energy intake compared to those snacking on chocolate chip cookies and potato chips (about 200 kcals vs. 450 kcals) $(p<0.001)$ [144]. For avocados, overweight adults consuming half an avocado at lunch meals significantly increased meal satisfaction by $23 \%$, decreased the desire to eat by $28 \%$ for up-to $5 \mathrm{~h}$ [145], and increased GLP-1 blood concentrations during the first 1-h followed by a decline over the next 2-h [146] compared to the avocado-free control lunch. For prunes, adults consuming 5 dried prunes $(40 \mathrm{~g})$ as a snack reduced lunch meal energy intake by $100 \mathrm{kcals}$ compared to after an isocaloric low fiber and energy dense snack [147]. Both fresh and dried fruits help to reduce hunger, increase meal satisfaction, and/or decrease energy intake when consumed as snacks or with meals compared to non-fruit control foods.

\section{Metabolizable Energy}

RCTs show that fiber-rich diets result in higher fecal energy loss, especially unabsorbed fat, compared to low-fiber diets [148-150]. A 1978 RCT (6 normal healthy male subjects; isocaloric diets; 5 to 8 days) found that fecal macronutrient energy loss on a low-fiber diet was less than half of that observed on a high-fiber diet [151]. The consumption of $>25 \mathrm{~g}$ fiber/day can lead to the excretion of $3-4 \%$ of macronutrient energy in the feces, which is equivalent to $80 \mathrm{kcals}$ in a $2000-\mathrm{kcal}$ diet. An energy balance intervention ( 8 healthy female students) showed that subjects with high fiber diets rich in fruits and vegetables had a significantly higher fecal metabolizable energy content of $220 \mathrm{kcal} /$ day compared to $108 \mathrm{kcal} /$ day for subjects with low fiber diets [152]. A small RCT (4 lean and 4 obese adults) found that obese subjects had lower mean fecal macronutrient energy loss (or more efficient energy absorption) than lean subjects [153].

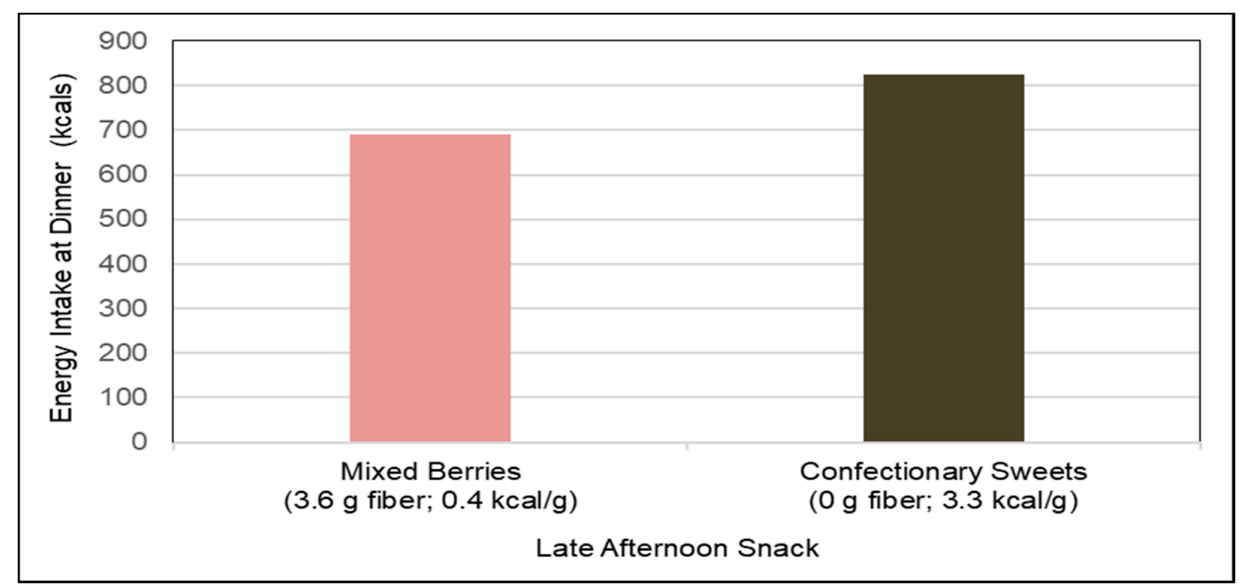

Figure 7. Mean energy intake at ad-libitum dinner after a late afternoon $65 \mathrm{kcal}$ pre-dinner snack of mixed berries vs. confectionary sweets $(p<0.001)$ [143]. 


\subsection{Cardiovascular Disease (CVD)}

Cardiovascular diseases are the leading cause of morbidity and mortality worldwide and healthy dietary patterns including fiber rich fruits, vegetables, whole-grains and nuts have an important role in prevention $[154,155]$.

\subsubsection{Fruit and Fruit Fiber}

Vascular Aging (Atherosclerosis)

Observational Studies. Vascular aging with the build-up of atheromatous plaques in medium-and large-sized blood vessels, raises CVD risk, which can be assessed by measuring the common carotid intima-media thickness (IMT), carotid artery stiffness or abdominal aortic calcification [154-156]. A 2017 analysis of data from cardiovascular disease-free adults in the World Health Organization (WHO) Study on Global Aging and Adult Health (29,094 adults) and US NHANES (6726 adults) observed that people with higher fruit intake had lower odds of excessive vascular aging as calculated by the Framingham CVD risk equation (Figure 8) [156]. The Los Angeles Atherosclerosis Study (573 participants; mean age 50 years; 2-year follow-up) observed that a higher intake of pectin significantly slowed IMT progression (Figure 9), which appears to be mediated by lowering the ratio of total to HDL cholesterol [157]. The Cardiovascular Risk in Young Finns cohort study (1809 participants; 27 years) observed that carotid IMT progression was inversely associated with fruit intake in childhood [158]. In a Mediterranean cohort of young adults, the Seguimiento Universidad de Navarra Follow-up study (17,000 participants; 10.3 years) observed an inverse association between fruit consumption and fruit fiber and CVD risk with a risk reduction of approximately $50 \%$ each ( $p$-trend $=0.024$ ) [159]. The consumption of $\geq$ two daily servings of fruit $(160 \mathrm{~g} /$ day) reduced CVD risk by $38 \%$ in young Mediterranean populations $(p=0.045)$. An Australian cohort study (1510 elderly women; 5 years) observed that each $50 \mathrm{~g} /$ day apple consumption (approx. 1/2 of a small apple) was significantly associated with $24 \%$ lower odds of having severe abdominal aortic calcification $(p=0.009)$ [160]. A Chinese prospective study (70,047 adults with physician-diagnosed CVD) observed a $29 \%$ reduction in CVD mortality for each daily $100 \mathrm{~g}$ intake of whole fruit [161]. The UK Women's Cohort Study (30,458 women; 17 years) observed that each serving of fresh fruit or dried fruit/day significantly reduced risk of mortality from CHD by $11 \%$ and CVD by $8 \%(p=0.007)$ [162]. A 2013 systematic review and meta-analysis found a lowered risk of CHD or CVD by $8 \%$ per each $4 \mathrm{~g}$ intake of fruit fiber/day, with substantial heterogeneity between type of fruit [163]. Although more research is needed, the sustained intake of whole fruits and fruit fiber has been associated with a reduced rate of vascular aging and lower risk of mortality from CVD.

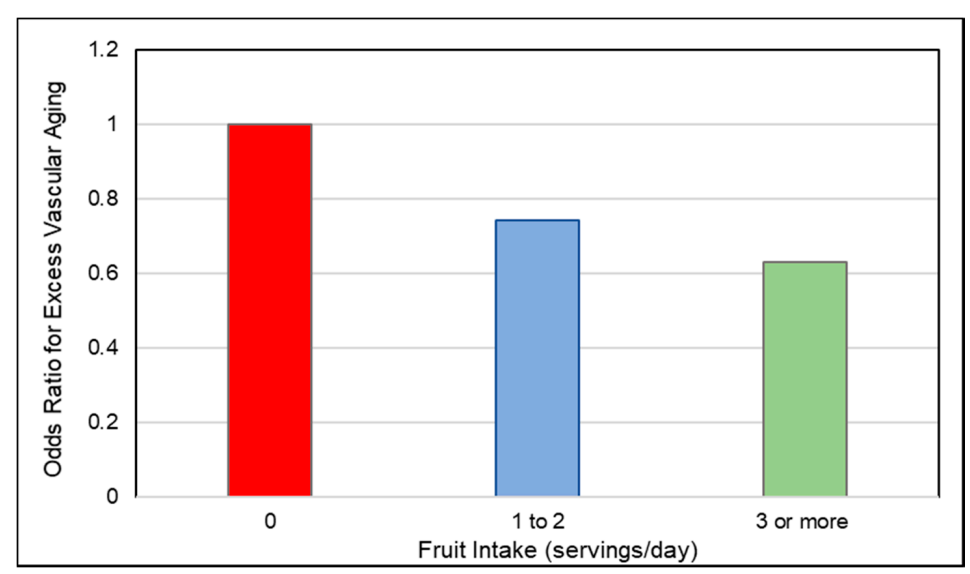

Figure 8. Association between the number of fruit servings/day and excessive vascular age from pooled estimates of World Health Organization (WHO) and US National Health and Nutrition Examination Survey (NHANES) data among adults aged 30-74 years $(p=0.038)$ [156]. 


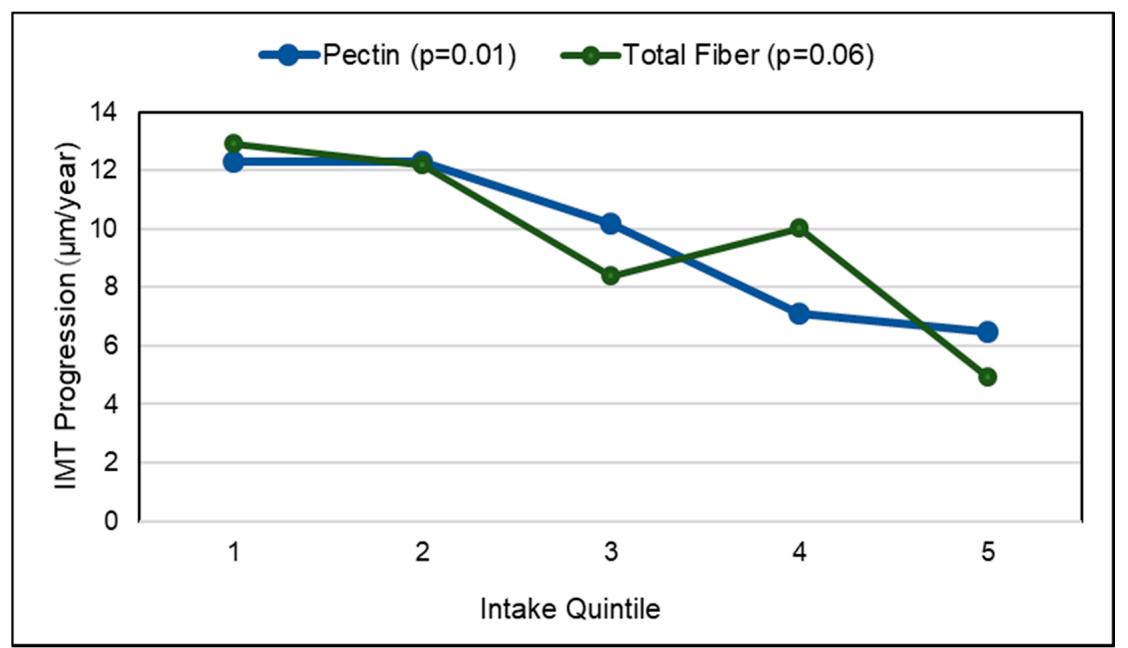

Figure 9. Progression of intima-media thickness (IMT) in the common carotid-artery by quintile of fiber intake among 500 participants in the Los Angeles Atherosclerosis Study [157].

Intervention Trial. An acute intervention trial (31 newly diagnosed CVD patients; elevated CVD risk profile; high fiber diet primarily consisted of fruits, vegetables, avocados and seeds) found that this diet significantly improved blood lipids and other CVD risk factors to reduce vascular aging compared to baseline values and rapidly reduce CVD risk profiles (Table 2) [164]. In newly diagnosed CVD patients, the consumption of an acute healthy diet rich in fruits and vegetables with approximately $50 \mathrm{~g}$ fiber/day has the potential to realign major CVD risk factors back to normal levels before a healthy dietary pattern is adapted for a longer-term CVD risk management.

Table 2. Mean change in cardiovascular disease (CVD) risk factors for newly diagnosed CVD patients after a 4-week prevention diet primarily of fruits, vegetables, avocados and seeds [164].

\begin{tabular}{ccccc}
\hline Variable & Baseline Value & 4-Week Value & \% Change & $p$-Value \\
\hline Total cholesterol $(\mathrm{mg} / \mathrm{dL})$ & 217 & 183 & -34 & $<0.0005$ \\
LDL-C $(\mathrm{mg} / \mathrm{dL})$ & 143 & 118 & -25 & $<0.0005$ \\
HDL-C $(\mathrm{mg} / \mathrm{dL})$ & 55 & 105 & -5 & $<0.0005$ \\
Triglycerides $(\mathrm{mg} / \mathrm{dL})$ & 124 & 105 & -20 & $=0.008$ \\
Insulin $(\mu \mathrm{IU} / \mathrm{mL})$ & 14.6 & 10.3 & -4.3 & $<0.0005$ \\
Glucose $(\mathrm{mg} / \mathrm{dL})$ & 90 & 87 & -2.9 & $=0.25$ \\
HbA1c $(\%)$ & 5.9 & 5.7 & -0.2 & $=0.002$ \\
hs-CRP $(\mathrm{mg} / \mathrm{L})$ & 7.8 & 5.3 & -2.5 & $=0.001$ \\
Weight $(\mathrm{kg})$ & 108 & 101 & -7.0 & $<0.0005$ \\
BMI $\left(\mathrm{kg} / \mathrm{m}^{2}\right)$ & 37.5 & 35.2 & -2.3 & $<0.0005$ \\
Diastolic BP $(\mathrm{mm} \mathrm{Hg})$ & 91 & 82 & -9.0 & $<0.0005$ \\
Systolic BP $(\mathrm{mm} \mathrm{Hg})$ & 147 & 130 & -17 & $<0.0005$ \\
Energy $(\mathrm{kcal} / \mathrm{day})$ & 2053 & 1369 & -684 & $<0.0005$ \\
Dietary Fiber $(\mathrm{g} / \mathrm{day})$ & 20 & 51 & +31 & $<0.0005$ \\
\hline
\end{tabular}

\section{Blood Lipids}

RCTs. A number of RCTs and meta-analyses of RCTs show that the consumption of pectin and whole fruits can lower total and LDL-cholesterol (LDL-C) levels and other cardiometabolic risk factors. The primary mechanism is related to the increased fruit fiber bulking, especially from viscosity/gelling of pectin, in the ileal region of the small intestine reducing the efficiency of bile acid reabsorption (the enterohepatic circulation) and leading to increased uptake of circulatory LDL-C by the liver to compensate for reduced availability of bile acids [165]. For citrus and apple pectin, each gram of pectin added to the diet has a mean lowering effect on serum total cholesterol by $1.7 \mathrm{mg} / \mathrm{dL} / \mathrm{g}$ and LDL-C by $2.2 \mathrm{mg} / \mathrm{dL} / \mathrm{g}$ [166]. A crossover RCT (30 mildly hypercholesterolemic subjects; age 18-70 years; $6 \mathrm{~g}$ /day of different types of pectins; 3 to 4 weeks; 1 -week washout) demonstrated that the most effective sources are citrus and apple pectin DE-70, which reduced LDL-C by 6-7\% [167]. 
Also, a crossover RCT showed that apple products lowered total and LDL-C levels in direct relation to the apple pectin content [168]. A whole apple ( $2.9 \mathrm{~g}$ pectin) was approximately 3 times more effective in lowering LDL-C than apple juice ( 0.5 g pectin). For avocados: (1) A crossover RCT found that eating a daily avocado (9.2 $\mathrm{g}$ fiber and estimated $3.6 \mathrm{~g}$ pectin) as part of a moderate $34 \%$ energy from healthy fat diet significantly reduced total-cholesterol by $6.5 \mathrm{mg} / \mathrm{dL}$, LDL-C by $5.3 \mathrm{mg} / \mathrm{dL}$ and non-HDL-C by $6.2 \mathrm{mg} / \mathrm{dL}$ compared to a similar energy matched moderate healthy fat diet without an avocado (Figure 10) [169]. (2) A crossover RCT (31 middle age adults; breakfast meal with a half or whole avocado vs. a higher carbohydrate control meal without avocado; 6 hrs postprandial) demonstrated both a half or whole avocado significantly improved postprandial glycemia, insulinemia and flow mediated vasodilation (FMD) compared to a control breakfast [170]. The consumption of a whole avocado significantly lowered levels of triglycerides (TG) and promoted high levels of larger HDL particles. (3) A 2016 meta-analysis of RCTs with all primary blood lipid outcomes (8 crossover RCTs and 2 parallel RCTs; 229 subjects) found that diet substitutions of avocado for other dietary fats significantly decreased total cholesterol by $19 \mathrm{mg} / \mathrm{dL}$, LDL-C by $17 \mathrm{mg} / \mathrm{dL}$, and TG levels by $27 \mathrm{mg} / \mathrm{dL}$ [171]. HDL-C was insignificantly decreased by $0.18 \mathrm{mg} / \mathrm{dL}$. (4) A 2018 meta-analysis (7 RCTs; 220 subjects) showed that consuming an avocado insignificantly reduced total cholesterol by $3.4 \mathrm{mg} / \mathrm{dL}$, LDL-C by $3.5 \mathrm{mg} / \mathrm{dL}$ and triglycerides by $12 \mathrm{mg} / \mathrm{dL}$, and significantly increased HDL-C by $2.8 \mathrm{mg} / \mathrm{dL}$ compared to a diet without an avocado [172]. For prunes, a crossover RCT (41 hypercholesteremic men; 12 prunes (100 g/ $6 \mathrm{~g}$ fiber) vs. grape juice control; 8 weeks) showed that prunes significantly lowered LDL-cholesterol by $7.7 \mathrm{mg} / \mathrm{dL}$ compared to the grape juice control $(p=0.02)$ [173]. Prunes also increased excretion of the bile acid lithocholic acid by $25 \mathrm{mg} / \mathrm{g}$ dry stool. For berries, a meta-analysis of berry consumption (22 RCTs; 1251 subjects; variety of whole berries, juices, and smoothies) concluded that whole berries and smoothies significantly reduced mean LDL-cholesterol by $8.1 \mathrm{mg} / \mathrm{dL}(p=0.003)$, systolic blood pressure by $2.7 \mathrm{mmHg}(p=0.04)$, BMI by $0.36 \mathrm{~kg} / \mathrm{m}^{2}(p<0.00001)$, hemoglobin A1c $(\mathrm{HbA} 1 \mathrm{c})$ by $0.20 \%(p=0.04)$ and tumor necrosis factor- $\alpha(\mathrm{TNF}-\alpha)$ by $0.99 \mathrm{\rho g} / \mathrm{mL}(p=0.04)$ compared to control diets [174]. Whole fruit fiber, especially pectin from citrus, apples, avocados, prunes, and berries, has an active role in helping to reduce LDL- and non-HDL-cholesterol by lowering bile acid reabsorption to attenuate CHD and CVD risk.

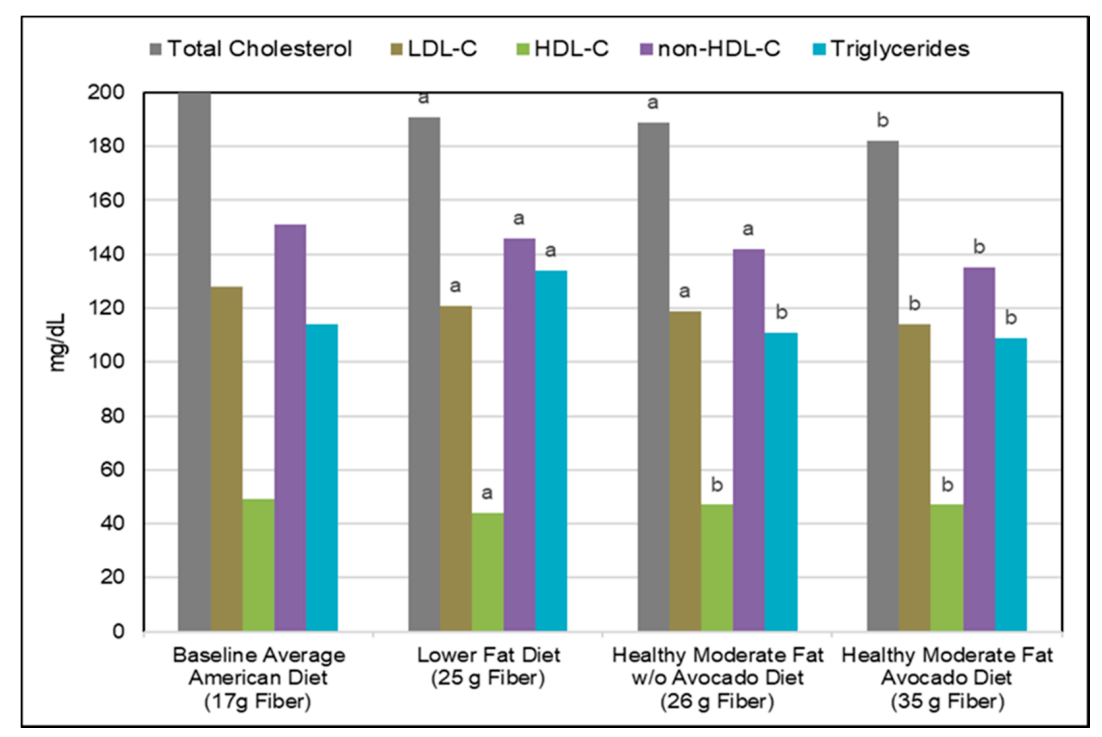

Figure 10. Effect of fiber and fat on total and LDL-cholesterol in a crossover Randomized Controlled Trial (RCT) of 45 overweight or obese adults over 5 weeks (based on $2100 \mathrm{kcal} /$ diets; total fat $34 \%$ of energy for all diets except $24 \%$ for the low-fat diet; protein approx. $16 \%$ of energy for all diets; saturated fat energy $13 \%$ for the American diet, $7 \%$ for the low-fat diet and $6 \%$ for the two moderate fat diets with healthy vegetable oil vs. 1 avocado. Values with different superscript letters ( $a$ and b) are significantly different $(p<0.05)$ [169]. 
Hypertension

Observational Studies. A number of prospective cohort and cross-sectional studies have observed associations between the effects of increased fruits and vegetables on blood pressure (BP) and the risk of hypertension. An analysis of 3 large, long-term cohorts (187,453 participants from Nurses' Health Study, Nurses' Health Study II, and Health Professionals Follow-up Study; >20 years) observed a lower mean risk of hypertension for whole fruit by $8 \%$ compared to a $5 \%$ lowering for vegetables ( $\geq 4$ servings/day vs. $\leq 4$ servings/week) [175]. The effect of specific fruits on risk of hypertension is summarized in Figure 11. A meta-analysis (28 cohort studies) observed an inverse association for the risk of hypertension for $30 \mathrm{~g}$ whole grains $/ \mathrm{d}$ by $8 \%, 100 \mathrm{~g}$ fruits $/ \mathrm{d}$ by $3 \%$ and $200 \mathrm{~g}$ dairy/d by $5 \%$, whereas there was a positive association for $100 \mathrm{~g}$ red meat/d by $14 \%, 50 \mathrm{~g}$ processed meat/d by $12 \%$, and $250 \mathrm{~mL}$ sugar sweetened beverages/d by 7\% [176]. Two meta-analyses: (1) 25 studies; 334,468 participants [177] and (2) 7 cohort studies; 185,676 participants [178] observed that each daily increased fruit serving intake lowered hypertension risk by approximately $2-3 \%$ per 80 -g serving. The Women's Health Study (28,082 health professionals; 13 years) observed that women who had a higher intake of fruits but not vegetables had significantly reduced hypertension risk, after adjustment for lifestyle and dietary factors [179]. A cross-sectional study (806 men; age 40-69 years) observed that fruit fiber was inversely associated with BP $(p=0.07)$ with no significant association observed for cereal or vegetable fiber [180]. An increase in one daily portion of fruit to the diet was associated with a reduction of approximately $0.7 \mathrm{~mm} \mathrm{Hg}$ in systolic BP and $0.5 \mathrm{~mm} \mathrm{Hg}$ in diastolic BP after adjusting for calcium, potassium, magnesium, education, and physical activity. The Spanish Seguimiento University of Navarra (SUN) study (8594 participants; 6 years) observed a significant inverse association between fruit intake and BP, but not for vegetable intake [181]. The Korean Genome and Epidemiology Study (4257 adults without hypertension at baseline; 8 years) observed that a higher intake of fruit was associated with a lower risk of hypertension in middle-aged and older Koreans (Figure 12] [182]. A US cross-sectional study (163 adolescents) observed that fruit intake was inversely associated with BMI and diastolic BP [183]. The INTERMAP population study (4680 adults from Japan, China, the United Kingdom, and the US) observed a significant reduction in systolic BP by $1.7 \mathrm{~mm} \mathrm{Hg}$ for each 7-g fiber/1000 kcals increase, independent of potassium and magnesium [184]. The Health Professionals Follow-up Study (30,681 men; 40-75 years; 4 years) observed that men consuming $<12 \mathrm{~g}$ fiber/day had a $57 \%$ increased risk of hypertension compared to men with an intake of $>24 \mathrm{~g} /$ day and fruit fiber but not vegetable or cereal fiber was inversely associated with hypertension risk [185]. The Nurses' Health Study (41,541 US women; 4 years) observed that women consuming $<10 \mathrm{~g}$ fiber/day had a $109 \%$ greater risk of elevated BP compared to women consuming $\geq 25 \mathrm{~g}$ fiber/day [186]. A NHANES analysis of data between $2007-2014$ (18,433 US adults; $\geq 18$ years) showed that the intakes of cereal and vegetable fibers were associated with significantly lower hypertension risk by $18-20 \%$, but fruit fiber was insignificantly associated with a $14 \%$ lower risk of hypertension, which is inconsistent with previous studies and potentially due to a younger demographic and the methodology used [187]. The consumption of whole fruits and fruit fiber lowers the risk of hypertension and reduces BP more effectively than vegetables, especially in middle aged or older adults. 


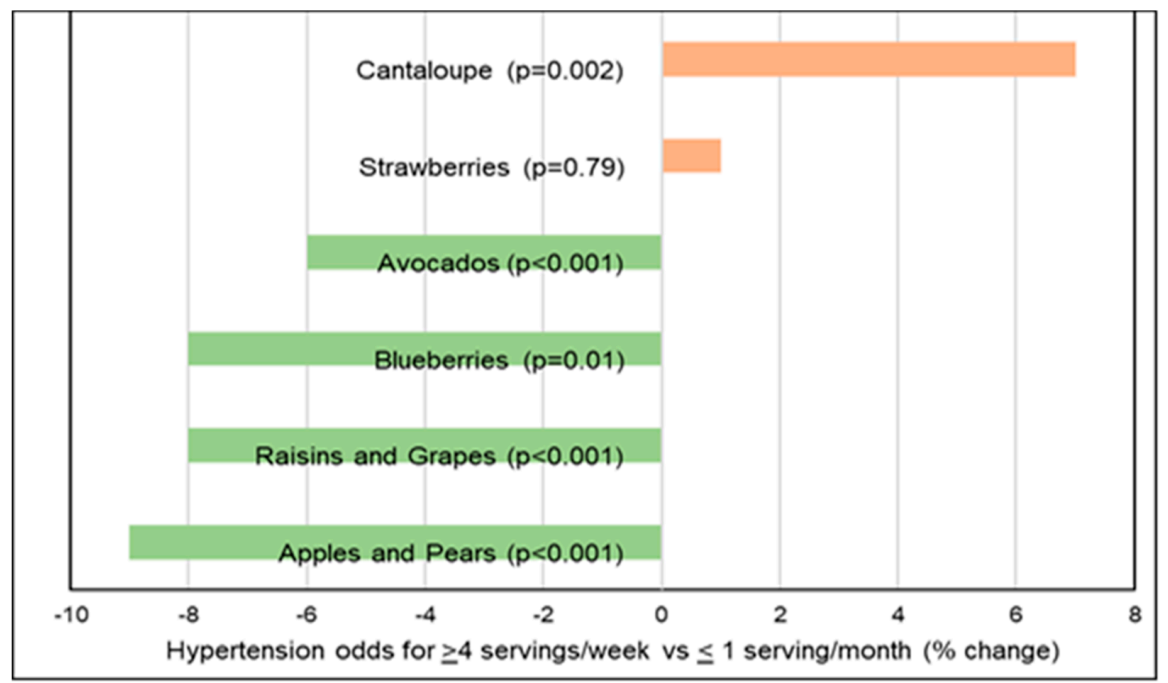

Figure 11. Change in the risk of hypertension associated with fruit consumption from pooled Nurses' Health Study, Nurses' Health Study II, and Health Professional Follow-up Study data [175].

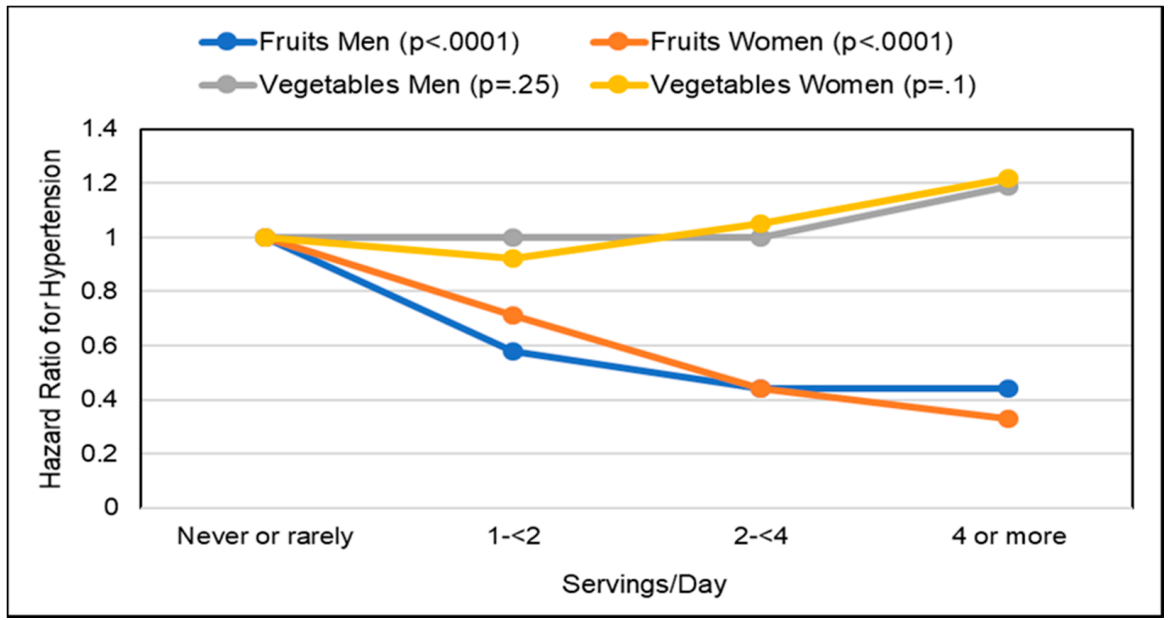

Figure 12. Association between the number of fruit or vegetable servings and hypertension risk in a cohort of middle-aged and older Koreans [182].

RCTs. A number of RCTs and systematic reviews or meta-analyses of RCTs have evaluated the effects of increased fruit and vegetable intake on BP. A Cochrane systematic review (2 RCTs; 891 generally healthy adults; 6-12 months) found that the consumption of at least 5 servings of fruits and vegetables significantly reduced mean systolic BP by $3.0 \mathrm{~mm} \mathrm{Hg}$ compared to low fruit and vegetable intake [188]. An RCT (459 hypertensive and normotensive adults) showed that hypertensive subjects significantly reduced systolic BP by $7.2 \mathrm{~mm} \mathrm{Hg}(p<0.001)$ and diastolic BP by $2.8 \mathrm{~mm} \mathrm{Hg}(p=0.01)$ with 8-10 servings/d vs. approximately 4 servings/d of fruits and vegetables [189]. Non-hypertensives had an insignificant reduction in systolic BP by $0.8 \mathrm{~mm} \mathrm{Hg}$ and diastolic BP by $0.3 \mathrm{~mm} \mathrm{Hg}$. A dose response RCT (117 adults; 12 weeks) showed that each serving of fruits and vegetables significantly increased forearm blood flow by $6 \%$ in hypertensive subjects [190]. An RCT (690 healthy middle age adults; mean BP 130/79 mm Hg; 6 months) found that at least 5 fruit and vegetable servings/day significantly reduced systolic BP by $4.0 \mathrm{~mm} \mathrm{Hg}$ and diastolic BP by $1.5 \mathrm{~mm} \mathrm{Hg}$ compared to 3.5 fruit and vegetable servings/day [191]. A double-blind RCT (52 middle aged women; 8 weeks) showed that the Dietary Guidelines for Americans with adequate fruit and vegetable intake significantly lowered systolic BP by $9 \mathrm{~mm} \mathrm{Hg}$ without weight loss compared to the typical American diet [192]. A systematic review and meta-analysis (20 RCTs; 1917 adults) found that the DASH diet (8-10 fruits 
and vegetables servings/d) significantly decreased systolic BP by $5.2 \mathrm{~mm} \mathrm{Hg}$ and diastolic BP by $2.6 \mathrm{~mm} \mathrm{Hg}$ (all $p<0.001$ ) with greater reductions in subjects with higher baseline BP and/or BMI [193]. A 2018 meta-analysis (22 RCTs; 1430 participants; 7 weeks) found that viscous soluble fibers including fruit pectin have a small but significant mean lowering effect on systolic BP by $1.6 \mathrm{~mm} \mathrm{Hg}$ and diastolic BP by $0.4 \mathrm{~mm} \mathrm{Hg}$ compared to control diets [194]. A 2016 Cochrane Systemic review (8 RCTs; 661 adults with high CVD risk; $>12$ weeks) found that increased fiber intake significantly lowered mean systolic BP by $1.9 \mathrm{~mm} \mathrm{Hg}$ and diastolic BP by $1.8 \mathrm{~mm} \mathrm{Hg}$ [195]. Two 2005 meta-analyses of RCTs showed that an increase in fiber intake by $11 \mathrm{~g} /$ day can significantly lower mean systolic BP by $6 \mathrm{~mm} \mathrm{Hg}$ and mean diastolic BP by $4.2 \mathrm{~mm} \mathrm{Hg}$ in hypertensive subjects $[196,197]$. RCTs generally show that increased fruit and vegetable intake results in a significant reduction of $\mathrm{BP}$ in older, overweight, prehypertensive or hypertensive subjects compared to younger, normal weight and normotensive subjects.

Mechanisms. There are a number of whole fruit and fruit fiber related mechanisms associated with $\mathrm{BP}$ and hypertension lowering effects: (1) reducing risk of weight gain or obesity; (2) lowering risk of insulin resistance, an important pathophysiological influence on the development of endothelial dysfunction; (3) promoting healthier lipoprotein profiles to slow the rate of vascular aging (arterial plaque build-up); (4) attenuating elevated systemic inflammation and LDL-oxidation risk; and (5) stimulating a healthier colonic microbiota and increased fermentation to SCFAs to upregulate receptor expression in the kidneys or other blood vessels thought to be associated with better BP regulation [198-201].

\subsection{Type 2 Diabetes (Diabetes)}

Prevention of diabetes is determined by controlling blood glucose and insulin, and systematic inflammation to preserve insulin receptor and pancreatic $\beta$ cell function, which is achievable by the implementation of early and sustainable lifestyle measures including modifying dietary and physical activity habits which induce better weight control or modest weight loss, a preferred approach to drug therapy, when possible, due to its safety, efficacy, and cost [202-204].

\subsubsection{Fruit and Fruit Fiber}

\section{Observational Studies}

Low glycemic index (GI) foods such as fiber containing whole fresh fruits can be healthy substitutes for high GI foods, as part of any meal, snack or dessert to reduce the risk of and management of diabetes. A 2016 meta-analysis (17 cohort studies) found that total fruit reduced diabetes risk (highest to lowest intake) by $9 \%$ and blueberry intake significantly reduced risk by $25 \%$ [205]. A 2015 meta-analysis of fruit (9 cohort studies; 403,259 participants) found a non-linear association for fruit intake and diabetes risk ( $p$ for nonlinearity $<0.001$ ) with a threshold of $200 \mathrm{~g} /$ day total fruit intake reducing risk of diabetes by $13 \%$ [206]. A Finnish prospective study observed that individuals in the highest quartile for intake of fruits, berries, and vegetables (with the exclusion of potatoes and fruit juices) had a significant $24 \%$ reduction in diabetes risk compared to those in the lowest quartile [207]. A pooled analysis of the Nurses' Health Studies and the Health Professionals Follow-up Study observed a high degree of heterogeneity in the effect of whole fruits on diabetes risk per 3 weekly servings (Figure 13) [208]. The 2017 China Kadoorie Biobank cohort study (0.5 million adults; 7 years) observed that among those without diabetes at baseline, higher fruit intake was associated with significantly lower risk of developing diabetes by $12 \%$ compared to non-consumers $(p<0.001)$ [209]. Among those individuals who had diabetes prior to the start of the study, consuming fresh fruit more than 3 days/week was associated with a 13\% to $28 \%$ lower risk of developing diabetes-related complications affecting large blood vessels (e.g., ischaemic heart disease and stroke) and small blood vessels (i.e., kidney diseases, eye diseases, and neuropathy) compared to individuals who consumed fruit $\leq$ one day/week $(p<0.001)$. A meta-analysis (9 cohort studies; 341,668 participants) observed that high versus low fruit fiber intake lowered diabetes risk by $6 \%$ but cereal fiber (11 cohort studies; 
389,047 participants) reduced diabetes risk by $23 \%$ [210]. The EPIC-Potsdam Study (9702 men and 15,365 women; 7 years follow-up) observed that increased soluble fiber was twice as effective in reducing diabetes risk as insoluble fiber (17\% vs. 7\%) [211]. The Australian Longitudinal Study (3607 young women; 12 years) observed that women in the highest quartile of fiber intake had a 33\% lower risk of developing gestational diabetes $(p=0.05)$ [212]. Higher fruit intake, especially fiber rich and low GI varieties, reduced gestational diabetes risk by $5 \%$ per $50 \mathrm{~g} /$ day whereas cereal intake may increase gestational diabetes risk by $5 \%$ per $20 \mathrm{~g} /$ day, especially high GI and low fiber sources. The EPIC-Norfolk Study (5996 healthy adults) observed that participants who reported consuming fruit $\geq 5$ times/week ( $20 \mathrm{~g}$ fiber/day) vs. never or seldom consuming fruit ( $13 \mathrm{~g}$ fiber/day) had significantly lower mean adjusted $\mathrm{HbA1c}$ by $0.1 \%(p=0.007)$ [213]. A cross-sectional study (40 women) observed that higher intake of fruits (>293 g/day; especially apples and citrus fruits) was related to significantly lower fasting blood insulin and HOMA-IR (Figure 14), which was mediated by higher fiber and antioxidant intake [214]. The Japan Diabetes Complications Study (978 diabetes patients; $\mathrm{HbA} 1 \mathrm{c} \geq 6.5 \%$; 8-years) observed that the consumption of $253 \mathrm{~g}$ fruit/day reduced the incidence of diabetic retinopathy by $52 \%$ compared to intake of $23 \mathrm{~g}$ fruit/day $(p<0.01)$ [215]. A cross-sectional study (264 women) observed that each $1 \mathrm{~g}$ increase in soluble fiber decreased HOMA-IR by $0.11(p=0.006)$ [216]. Also, women with high soluble fiber intake had a $48 \%$ lower risk of insulin resistance vs. women with low soluble fiber intake. A cross-sectional analysis of the Nurses' Health Study observed that fruit fiber intake was inversely associated with $\mathrm{HbA1c}$ concentrations ( $p$-trend < 0.03) [217]. A Japanese longitudinal study (190 adults 5 months) observed that increasing the diet's fiber to total carbohydrate ratio was associated with significant reductions in HbA1c $(p<0.001)$ [218]. The Cohort Diabetes and Atherosclerosis Maastricht prospective study (303 adults; 7 years) observed that combined increased intake of fiber and monounsaturated fatty acids (MUFA) were the primary nutrients associated with better pancreatic $\beta$-cell function [219]. A cross-sectional study (68 adults) observed that lower intake of whole fruit was associated with increased diabetes risk due to higher free radical and pro-inflammatory status [122]. The Nurses' Health Study (70,025 women; mean baseline age 50 years; 24 years follow-up) observed that both total and fruit fiber were associated with $20 \%$ lower odds of diabetes compared to a $30 \%$ lower risk for cereal fiber [220]. Also, a higher starch or total carbohydrate to total fiber ratio was associated with an approximately $10 \%$ increased odds of diabetes risk. Observational studies generally observe that higher fiber containing fruits are associated with lower diabetes risk and better control of diabetes risk biomarkers such as HOMA-IR, HbA1c and fasting insulin, and lower risk of diabetic retinopathy.

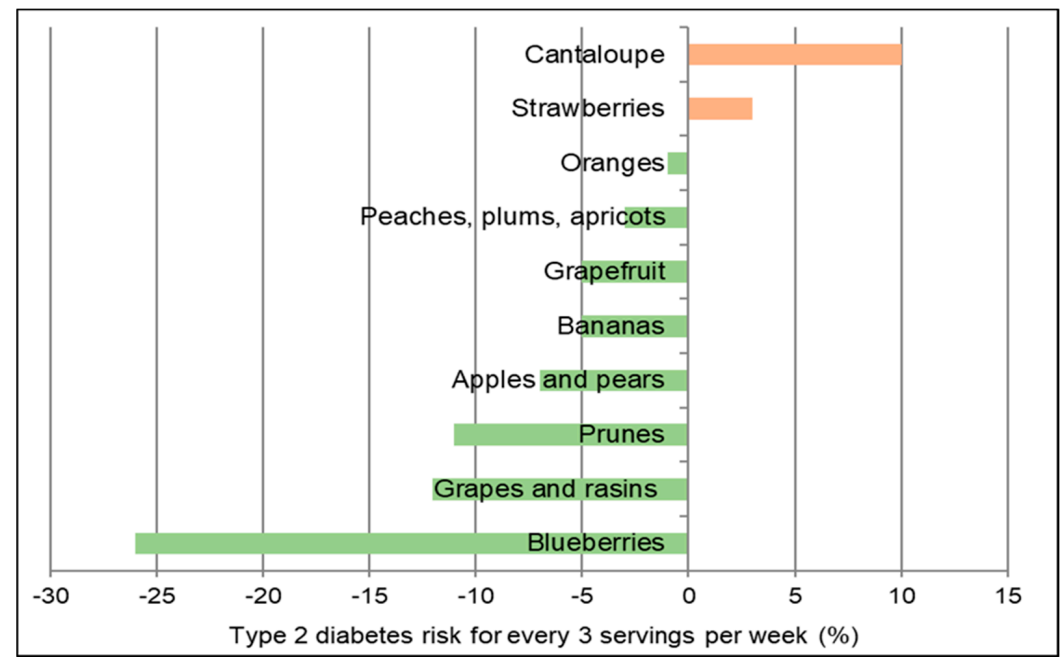

Figure 13. Effect of 3 servings per week of fruit varieties on type 2 diabetes (diabetes) risk from pooled data from US men and women in the Nurses' Health Studies and the Health Professionals Follow-up Study [208]. 


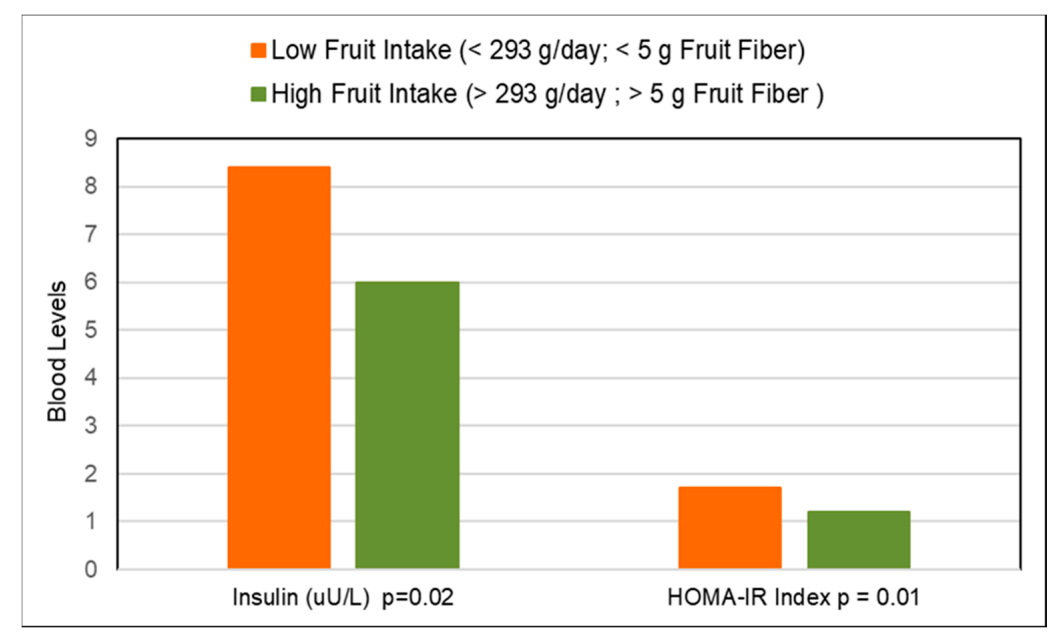

Figure 14. Association between fruit and fruit fiber intake on insulin sensitivity measures in 40 normal-weight young women with low to normal TNF- $\alpha$ values [214].

\section{RCTs}

Postprandial Glycemic Control. Eating whole fruit increases gastrointestinal bulk from chewed fruit pulp and edible skins and viscosity from soluble fiber to the stomach which delays its emptying compared to purees or juice, and attenuates postprandial sugar absorption from the small intestine and insulin secretion to prevent the potential postprandial dip in blood glucose and increase in insulin often observed after consuming fruit juices [221]. For apples, a crossover RCT in healthy adults found that as the degree of apple processing increases and the fruit is broken down into smaller particles and cell walls further disrupted, the rate and completion of digestion in the small intestine significantly increases, which results in higher postprandial plasma glucose and serum insulin levels (Figures 15 and 16) [221]. In another similar RCT, the glycemic and insulinemic effects of whole oranges and orange juice responded similarly to whole and processed apples [222]. For orange pomace, a double blind, crossover RCT showed that orange pomace, a fiber rich orange juice processing by-product, added to a high carbohydrate breakfast beverage significantly lowered glycemic response by $36 \%$ and insulinemic response by $23 \%$ in overweight men compared to the control beverage [223]. For a berry puree, a crossover RCT found that adding a berry puree to bread during breakfast significantly reduced postprandial glycemic and insulin responses by $38 \%$ compared to plain bread [224]. For a mixture of whole fruits, a crossover RCT found that a high carbohydrate breakfast high in whole fruit significantly reduced glucose response by $18 \%$ compared to a breakfast low in whole fruits [225]. For avocados, a single-blind crossover RCT (31 middle age, overweight adults; $6 \mathrm{~h}$ ) showed that consuming test meals containing either a half or full avocado significantly decreased the postprandial glycemic and insulinemic responses to meals over $6 \mathrm{~h}$ compared to control meals (both $p<0.0001$ ) [170]. Postprandial glucose peak concentrations were also significantly lower after consuming both avocado-containing meals at approx. $7 \mathrm{mmol} / \mathrm{L}$ compared to the control meal at approx. $8.1 \mathrm{mmol} / \mathrm{L}(p<0.0001)$. Similar effects were observed in postprandial insulin peak concentrations after avocado-containing meals compared to a control meal $(p<0.005)$. There were no significant differences between the half and whole avocado meals on glucose and insulin response. Also, another crossover RCT showed that consuming half an avocado with a lunch meal significantly attenuated postprandial blood insulin by up to $37 \%(p=0.04)$ within $30 \mathrm{~min}$ and lowered blood insulin levels over a $3 \mathrm{~h}$ postprandial period compared to the similar avocado-free control lunch meal [145]. For dried bananas, a crossover RCT showed that adding dried whole banana powder (rich in resistant starch) to a milkshake reduced postprandial glucose response by $43 \%(p=0.03)$ compared to the control milkshake [226]. For raisins, a crossover RCT found that adding raisins to a meal resulted in significantly reduced postprandial glucose and insulin responses when compared to a raisin-free meal $(p<0.05)$ [227]. The bulking and soluble, viscous fibers from both fresh and dried 
fruits help to attenuate postprandial insulin responses to protect against the risk of insulin resistance and $\beta$-cells dysfunction and senescence, major factors in developing diabetes [228-230].

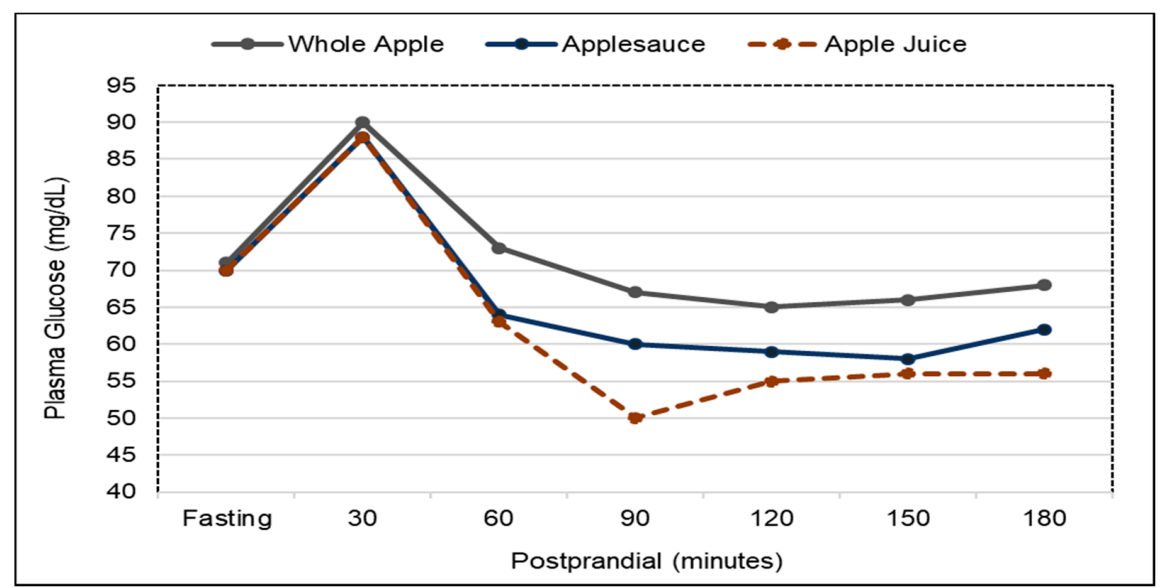

Figure 15. Mean postprandial plasma glucose levels after eating whole apples, applesauce, and apple juice (applesauce and apple juice plasma glucose significantly fell below whole apple levels after 75 to $180 \min [p<0.05])$ [221].

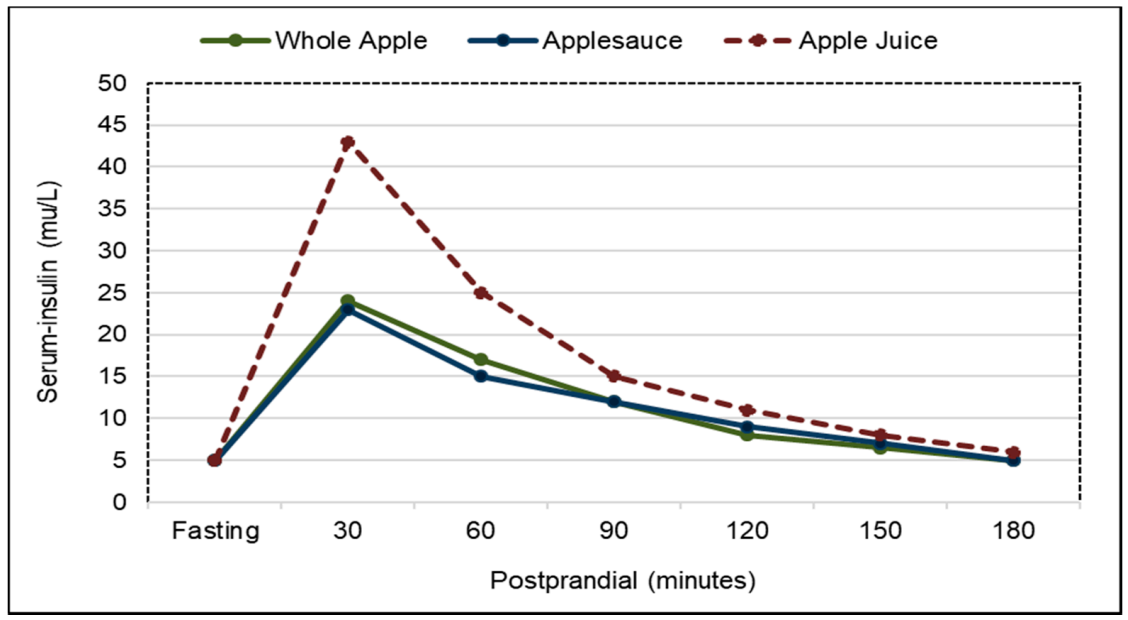

Figure 16. Mean postprandial serum insulin levels after eating whole apples, applesauce, and apple juice with serum insulin significantly increased for apple juice above whole apples and applesauce after 10 to $40 \min (p<0.01])$ [221].

Fasting Biomarkers. A number of RCTs show that whole fruit, especially fruits with higher fiber and polyphenols, improved biomarkers of diabetes risk. For berries: (1) A meta-analysis (22 RCTs; 1251 subjects) observed that mixed berries significantly reduced mean fasting glucose by $1.8 \mathrm{md} / \mathrm{dL}$, hemoglobin A1c (HbA1c) by $0.2 \%$, BMI by $0.4 \mathrm{~kg} / \mathrm{m}^{2}$, and tumor necrosis factor- $\alpha(\mathrm{TNF}-\mu)$ by $1.9 \mathrm{pg} / \mathrm{mL}$ compared to non-fruit controls [174]; and (2) A double-blinded, placebo-controlled RCT (32 obese, nondiabetic, and insulin-resistant subjects; 6 weeks) showed that whole blueberry smoothies significantly improved insulin sensitivity by $1.7 \mathrm{mg} \times \mathrm{kg}$ FFM $21 \times \min 21$ compared to the placebo smoothie $(0.4 \mathrm{mg} \times \mathrm{kg}$ FFM $21 \times \min 21)(p=0.04)$ [231]. For raisins, a parallel RCT (46 adults; raisins vs. conventional processed snacks; 12 weeks) showed that raisins significantly lowered HbA1c by $0.12 \%$ compared to commonly consumed carbohydrate-rich processed snacks $(p=0.036)$ [232]. For high vs. low fruit, a parallel RCT (63 men and women with newly diagnosed type 2 diabetes; fruit intake 319 vs. $135 \mathrm{~g} /$ day; 12 weeks) found that the higher fruit group directionally reduced mean $\mathrm{HbA} 1 \mathrm{c}$ by $0.2 \%$, lowered body weight by $0.8 \mathrm{~kg}$ and waist circumference by $1.3 \mathrm{~cm}$ compared to the lower fruit group [233]. Two meta-analyses of RCTs in patients with diabetes estimated that fiber-rich 
diets increased by a mean of $18 \mathrm{~g}$ fiber/day and/or by 3-15 $\mathrm{g}$ of viscous soluble fiber supplementation, such as fruit pectin, can have significant beneficial effects on glycemic control by reducing mean fasting blood glucose levels by $10-15 \mathrm{mg} / \mathrm{dL}$ and $\mathrm{HbA} 1 \mathrm{c}$ by $0.26-0.55 \mathrm{mg} / \mathrm{dL}$ compared to a control over 3-24 weeks [234,235]. The protective mechanisms associated with whole fruits and lower diabetes risk include improved weight control, satiety, glucose tolerance, insulin sensitivity, microbiota ecosystem health and reduced systemic inflammation [236-238]. In recent years, fiber's role in promoting and maintaining colonic microbiota health has been shown to have a critical effect on alleviating risk of and in management of diabetes. A 2018 RCT found that when fiber dependent-SCFA producing bacteria were present with greater diversity and abundance in the microbiota, the subjects had lower HbA1c levels, partly via increased glucagon-like peptide-1 production [239]. Increased fiber intake, beneficial microflora and SCFAs are protective against T-cell infiltration into pancreatic $\beta$-cells. A double-blind crossover trial (16 healthy adults) showed that soluble fiber fermentation by microbiota resulting in the SCFA propionic acid, increased hepatic derived heptadecanoic acid (17:0), which is inversely associated with diabetes risk [240]. Both fresh and dried fruits help to maintain healthy glycemic and insulinemic risk biomarker levels, which appears to be in response to fruit fiber effects on promoting a healthy microbiota ecosystem, to protect against diabetes risk or associated co-morbidities.

\subsection{Metabolic Syndrome}

Metabolic syndrome is defined as a pathologic condition characterized by abdominal obesity, insulin resistance, hypertension, and hyperlipidemia by the WHO [241]. The two basic risk factors are the increase in consumption of high calorie-low fiber foods and the decrease in physical activity due to motorized transportations and sedentary leisure time activities. The syndrome is linked to the increased prevalence of diseases like diabetes, CVD, and other disabilities, which are associated with higher cost of health care and loss of potential economic activity in the trillions of dollars, worldwide.

\subsubsection{Fruit}

Observational studies support the beneficial effects of adequate whole fruit intake in helping to lower the risk of metabolic syndrome. Two 2018 meta-analyses of observational studies found that the higher intake of whole fruit was associated with a lower risk of metabolic syndrome by $15-19 \%$ [242] compared to an 11\% risk reduction for vegetables [243]. A Korean cross-sectional study (243 healthy non-diabetic participants) observed that higher fruit intake was associated with increased HDL-cholesterol, and lower waist circumference, triglycerides, LDL-cholesterol, and insulin resistance, which are important attributes associated with reducing the risk of metabolic syndrome [244]. Two intervention studies show that whole berries are among the most effective fruit types in lowering hypertension, insulin resistance, dyslipidemia, and lipid oxidation related to metabolic syndrome risk [245,246]. A NHANES analysis (2001-2008) observed that avocado consumers had significantly smaller waist circumference, higher HDL-C and 50\% lower risk for metabolic syndrome compared to non-consumers [247]. A comprehensive systematic review concluded that avocados provide strong protection against metabolic syndrome risk and help mitigate metabolic syndrome symptoms [248]. A NHANES analysis (2001-2011) observed that raisin consumers compared to non-consumers had significantly lower waist circumferences and a 54\% reduced risk of metabolic syndrome [249]. A cross-sectional study (486 Tehrani female teachers) observed that women in the highest quintile of fruit intake had a $34 \%$ lower risk of metabolic syndrome and $25 \%$ reduction in CRP levels compared to women eating the lowest fruit intake [250]. Healthy diets rich in whole fruits help to attenuate metabolic syndrome risk because of their low energy density, high fiber to total carbohydrate ratios, and high content of antioxidant and anti-inflammatory vitamins ( $C$ and $E$ ) and phytochemicals (polyphenols and carotenoids). 


\subsubsection{Fruit Fiber}

Adequate fiber intake is associated with reduced odds of having metabolic syndrome. A 2017 meta-analysis ( 8 cross-sectional and 3 cohort studies; 28,241 participants) observed a curvilinear relationship between fiber consumption and prevalence of metabolic syndrome [251]. Fiber intake levels including fruit fiber were inversely associated with metabolic syndrome with 30-40 g fiber/day lowering risk by $27 \%$. The Tehran Lipid and Glucose Study (1582 adults; 3-years) observed that fruit fiber provided the best protection against metabolic syndrome compared to other fiber sources (Figure 17) [252]. The risk of metabolic syndrome was reduced by $6 \%$ for each $1 \mathrm{~g}$ of fruit fiber intake per 1000 kcals. A 2018 Mexican longitudinal study (30 participants with metabolic syndrome; increased daily fiber intake by $15 \mathrm{~g}$; 4 months) observed significant reductions in BMI by $1.05 \mathrm{~kg} / \mathrm{m}^{2}$, fasting blood glucose by $26 \mathrm{mg} / \mathrm{dL}$, triglycerides by $30 \mathrm{mg} / \mathrm{dL}$, and total cholesterol by $6.7 \mathrm{mg} / \mathrm{dL}$ (all $p<0.05$ ) with whole fruit being an important contributor to adequate total fiber intake [253]. A South African cross-sectional study (627 young adults) observed $97 \%$ of the participants consumed $<2 \mathrm{~g}$ soluble fiber/day, which is suggestive of a possible association between low fruit intake and increased risk for metabolic syndrome [254]. Fruit fiber intake reduces metabolic syndrome risk by a number of mechanisms including: (1) reducing the risk of central obesity, insulin resistance, dyslipidemia, and systemic inflammation; and (2) promoting colonic microbiota health and diversity associated with higher SCFAs levels, reduced risk of low-grade systemic inflammation and metabolic endotoxemia [255].

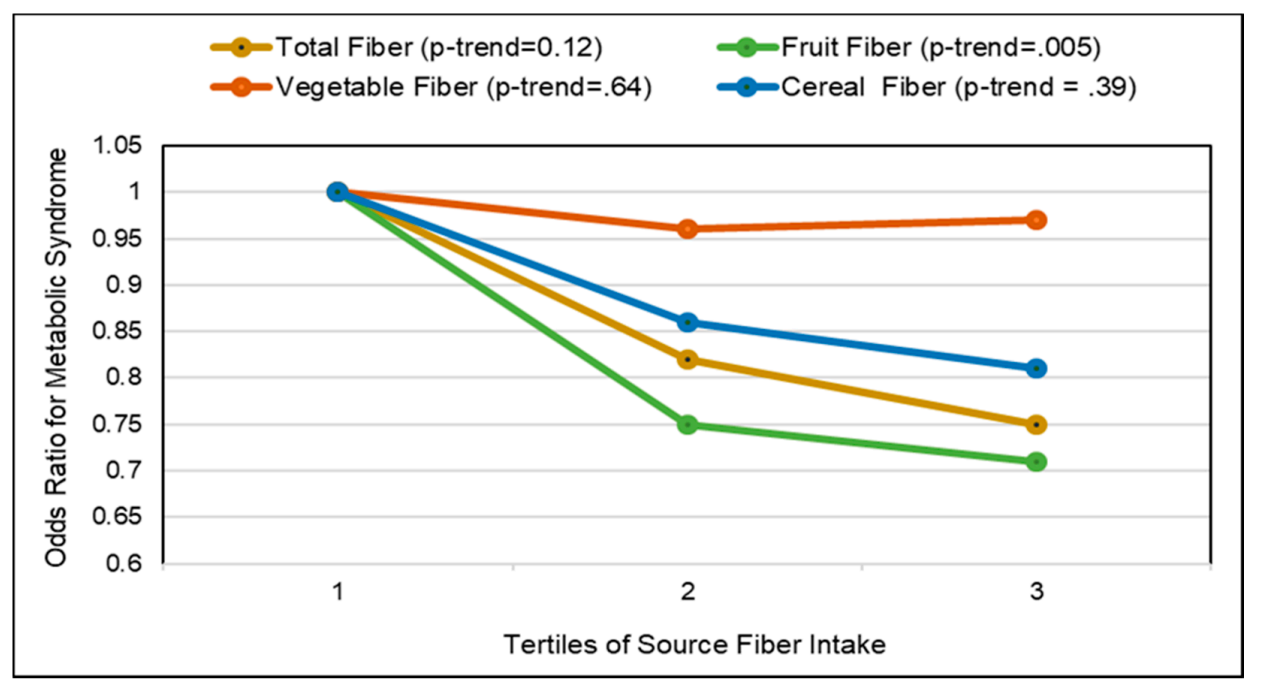

Figure 17. Odds ratio for Metabolic Syndrome by categories of fiber sources of intake (median) at baseline examination from the Tehran Lipid and Glucose Study (multivariate adjusted; total fiber $(\mathrm{g})=10.2,14.1$, and 21.6; fruit fiber $(\mathrm{g})=1.2,2.7$ and 5.2; vegetable fiber $(\mathrm{g})=1.2,2.6$ and 5.9; and cereal fiber $(\mathrm{g})=1.6,3.2$ and 4.5$)$ [252].

\subsection{Cancer}

Excess body weight, sedentary lifestyles, unhealthy dietary habits such as low fiber, fruits and vegetables and high meat intake can increase cancer risk [256]. The American Cancer Society recommends eating $>2.5$ cups/day of fruits and vegetables for cancer prevention [257].

\subsubsection{Colorectal Cancer}

Colorectal cancer (CRC) is one of the most commonly diagnosed cancers in the world and a leading cause of cancer death, despite major advances in screening, surgery and oncology. The 2007 and 2011 World Cancer Research Fund (WCRF) and the American Institute for Cancer Research (AICR) reports showed convincing meta-analyses evidence that fiber, fruit and vegetables are inversely 
associated with CRC risk [258,259]. A 2011 meta-analysis (19 cohort studies; 1.7 million subjects) found an inverse association between intake of fruits and vegetables and CRC risk with most of the risk reduction observed at about $100 \mathrm{~g} / \mathrm{d}$ (Figure 18) [260]. An EPIC prospective cohort study (>500,000 participants) observed that the risk of CRC was inversely associated with intakes of total fruits and vegetables, and total fiber [261]. The Shanghai Men's Health Study (61,274 men) observed that increased fruit intake was significantly inversely associated with CRC risk, whereas vegetable intake was not associated with CRC risk [262]. A systematic review and meta-analysis observed a lower risk of CRC for whole grains by $5 \%$ per $30 \mathrm{~g} / \mathrm{d}$, fruits and vegetables by $3 \%$ per $100 \mathrm{~g} / \mathrm{d}$, dairy by $7 \%$ per $200 \mathrm{~g} / \mathrm{d}$ and an increased CRC risk for red meat by $12 \%$ per $100 \mathrm{~g} / \mathrm{d}$ and for processed meat by $17 \%$ per $50 \mathrm{~g} / \mathrm{d}$ [263]. A meta-analysis (2 cohort and 5 case-control studies) estimated that higher apple intake reduced CRC risk by 28\% ( $p=0.001)$ [264]. The Malmö Diet and Cancer Study (27,931 participants) observed high intakes of total fiber, and fruits and berries significantly lowered risk for colon cancer by approximately 30\% compared to no lowering effects for vegetables and fiber rich cereals [265], which is consistent with a 2018 systematic review and meta-analysis (25 observational studies) observation that higher total fiber intake reduced colon cancer risk by $26 \%(p=0.000)$ [266]. A meta-analysis of 20 observational studies [267] and another meta-analysis of 5 cohort and 17 case-control studies [268] showed that each 10 -g fruit fiber and high fruit intake reduced adenoma risk by $21 \%$ compared to a reduced risk of $9 \%$ for vegetables. Secondary analyses of the Polyp Prevention Trial found that super dietary compliers consuming $12 \mathrm{~g}$ fiber and 3 fruit and vegetable servings/1000 kcals significantly reduced adenoma recurrence risk by $32 \%$ and lowered multiple and/or advanced adenoma recurrence risk by 50\% compared to less compliant controls $(p<0.05)$ after 4 years [269]. The Prostate, Lung, Colorectal and Ovarian Cancer Screening Trial (57,774 subjects; 12 years of follow-up) found that higher fruit and vegetable intake significantly reduced the risk of multiple adenomas by $39 \%$ and risk of CRC in individuals with high processed meat intakes by 26\% [270]. Pooled data from the Nurses' Health Study and Health Professionals Follow-up Study (1575 participants) observed lower multivariate adjusted CRC specific mortality risk per 5-g increment for fruit fiber by $9 \%$ lower risk $(p=0.58)$, vegetable fiber by $18 \%(p=0.22)$, and cereal fiber by $33 \%(p=0.007)$ [271]. Fiber is the primary dietary component of whole plant foods associated with promoting a healthy colonic microbiota which aids in reducing tumorigenic inflammation, carcinogen production, and altered cellular responses in susceptible individuals [272].

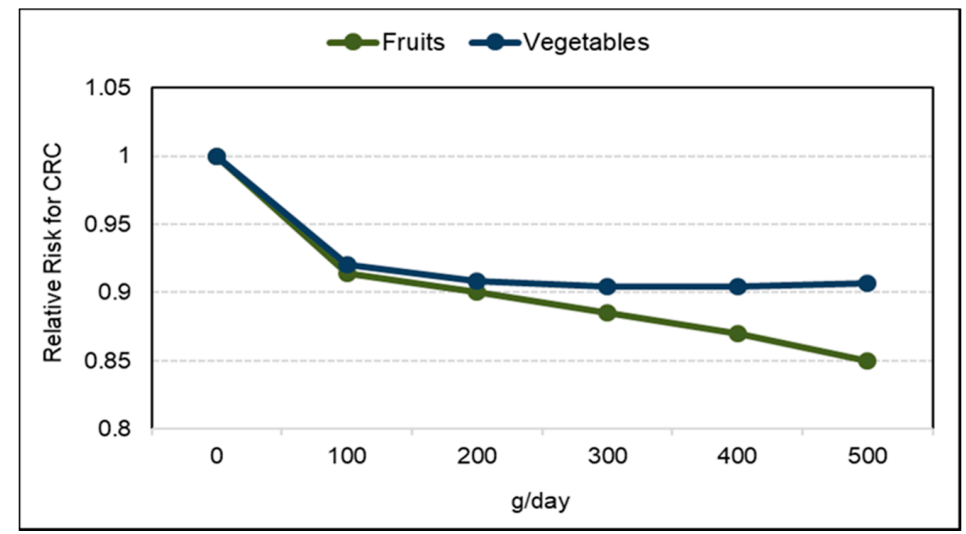

Figure 18. Non-linear dose-response effect of increasing intake of fruits and vegetables on colorectal cancer (CRC) risk from meta-analysis of cohort studies [260].

\subsubsection{Lung Cancer}

Lung cancer is the leading cause of cancer death worldwide with approximately 2 million global deaths attributed to cigarette smoking [273]. Tobacco use is the leading cause of lung cancer resulting in $55 \%$ of lung cancer deaths in women and over $70 \%$ of lung cancer deaths in men. The current evidence from prospective studies suggest a potential protective role for fruit in lung cancer etiology. 
A 2015 dose-response meta-analysis of cohort studies (19 studies; approx. 2 million participants) found that each one serving of fruits reduced lung cancer risk by $5 \%$ compared to a $3 \%$ reduction for each serving of vegetables [274]. Another 2015 meta-analysis of fruit (38 observational studies; 20,213 lung cancer cases) showed that increased fruit intake lowered lung cancer risk by $20 \%$ compared to lower fruit intake [275]. The associations with fruit and lower lung cancer risk were stronger for women than for men. A 2016 systematic review and meta-analysis (18 prospective studies) found that high fruit intake reduced lung cancer risk by $18 \%$ with each $100-\mathrm{g}$ intake lowering risk by $8 \%$ up to $400-\mathrm{g} /$ day [276]. These risk reductions were significant in current smokers but not in former or never smokers. A 2014 EPIC prospective cohort study (>500,000 participants; 10 European countries) observed that the risk of lung cancer was inversely associated with fruit intake but was not associated with vegetable intake; this association with fruit intake was restricted to smokers [261]. In a 2016 meta-analysis (3 case-controlled and 7 cohort studies) the high intake of apples was found to significantly lower lung cancer risk by $25 \%$ in case-control studies $(p=0.001)$ and $11 \%$ in cohort studies $(p<0.001)$ compared to low intake [264]. The Black Women's Health Study $(47,000$ women) observed an insignificant $14 \%$ lower lung cancer risk for high vs. low fruit and vegetable intake, regardless of smoking history, but the overall fruit and vegetable intake was relatively low in this study population [277].

\subsection{Successful Aging}

Successful aging is associated with being free of excessive progressive deterioration of physical and mental functions and chronic disease (obesity, coronary artery disease, stroke, diabetes, and cancer); having good mental, physical and respiratory health, and functional independence [278]. Health issues such as increased prevalence of chronic disease and risk of premature death increase substantially beginning in middle-age, but an estimated $80 \%$ of health problems in older age could be prevented or delayed by healthy lifestyle changes. A French cohort study (2796 middle aged; 13 years) observed that a higher adherence to: (1) a Western dietary pattern reduced the odds for successful aging by $17 \%$; (2) a healthy high energy dietary pattern improved odds for successful aging by 7\%; and (3) a healthy moderate energy dietary pattern improved odds for successful aging by 46\% (Figure 19) [279].

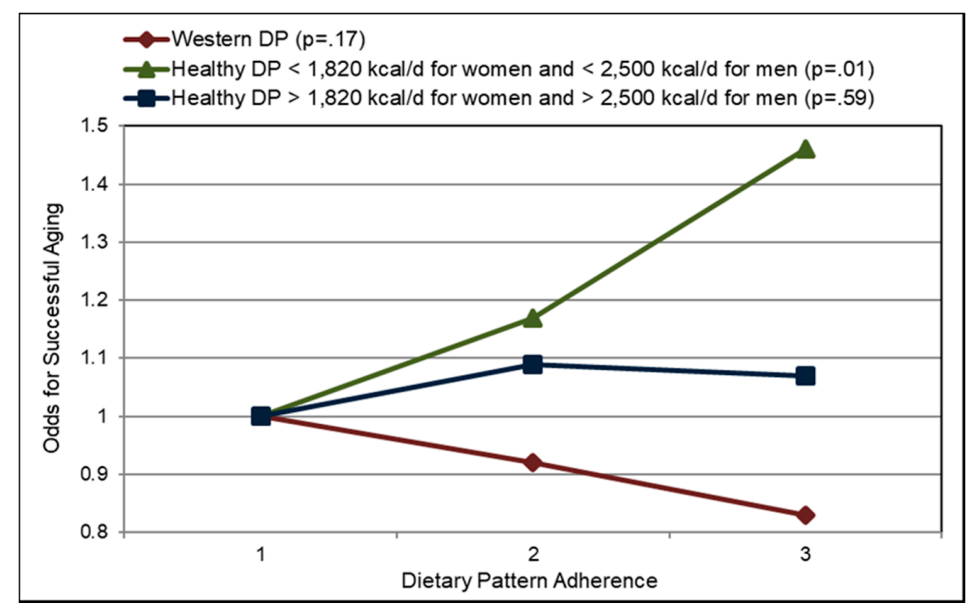

Figure 19. Effects of a healthy dietary pattern (DP) stratified by energy intake level, and the Western DP on the odds for successful aging (multivariate adjusted) [279].

\subsubsection{Fruit and Fiber}

Whole fruits are among the best low energy dense and fiber-rich healthy food options. A UK EPIC-Norfolk study cross-sectional analysis (16,792 adults; mean age 62 years) showed that each daily intake of two servings of fruits and vegetables increased the odds of good functional health by 11\% [280]. An Australian prospective study (6308 healthy adults at baseline; 11.7 years) observed that 
the likelihood of successful aging for dietary patterns rich in fruit was improved by $30 \%$ and odds reduced by $30 \%$ for patterns rich in meat and fried foods (Figure 20) [281]. The (Australian) Blue Mountains Eye Study (1609 participants; mean age 61; 10 years) observed that a higher dietary nutrient quality score was associated with better odds of successful aging by 58\% [282]. Participants with the highest intake of fruit had $49 \%$ better odds for successful aging and lower risk of premature death by $23 \%$ compared to those with low fruit intake. Successful aging odds improved by $2 \%$ for each 1 -g increase in total fiber intake and those consistently consuming fruit fiber below the median intake were 36\% less likely to age successfully compared to those above the median intake of fruit fiber [283]. A meta-analysis (20 cohort studies; 760,629 participants) found a linear dose-response relationship with reduced stroke risk for fruits by $32 \%$ and for vegetables by $11 \%$ per $200 \mathrm{~g} /$ day with citrus fruits, apples, pears, and green leafy vegetables being the most effective in reducing stroke risk [284]. A 2017 systematic review and dose-response meta-analysis (94 cohort studies; 2,123,415 participants) found significantly reduced all-cause mortality risk by $15 \%$ per $200 \mathrm{~g}$ total fruit intake/day [285]. Specific fruits varied in their effects on lowering odds of all-cause mortality per $100 \mathrm{~g}$ intake; for apples and pears by $20 \%$, bananas by $5 \%$, berries by $15 \%$, and citrus fruit by $6 \%$. Prevencion con Dieta Mediterranea (PREDIMED) trial (7216 older adults with high CVD risk; 9 years) showed that a person who consumed $>210 \mathrm{~g}$ fruit/day or had fiber intake of $>20 \mathrm{~g} /$ day had significantly lower risk of premature death by about 40\% for each [286]. The UK Women's Cohort Study found that women consuming 7 portions of fruit/day had a $43 \%$ lower risk of death from CVD compared with women consuming 2.5 portions/day $(p=0.013)$ [163]. A cross-sectional study (1000 middle age adults; 12 weeks) observed that higher fruit intake significantly reduced BMI and inflammatory biomarkers, which are associated with increased odds of successful aging (Table 3) [287]. A cross-sectional study (600 postmenopausal women) observed a significant association between reduced urinary metabolite prostaglandin E2 (PGE2), an inflammatory mediator that plays key roles in promoting tumor development and progression, and increased consumption of fruits $(p$-trend $=0.02)$ [288]. Microbiota SFCAs can act as anti-inflammatory mediators by regulating PGE-2 and cytokines. The Prospective Urban Rural Epidemiology [PURE] study (135,335 adults from Europe, US, Japan and China; 7.4 years) observed that fruit intake was associated with lower risk of cardiovascular, non-cardiovascular, and total mortality (Figure 21) [4]. A 2018 umbrella review (18 meta-analyses including a total of 298 prospective observational studies) found that a higher fiber intake was convincingly associated with decreased odds of all-cause and CVD mortality [3]. Suggestive evidence was also found for associations with lower risk of stroke, type 2 diabetes and several cancers (i.e., pancreatic, gastric, esophageal, colon, endometrial, breast, and renal). A Canadian cost-of-illness analysis estimated that each additional $1 \mathrm{~g}$ fiber/day resulted in an annual $\$ 3$ to 51 million in savings in type 2 diabetes care and \$5 to 92 million in cardiovascular disease care [289].

Table 3. Servings of fruit and BMI and inflammatory biomarkers in US adults [287].

\begin{tabular}{ccccc}
\hline Variables & <2 Fruit Servings/Day & 2 Fruit Servings/Day & >2 Fruit Servings/Day & $p$-Trend \\
\hline BMI $\left(\mathrm{kg} / \mathrm{m}^{2}\right)$ & $27.9 \pm 5.8$ & $26.9 \pm 5.8$ & $25.9 \pm 5.0$ & $<0.0001$ \\
$\mathrm{CRP}(\mathrm{mg} / \mathrm{L})$ & $1.80(1.55-2.08)$ & $1.42(1.26-1.62)$ & $1.16(1.02-1.33)$ & $<0.0032$ \\
$\mathrm{IL}-6(\mathrm{pg} / \mathrm{mL})$ & $1.81(1.69-1.94)$ & $1.59(1.50-1.69)$ & $1.34(1.26-1.42)$ & $<0.0001$ \\
$\mathrm{TNF}-\alpha(\mathrm{pg} / \mathrm{mL})$ & $1.95(1.79-2.13)$ & $1.67(1.54-1.80)$ & $1.46(1.35-1.58)$ & $<0.0001$ \\
$\mathrm{~F}_{2}$-isoprostanes $(\mathrm{pg} / \mathrm{mL})$ & $43.9(42.3-45.4)$ & $40.9(39.6-42.1)$ & $36.8(35.6-37.9)$ & $<0.0001$ \\
\hline
\end{tabular}




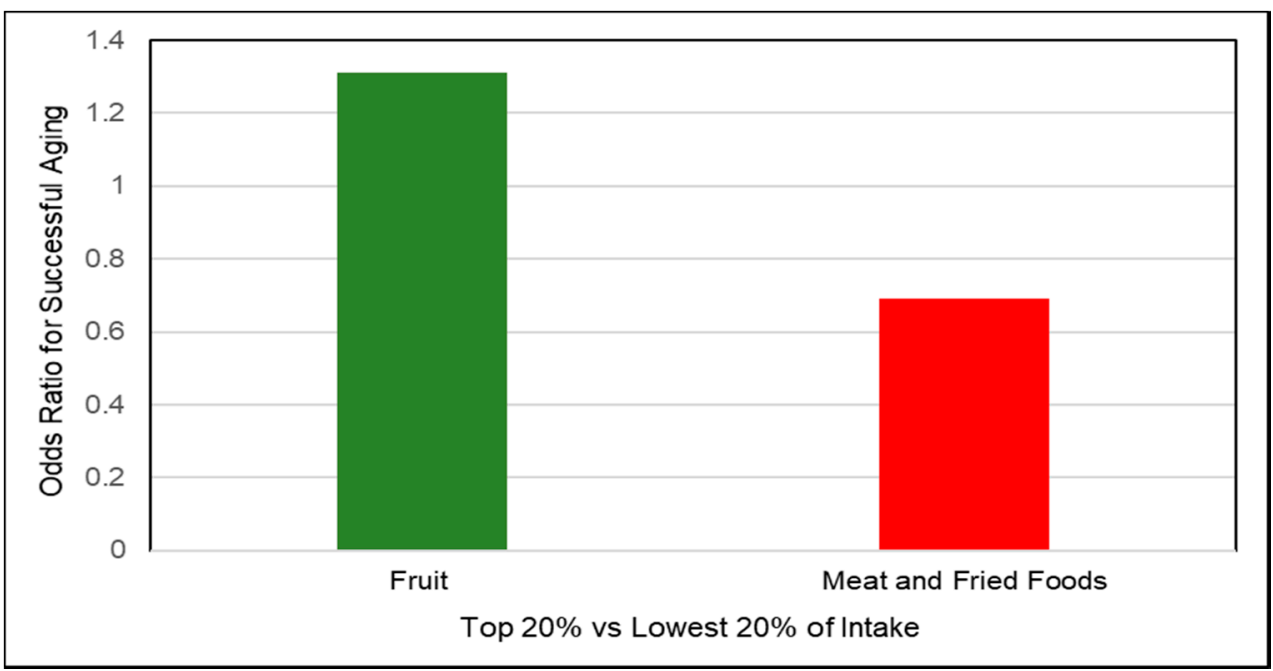

Figure 20. Effect of key dietary pattern food items associated with the odds of successful aging (all $p$-trend across quintile groups $=0.001)$ [281].

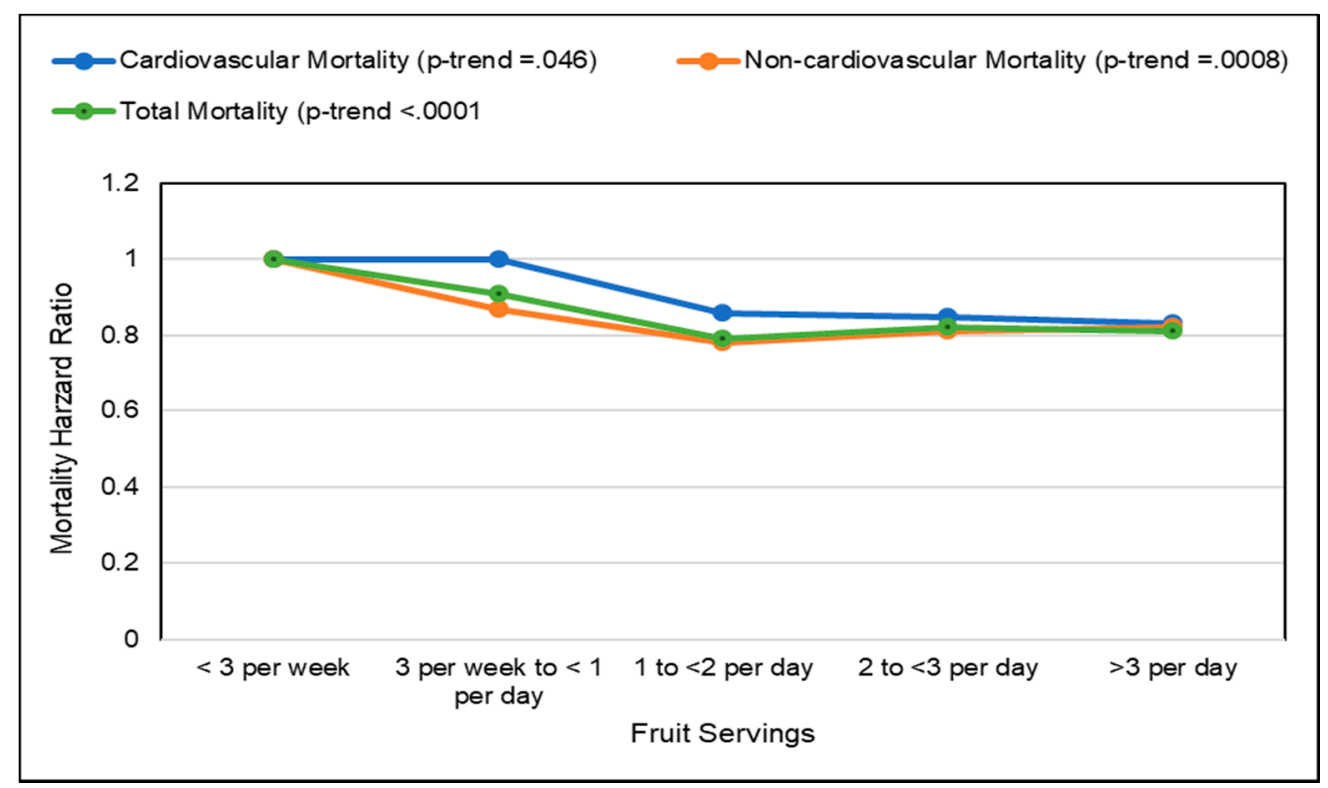

Figure 21. Association of fruit intake with mortality risk for a composite of European, American, Japanese and Chinese adults (mean age 50 years over 7.4 years; multivariate adjusted) [4].

\subsubsection{Mechanisms}

Aging is a complex process at the cellular level involving genetic changes that cause a progressive loss of physical capabilities [290]. Many of the factors that control aging are related to gene expression including epigenetic and telomeric changes that are outside of the information encoded in the DNA. Lifestyle factors such as diet, exercise, and stress can modify cell function and change epigenetic and telomere information that affect gene expression and nucleic stability. Long telomeres in old age help to maintain key cellular processes that reduce the number of years a person experiences poor health during aging. A 2018 NHANES analysis (5674 adults) found that fiber intake of $10 \mathrm{~g}$ per $1000 \mathrm{kcal}$ increased leukocyte telomere length by 67 base pairs $(p=0.01)$, which reduced biologic (cellular) aging by 4.3 years compared to the low fiber Western diets of $6.6 \mathrm{~g}$ fiber per $1000 \mathrm{kcal}$ [291]. Two longitudinal studies (521 subjects; 5 years) found that longer telomere length was significantly predictive of lower body weight, BMI, waist circumference, and dietary inflammatory index, and was associated with the higher fruit and fiber intake associated with high adherence to the Mediterranean 
diet [292,293]. The Framingham Heart Study Offspring cohort study observed that the intake of whole fruit up-regulated epigenetic gene function for immunosurveillance, and chromosome and telomere maintenance pathways, attributed to the effects of fruit fiber on colonic microbiota health [294]. Emerging fiber mechanisms associated with successful aging include: (1) enhancing the colonic probiotic microflora profile and production of SCFAs; (2) improving the colonic barrier function to protect against clinical inflammation; (3) increasing colonic peptides that are important in glucose and insulin homeostasis and lipid metabolism; and (4) mimicking many of the effects of caloric restriction including upregulation of genes involved in energy metabolism [295].

\subsection{Lung Function}

Impaired lung function related to allergies, asthma, environmental factors and tobacco usage is a major worldwide health issue affecting $100 \mathrm{~s}$ of millions of children and adults.

\subsubsection{Asthma Severity and Wheezing}

Asthma, a chronic respiratory inflammatory condition, represents a major public health burden worldwide. It affects about 300 million people of all ages and is increasing in prevalence [296,297]. Symptoms of asthma in low- and middle-income countries can be as high as rates found in more developed countries. Among children aged 5-14 years, asthma is among the top ten global ranking conditions for disability-adjusted life years. Growing evidence from observational studies indicates that increased whole fruit intake is associated with reduced severity of asthma symptoms such as airway constriction, inflammation, bronchial hyper-responsiveness, coughing, wheezing, and chest tightness. A 2017 meta-analysis of fruit and vegetable intake on risk of asthma/wheeze and immune responses (30 cross-sectional, 13 cohort, 8 case-control and 7 experimental studies; children and adults) found no significant association between fruit intake and risk of prevalence of asthma but the intake of fruit was inversely associated with the severity of asthma in secondary prevention studies, with a higher fruit intake lowering severity by 39\% [297]. Fruit intake was also negatively associated with risk of wheezing. Vegetable intake was not associated with the severity of asthma or wheezing. A systematic review by the European Academy of Allergy and Clinical Immunology recommended an increased intake of fresh fruits as a way of reducing the number and severity of asthma flare-ups, particularly in children [298]. The Prevention and Incidence of Asthma and Mite Allergy study (2870 children; followed from birth to 8 years of age) observed that each day of fresh fruit consumption per week at 2-3 years of age was associated with reduced asthma symptoms and atopy by $7 \%$ at age 8 years, but no asthma protection was observed for cooked vegetables [299]. Long-term fruit intake was inversely associated with asthma symptoms and sensitization to inhaled allergens with $10 \%$ reduction for each daily serving. A Brazilian case-controlled study (171 children; 30 days) observed that regular consumption of fruits was associated with an $81 \%$ lower risk of asthma severity or persistence [300]. A Portuguese cross-sectional study (174 asthmatics) observed that higher fresh fruit intake significantly decreased risk of uncontrolled asthma by $71 \%(p=0.015)$ [301]. Also, high adherence to the Mediterranean diet reduced the risk of uncontrolled asthma by $78 \%$, after adjusting for gender, age, education, inhaled corticosteroids and energy intake $(p$-trend $=0.028)$. In children, a 2014 systematic review and meta-analysis (1 cohort study and 13 cross-sectional studies) found higher fruit intake significantly reduced wheezing in children $\leq 11$ years old by $17 \%$, and for children $>11$ years old by $19 \%$ and reduced asthma severity in children $>11$ years old by $24 \%$, but not for children $\leq 11$ years old who showed an insignificant reduced risk of $11 \%$ [302]. In adults, a meta-analysis (3 cohorts, 2 case-controls, and 4 cross-sectional studies) found that higher intake of fruit reduced the overall risk of asthma severity by $23 \%$ compared with the lowest intake. In subgroup analysis, increased intake of apples or citrus fruit reduced the risk of asthma severity by about $24 \%$. A 2016 RCT ( 90 adults with uncontrolled asthma; fruit and vegetable rich DASH diet vs. usual-care control; 6 months) found that the DASH diet modestly but significantly improved overall asthma control score by $19 \%(p=0.04)$ and quality of life score by 39\% $(p=0.004)$ compared to the subjects' usual diet [303]. The 2017 (Latin 
American) International Study of Asthma and Allergies in Childhood Phase III (143,967 children with asthma; 11 Latin American countries) observed in children 6 to 7 years of age that adequate fruit intake can reduce wheezing risk by up to 35\% compared to low fruit intake [304]. For 13 to 14-year-old children, there were similar but slightly attenuated wheezing lowering effects for increased fruit intake. A 2018 meta-analysis showed that higher fruit intake was associated with increased colonic microbiota SCFAs levels which suppressed asthma airway restrictions by helping to lower levels of CRP, TNF- $\alpha$, and mast cell, and increasing $\gamma \delta$-T cell and $\mathrm{T}_{\text {reg }}$ cell numbers and function $(p<0.05)$ [305]. Low fruit (e.g., fiber and polyphenols) can increase microbiota dysbiosis, which is associated with increased risk of asthma severity [303-305]. Individuals with severe persistent asthma often have a high adherence to the Western diet and consume significantly less fruit fiber compared to healthy controls, which is partly associated with the increased colonic microbiota dysbiosis and lung axis effects associated with increased airway inflammation and adverse immune response reducing breathing capacity of the lungs [306-308]. A meta-analysis (2 RCTs; 249 children; age range 2-5 years) found that prebiotic fiber reduced the risk of asthma or wheezing by $63 \%$ when compared to the control group [309]. Adequate intake of whole fruits is associated with reduced severity of asthma in children and adults through fruit fiber effects linked to a healthier colonic microbiome that actively suppresses the severity of airway inflammatory restrictions.

\subsubsection{Chronic Obstructive Pulmonary Disease (COPD)}

The estimated global number of cases of COPD is approximately 400 million [310]. COPD is multifactorial, and the risk factors include genetic and environmental quality factors (e.g., tobacco smoke, occupational inhalants and air pollutants originating from biomass burning and traffic exhaust) [310,311]. Although tobacco smoking is an established risk factor for COPD, up to 50\% of cases of COPD can be attributed to nonsmoking risk factors. Observational studies suggest that fruit intake is positively associated with lung function and inversely related to COPD respiratory symptoms and death and more effective than increased vegetable and whole-grain intake [312]. A cross-sectional analysis of the Atherosclerosis Risk in Communities Study (15,792 adults) observed that high adherence to a prudent diet rich in fruits and vegetables was associated with a lower prevalence of COPD by $18 \%$, coughing by $23 \%$, and a higher forced expiratory volume compared to $62 \%$ increased prevalence of COPD, a higher level of wheezing, coughing and phlegm by 27 to $37 \%$ and a reduced forced expiratory volume for high adherence to the Western diet [313]. A 2017 Cohort of Swedish Men study (44,335 men; 13.2 years) observed a strong inverse association for total fruit and vegetable intake and COPD in smokers but not in never smokers ( $p$-interaction $=0.02)$ [314]. The risk of COPD was significantly reduced in current smokers by $8 \%$ and in ex-smokers by $4 \%$ for each one serving/day of total fruit and/or vegetables. A Swedish Mammography Cohort (34,739 women; age range 48-83 years; 12-year follow-up) observed that women consuming 2.5 or more fruit servings/day had a $37 \%$ lower risk of COPD ( $p$-trend < 0.0001) compared to those consuming <0.8 serving/day [315]. Long-term vegetable intake was not associated with lower COPD risk. In current and ex-smokers, women with low fruit intake (<1 serving/day) had a 38-fold and 13-fold higher COPD risk, respectively, than those consuming 3 or more fruit servings/day. A 2016 NHANES analysis (1921 adults) observed that participants with higher fiber intake had healthier mean forced expiratory volume by $82 \mathrm{~mL} / \mathrm{s}$ and forced vital capacity by $129 \mathrm{~mL} / \mathrm{s}$, than those with lower fiber intake ( $p=0.05$ and 0.01 ), which is consistent with the consumption of higher vs. lower fruit intake [316]. The 2018 Cohort of Swedish Men study (45,058 men w; 13.1 years) observed an inverse association between total fiber intake ( $\geq 37$ g/day vs. $<24 \mathrm{~g} /$ day) and COPD in smokers by $46 \%$ and ex-smokers by $38 \%$ [317]. Never smokers had a $7 \%$ reduction in COPD with higher fiber intake $(p$ interaction $=0.04)$. Fruit fiber reduced COPD risk in smokers by $35 \%(p$-trend $=0.001)$ and in ex-smokers by $23 \%$ ( $p$-trend $=0.17)$. The development or progression of COPD is associated with an over-active immune system characterized by increased neutrophil and macrophage activation [318]. Adequate fruit fiber intake promotes healthy lung 
immune function via the colonic microbiota-liver-lung axis, which affects systemic inflammatory cytokines and immune mediators (notably, IL-6 and CRP).

\subsection{Psychological Well-Being}

The consumption of low fiber Western diets can increase the risk of microbiota dysbiosis and associated reductions in psychological well-being, which in turn can induce poor stress response behavior and moods through the vagus nerve, whereas fiber rich healthy diets can improve microbiota health to positively impact psychological well-being [319-323]. SCFAs such as butyrate and propionate directly affect brain physiology and behavior by acting on microglial cells and astrocytes to promote anti-inflammatory action and manage overall brain maintenance by scavenging for damaged or unnecessary neurons and synapses, and infectious agents.

\subsubsection{Children}

Emerging observational studies suggest that increased fruit intake may improve psychological well-being. The Canadian CHILD-Edmonton sub-cohort study (688 mothers and infants) observed that each maternal daily serving of fruit consumed during pregnancy was associated with a 2.4-point increase in a child's 1-year cognitive development and 0.67-point increase in 1-year adaptive development ( $p=0.05$; adjusted for maternal education and vitamin supplementation, socioeconomic status, and other related factors) [324]. The Australian Victorian Child's Health and Well-being study (3370 children) observed that children with a higher number of daily fruit servings had significantly better odds of emotional control, and problem management and relationship building skills (pro-social behavior) [325]. The Western Australian Pregnancy Cohort (Raine) Study (1324 adolescents) observed that withdrawal/depression and delinquent/aggressive behaviors were significantly associated with Western diets and prosocial/positive behaviors were significantly associated with higher intake of fresh fruits and green leafy vegetables (components of a healthy diet) [326].

\subsubsection{Adults}

In adults, emerging evidence suggests that higher daily intake of fiber-rich fruit and vegetable servings is associated with lower incidences of anxiety, greater happiness, higher life satisfaction, and greater social-emotional well-being. A cross-sectional study observed that adults consuming high quality diets had $67 \%$ better psychological well-being relative to those with low quality diets $(p=0.007)$ [327]. Of the food groups, this improvement in well-being was only significant for higher servings of fruits and vegetables. A New Zealand and US on-line cross-sectional study observed that the consumption of raw fruits and vegetables had a stronger correlation with psychological well-being (positive mood) than the consumption of cooked or canned (processed) fruits and vegetables [328]. A 2016 Household, Income, and Labour Dynamics in Australia Survey longitudinal study observed that increased fruit and vegetable intake was predictive of increased happiness, life satisfaction, and well-being [329]. For 8 servings per day, there was up to 0.24 life-satisfaction points, which is equal in size to the psychological gain of going from unemployment to employment (Figure 22). A longitudinal study in young adults observed that eating adequate fruits and vegetables was associated with improved indicators of flourishing including greater well-being, creativity, and curiosity, which can play an important role in psychological resilience [330]. Another longitudinal study in young adults observed that those consuming more fruits and vegetables had higher scores in openness and extraversion, and to some extent conscientiousness, than their lower fruit and vegetable consuming peers [331]. A parallel RCT of low fruit and vegetable consuming young adults found that providing 2 added daily servings of fruits and vegetables to eat significantly improved psychological well-being (e.g., feelings of vitality, flourishing, and motivation) compared to just reminding them to eat their fruits and vegetables [332]. 


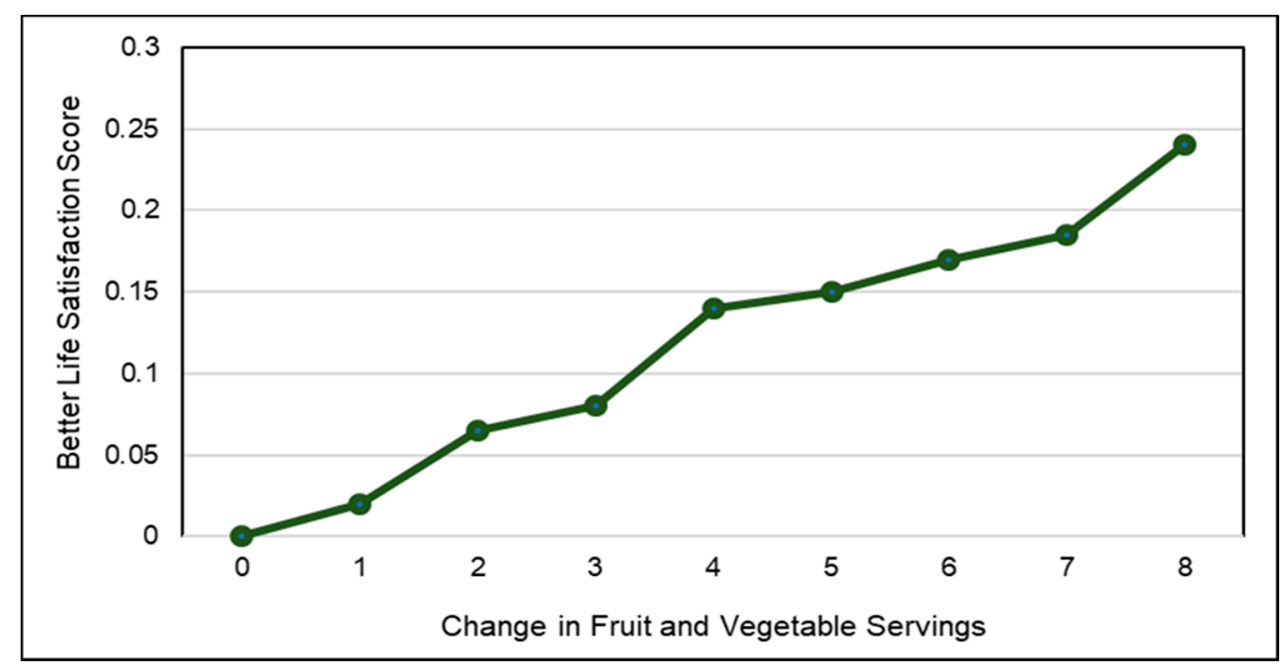

Figure 22. Association between the number of servings of fruits and vegetables/day and increases in life satisfaction $(p<0.001)$ [329].

\subsection{Depression}

Chronic depression progressively worsens a person's state of health, which makes it one of the largest contributors to global disability and suicide deaths $[333,334]$. Emerging observational studies suggest that higher fruit and fiber intake are associated with lower risk of depression, anxiety, and high psychological distress. An Iranian cross-sectional study found that women in the highest quintile of fruit intake ( $\geq 464 \mathrm{~g}$ fruit/day) had significantly lower odds of depression by $57 \%$, anxiety by $50 \%$, and psychological distress by $60 \%$ compared to those with the lowest intake of fruit $(<144 \mathrm{~g}$ fruit/day) [333]. A 2018 systematic review and meta-analysis (6 cohort studies) found that the pooled risk for depression was reduced by $17 \%$ for the highest vs. the lowest category of fruit intake and a dose response analysis (3 cohort studies) showed a 3\% lower risk of depression for every $100 \mathrm{~g}$ of fruit consumed [334]. A nationally representative longitudinal study ( $>6000$ Canadian adults; 2 years) observed that increased intake of fruits and vegetables at any timepoint was associated with decreased distress, and lower risk of depression [335]. The associations between fruit and vegetable consumption and reduction of mental distress and depression can be further modified by a person's level of social support, physical exercise and smoking habits, especially at the extremes. The Furukawa Nutrition and Health Study (1977 employees) found that fiber from fruits and vegetables was 21\% more effective in reducing depression symptoms or improving mood than cereal fiber (Figure 23) [336]. A NHANES study of 2007 to 2014 data (16,807 adults) observed that total, vegetable, and fruit fiber intakes were significantly associated with an approximately $40 \%$ lower risk of depressive symptoms, whereas the association of cereal fiber intake with depressive symptoms was insignificant with a $10 \%$ lower risk [337]. In dose-response analyses, the daily intake of fruit or vegetable fiber was associated with a 30\% reduction in the risk of depression. The 2017 English Longitudinal Study of Ageing observed that conscientiousness (a personality trait of being thorough, efficient and organized with a desire to do a task well) was associated individuals being physically active, having lower body weight, higher fruit and vegetable intake and a reduced risk of depression (all $p<0.001$ ) [338]. The evidence of adequate intake of fruits and vegetables and their fiber components for reducing the risk of depression or helping manage depressive symptoms is limited but consistent. 


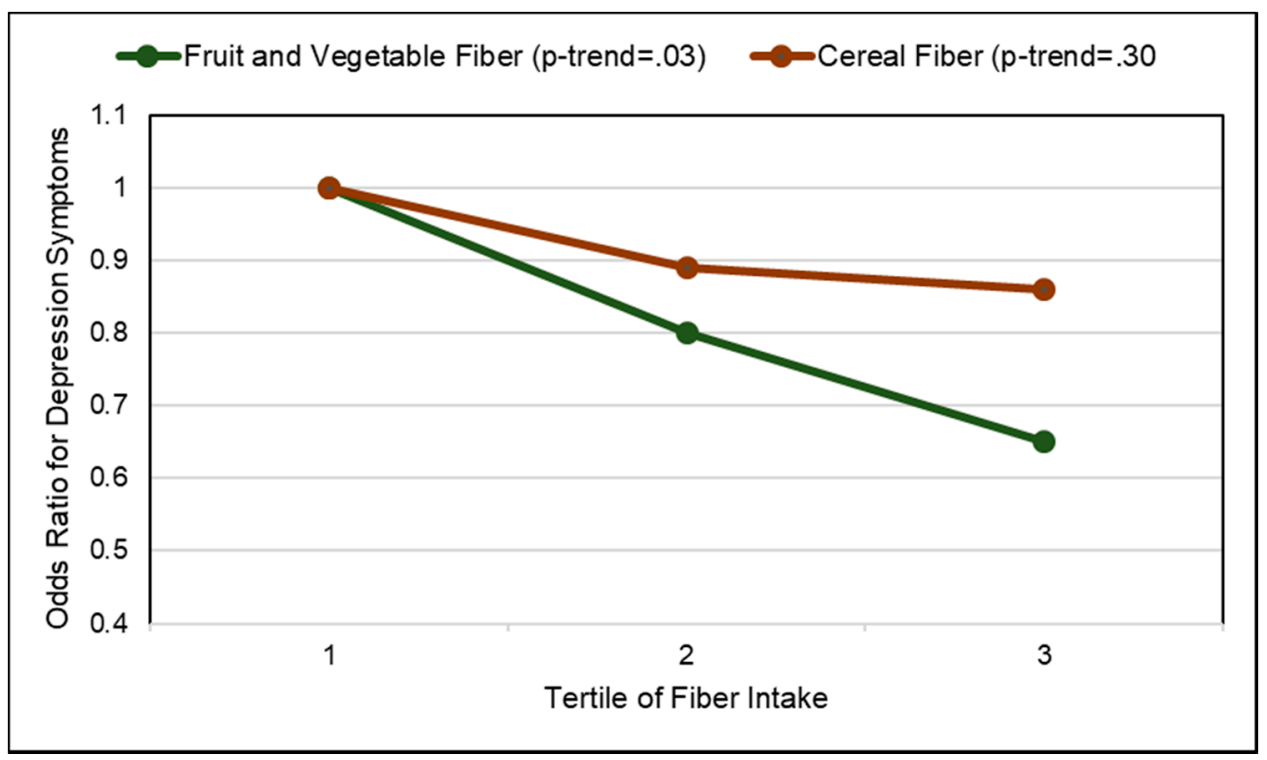

Figure 23. Odds ratio for depressive symptoms with fruit and vegetable fiber intake compared to cereal fiber (fruit and vegetable fiber tertiles $=1.5 \mathrm{~g}, 2.5 \mathrm{~g}$ and $4.0 \mathrm{~g}$ ) [336].

\subsection{Bone Mineral Density}

Adequate intake of whole fruit and fruit fiber has been associated with increased bone mineral density, especially the attainment of peak bone mass during adolescence and minimized bone resorption among postmenopausal women [339]. Between 25 and 40 years of age, women are still gaining or stabilizing bone mass in all skeletal sites, whereas the bone density among men, particularly in the hips, is declining [340]. Accelerated loss among women during the perimenopausal period occurs between ages approximately 40 to 54 years, and then stabilizes. This accelerated loss is a major determinant of the differences in the patterns of bone loss between women and men. A second period of accelerated bone loss begins at age 70 among women, notably in the total hip, which is substantial by age 75 years and is associated with the increased incidence of hip fractures among elderly patients. Diets rich in prebiotic fiber such as fruit pectin can improve calcium absorption and inhibit osteoclast bone resorption, while maintaining osteoblast bone formation activity [341]. Specifically, three mechanisms are occurring: (1) calcium is an important component of fruit cell walls for structure and function and the fermentation of fiber in the colon releases bound calcium for absorption; (2) fiber fermentation SCFA metabolites propionate and butyrate induce metabolic reprogramming of osteoclasts by downregulating critical osteoclast genes; and (3) increased SCFAs lower colonic $\mathrm{pH}$ to enhance calcium absorption.

\subsubsection{Observational Studies}

Several observational studies support the benefits of increased fruit intake on bone mineral density, especially in adolescent children and older postmenopausal women. A 2014 Northern Ireland cross-sectional study observed that 12-year old girls consuming high amounts of fruit had significantly improved heel bone mineral density compared to the lower fruit consumers (lower fruit intake was defined as $\leq 83 \mathrm{~g} /$ day and high fruit intake as $>200 \mathrm{~g} /$ day) [342]. A UK cross-sectional study observed in adolescent boys and girls and older women that fruit intake was positively associated with spine bone mineral content, after adjusting for body size and type, however, no significant positive association was shown for the intake of vegetables [343]. No significant associations were found for young women or older men. A 2018 Framingham Offspring Study (792 men, mean age 58 years; 1065 women; mean age 57 years; 8 years follow-up) observed significantly reduced annualized loss of femoral neck bone mineral density (predictive of hip fracture risk) per $5 \mathrm{~g} /$ day total fiber by $0.06 \%$ or fruit fiber by $0.04 \%$ [344]. A 2017 Chinese cross-sectional study (3089 participants; age range 40 to 75 
years; $66 \%$ women) observed that high fruit intake had dose-dependent associations with greater bone mineral density and a lower risk of osteoporosis; but this was not shown for vegetables [345]. Higher intake of apples, pears, peaches, pineapples and plums significantly improved the mineral density for whole body and spine, total hip and femoral neck bone regions by approximately $0.014 \mathrm{~g} / \mathrm{cm}^{3} /$ year. Also, an increased intake of fruits and vegetables from 349 to $685 \mathrm{~g} /$ day reduced the risk of an osteoporotic fracture 8.3\%. A 2012 Chinese cross-sectional study (adolescent boys and girls, young women and postmenopausal women) observed that there was a significant positive association between higher fruit intake and bone mineral density for all participants combined ( $p$-trend $<0.001$ to 0.002 ) in total body and lumbar spine, total hip and femoral neck regions vs. lower fruit intake [346].

\subsubsection{RCTs}

Several RCTs support the bone protective effects of increased dried plum intake in postmenopausal women by slowing rate of bone resorption. A parallel RCT (160 post-menopausal women; mean age 57 years; $100 \mathrm{~g} / \mathrm{d}$ dried plums or dried apples plus $500 \mathrm{mg}$ calcium plus $400 \mathrm{IU}$ vitamin D daily; 12 months) found that both plums and apples increased bone mineral density from baseline in forearm ulna, spine, femoral neck, total hip and whole-body and plums promoted significantly more bone mineral density of forearm ulna and spine than dried apples [347]. A dose-response RCT (48 osteopenic women; age 65-79 years old; $50 \mathrm{~g}$ and $100 \mathrm{~g}$ of dried plums vs. control; 6-months) showed that both dried plum doses significantly increased total body bone mineral density resulting in a higher bone-specific alkaline phosphatase: tartrate-resistant acid phosphatase ratio compared to no change in the control group $(p<0.05)$ [348].

\subsection{Seborrheic Dermatitis}

Seborrheic dermatitis is a common chronic relapsing skin condition that causes redness, scaly patches, and dandruff, which most often affects the scalp, but it can also develop in oily areas of the body, such as the face, upper chest, and back [349]. A 2018 Dutch cross-sectional study observed that high adherence to the Western diet increased seborrheic dermatitis risk by $34 \%$ ( $p$-trend $=0.07$ ] [349]. For women, a higher adherence to the Western diet was associated with an increased risk of seborrheic dermatitis by $47 \%(p=0.03)$ but there was no significant association between the Western pattern and seborrheic dermatitis in men (increased risk of $18 \% ; p=0.67$ ). Increased fruit intake (highest vs. lowest quartile) reduced seborrheic dermatitis risk by $25 \%(p=0.03)$ but increased vegetable intake had no effects on risk. This study did not find an association between increased antioxidant intake (FRAP-score) and seborrheic dermatitis with a $6 \%$ reduced risk ( $p$-trend $=0.88$ ). Since colonic microbiota dysbiosis has been associated with chronic inflammatory skin disorders, such as atopic dermatitis and psoriasis, the beneficial effect of increased fruit intake on seborrheic dermatitis may be partially due to the prebiotic effects of fruit fibers such as pectin, which promote a healthy colonic microbiota associated with lower systemic inflammation and better immune function [350].

\subsection{Autism Spectrum Disorder (ASD)}

Children with ASD are often picky eaters with low intake of fiber-rich foods, including fruits and vegetables and have an increased prevalence of gastrointestinal abnormality and microbial dysbiosis. This can interfere with gut-brain axis communications, which may exacerbate ASD behavior traits [351,352]. Increased fruit fiber such as pectin intake has been suggested to correct gastrointestinal abnormality and promote microbial health to potentially enhance gut-brain communication and potentially reduce the ASD symptoms. Diets of children with ASD often consist of fewer than 20 foods, repetitive eating patterns, and nutrient inadequacies, which can lead to increased colonic microbiota dysbiosis, gastrointestinal distress, flatulence and abdominal pain and lower intakes of fiber such as pectin and vitamin C, suggesting low fruit intake [353,354]. A 2018 intervention trial (41 autistic children; 75\% male; mean age 8 years old; 6 weeks) showed that supplementation of the diet with a prebiotic resulted in significant improvement in anti-social behavior, and gastrointestinal 
and microbiota health relative to baseline diets [355]. A recent case report, described a 4-year old boy with ASD who developed scurvy secondary to selectively eating a diet very low in fruits and vegetables [356]. Larger studies are needed to investigate whether prebiotics such as increased fruit intake may have beneficial effects on ASD symptoms.

Author Contributions: M.L.D. is solely responsible for all literature searches, data interpretation and writing of this manuscript.

Funding: Funding was provided by the Hass Avocado Board, which had no input as to the content of this manuscript.

Conflicts of Interest: M.L.D. is an ad hoc nutrition research consultant for the Hass Avocado Broad, which had no role in the writing of this manuscript.

\section{References}

1. U.S. Department of Health and Human Services and U.S. Department of Agriculture. Dietary Guidelines for Americans 2015-2020. Available online: http://health.gov/dietaryguidelines/2015/guidelines/ (accessed on 4 August 2018).

2. Slavin, J.C.; Lloyd, B. Health benefits of fruits and vegetables. Adv. Nutr. 2012, 3, 506-512. [CrossRef] [PubMed]

3. Veronese, N.; Solmi, M.; Caruso, M.G.; Giannelli, M.G.; Osella, A.R.; Evangelou, E.; Maggi, S.; Fontana, L.; Stubbs, B.; Tzoulaki, I. Dietary fiber and health outcomes: An umbrella review of systematic reviews and meta-analyses. Am. J. Clin. Nutr. 2018, 107, 436-444. [CrossRef] [PubMed]

4. Miller, V.; Mente, A.; Dehghan, S.; Rangarajan, S.; Zhang, X.; Swaminathan, S.; Dagenais, G.; Gupta, R.; Mohan, Y.; Lear, S.; et al. Fruit, vegetable, and legume intake, and cardiovascular disease and deaths in 18 countries (PURE): A prospective cohort study. Lancet 2017, 390, 2037-2049. [CrossRef]

5. Dreher, M.L. Connection between fiber, colonic microbiota, and health across the human life cycle. In Dietary Fiber in Health and Disease; Springer International Publishing AG: Basel, The Switzerland, 2018; pp. 67-93.

6. Marlett, J.A.; Cheung, T.-F. Database and quick methods of assessing typical dietary fiber intakes for 228 commonly consumed foods. J. Am. Diet. Assoc. 1997, 97, 1139-1148. [CrossRef]

7. USDA. National Nutrient Database for Standard Reference; Release Legacy; USDA: Washington, DC, USA, 2018.

8. Baker, B.A. Reassessment of some fruit and vegetable pectin levels. J. Food. Sci. 1997, 62, 225-229. [CrossRef]

9. Padayachee, A.; Day, L.; Howell, K.; Gidley, M.J. Complexity and health functionality of plant cell wall fibers from fruits and vegetables. Crit. Rev. Food Sci. Nutr. 2017, 57, 59-81. [CrossRef] [PubMed]

10. Byrd-Bredbenner, C.; Ferruzz, M.G.; Fulgoni, V.L.; Murray, R.; Pivonka, E.; Wallace, T.C. Satisfying America's fruit gap: Summary of an expert roundtable on the role of 100\% fruit juice. J. Food Sci. 2017, 82, 1523-1534. [CrossRef] [PubMed]

11. Burton-Freeman, B.M.; Guenther, P.M.; Oh, M.; Stuart, D.; Jensen, H.H. Assessing the consumption of berries and associated factors in the United States using the National Health and Nutrition Examination Survey (NHANES), 2007-2012. Food Funct. 2018, 9, 1009-1016. [CrossRef] [PubMed]

12. U.S. HHS; USDA. Part D, Chapter 2: Dietary patterns, foods and nutrients and health outcomes. In 2015-2020 Dietary Guidelines for Americans; Scientific Report; Dietary Guidelines Advisory Committee (DGAC): Washington, DC, USA, 2015; pp. 1-35.

13. Jew, S.; Abumweis, S.S.; Jones, P.J.H. Evolution of the human diet: Linking our ancestral diet to modern functional foods as a means of disease prevention. J. Med. Foods 2009, 12, 925-934. [CrossRef] [PubMed]

14. Deehan, E.C.; Walter, J. The fiber gap and disappearing gut microbiome: Implications for human health. Trends Endocrinol. Metab. 2016, 27, 239-241. [CrossRef] [PubMed]

15. Lie, L.; Brown, L.; Forrester, T.E.; Plange-Rhule, J.; Bovet, P.; Lambert, E.V.; Layden, B.T.; Luke, A.; Dugas, A. The association of dietary fiber intake with cardiometabolic risk in four countries across the epidemiologic transition. Nutrients 2018, 10, 628. [CrossRef] [PubMed]

16. Rivière, A.; Selak, M.; Lantin, D.; Leroy, F; De Vuyst, L. Bifidobacteria and butyrate-producing colon bacteria: Importance and strategies for their stimulation in the human gut. Front. Microbiol. 2016, 7, 979. [CrossRef] [PubMed] 
17. Wang, F.; Yu, T.; Huang, G.; Cai, D.; Liang, X.; Su, H.; Zhu, Z.; Li, D.; Yang, Y.; Shen, P.; et al. Gut microbiota community and its assembly associated with age and diet in Chinese centenarians. J. Microbiol. Biotechnol. 2015, 25, 1195-1204. [CrossRef] [PubMed]

18. Institute of Medicine. Dietary Reference Intakes for Energy, Carbohydrate, Fiber, Fat, Fatty Acids, Cholesterol, Protein, and Amino Acids; National Academies Press: Washington, DC, USA, 2002/2005.

19. European Food Safety Authority. Scientific opinion on dietary reference values for carbohydrates and dietary fibre. EFSA Panel on Dietetic Products, Nutrition, and Allergies. EFSA J. 2010, 8, 1462.

20. Dahl, W.J.; Stewart, M.L. Position of the Academy of Nutrition and Dietetics: Health implications of dietary fiber. J. Acad. Nutr. Diet. 2015, 115, 1861-1870. [CrossRef] [PubMed]

21. Stephen, A.M.; Champ, M.M.-J.; Cloran, S.J. Dietary fibre in Europe: Current state of knowledge on definitions, sources, recommendations, intakes and relationships to health. Nutr. Res. Rev. 2017, 30, 149-190. [CrossRef] [PubMed]

22. Klurfeld, D.M.; Davis, C.D.; Karp, R.W.; Allen-Vercoe, E.; Chang, E.B.; Chassaing, B.; Fahey, G.V.; Hamaker, B.R.; Holscher, H.D.; Lampe, J.W.; et al. Considerations for best practices in studies of fiber or other dietary components and the intestinal microbiome. Am. J. Physiol. Endocrinol. Metab. 2018. [CrossRef] [PubMed]

23. Schmier, J.K.; Miller, P.E.; Levine, J.A.; Perez, V.; Maki, K.C.; Rains, T.M.; Devareddy, L.; Sanders, L.M.; Alexander, D.D. Cost savings of reduced constipation rates attributed to increased dietary fiber intakes: A decision-analytic model. BMC Public Health 2014, 14, 374. [CrossRef] [PubMed]

24. Slavin, J. Fiber and prebiotics: Mechanisms and health benefits. Nutrients 2013, 5, 1417-1435. [CrossRef] [PubMed]

25. Kashtanova, D.A.; Popenko, A.S.; Tkacheva, O.N.; Tyakht, A.B.; Alexeev, D.G.; Boytsov, S.A. Association between the gut microbiota and diet: Fetal life, early childhood, and further life. Nutrition 2016, 32, 620-627. [CrossRef] [PubMed]

26. Williams, B.A.; Grant, L.J.; Gidley, M.J.; Mikkelsen, D. Gut fermentation of dietary fibres: Physico-chemistry of plant cell walls and implications for health. Int. J. Mol. Sci. 2017, 18, 2203. [CrossRef] [PubMed]

27. Low, D.Y.; Williams, B.A.; D'Arcy, B.R.; Flanagan, B.M.; Gidley, M.J. In vitro fermentation of chewed mango and banana: Particle size, starch and vascular fibre effects. Food Funct. 2015, 6, 2464-2474. [CrossRef] [PubMed]

28. Tuohy, K.M.; Conterno, L.; Gasperotti, M.; Viola, R. Up-regulating the human intestinal microbiome using whole plant foods, polyphenols, and/or fiber. J. Agric. Food Chem. 2012, 60, 8776-8782. [CrossRef] [PubMed]

29. Tap, J.; Furet, J.P.; Bensaada, M.; Philippe, M.; Roth, H.; Rabot, S.; Lakhdari, O.; Lombard, V.; Henrissat, B.; Corthier, G.; et al. Gut microbiota richness promotes its stability upon increased dietary fibre intake in healthy adults. Environ. Microbiol. 2015, 17, 4954-4964. [CrossRef] [PubMed]

30. O’Keefe, J.D.; Li, J.V.; Lahti, L.; Ou, J.; Carbonero, F.; Mohammed, K.; Posma, J.M.; Kinross, J.; Wahl, E.; Ruder, E.; et al. Fat, fiber and cancer risk in African Americans and rural Africans. Nat. Commun. 2015, 6, 6342. [CrossRef]

31. De Filippis, F.; Pellegrini, N.; Vannini, L.; Jeffery, I.B.; La Storia, A.; Laghi, L.; Serrazanetti, D.I.; Di Cagno, R.; Ferrocino, I.; Lazzi, C.; et al. High-level adherence to a Mediterranean diet beneficially impacts the gut microbiota and associated metabolome. Gut 2016, 65, 1812-1821. [CrossRef] [PubMed]

32. Garcia-Mantrana, I.; Selma-Royo, M.; Alcantara, C.; Collado, M.C. Shifts on gut microbiota associated to Mediterranean Diet adherence and specific dietary intakes on general adult population. Front. Microbiol. 2018, 9, 890. [CrossRef] [PubMed]

33. Hjorth, M.F.; Beaedel, T.; Bendtsen, L.Q.; Lorenzen, J.K.; Holm, J.B.; Killerich, P.; Roager, H.M.; Kristiansen, K.; Larsen, L.H.; Astrup, A. Prevotella-to-Bacteroides ratio predicts body weight and fat loss success on 24-week diets varying in macronutrient composition and dietary fiber: Results from a post-hoc analysis. Int. J. Obes. (Lond.) 2018. [CrossRef] [PubMed]

34. Tabernero, M.; Venema, K.; Maathuis, A.J.H.; Saura-Calixto, F.D. Metabolite production during in vitro colonic fermentation of dietary fiber: Analysis and comparison of two European diets. J. Agric. Food Chem. 2011, 59, 8968-8975. [CrossRef] [PubMed]

35. Klinder, A.; Shen, Q.; Heppel, S.; Lovegrove, J.A.; Rowland, I.; Tuohy, K.M. Impact of increasing fruit and vegetables and flavonoid intake on the human gut microbiota. Food Funct. 2016, 7, 1788-1796. [CrossRef] [PubMed] 
36. Chung, W.S.F.; Meijerink, M.; Zeuner, B.; Holck, J.; Louis, P.; Meyer, A.S.; Wells, J.M.; Flint, H.J.; Duncan, S.H. Prebiotic potential of pectin and pectic oligosaccharides to promote anti-inflammatory commensal bacteria in the human colon. FEMS Microbiol. Ecol. 2017, 93. [CrossRef] [PubMed]

37. Paniagua, C.; Pose, S.; Morris, V.J.; Kirby, A.R.; Quesada, M.A.; Mercado, J.A. Fruit softening and pectin disassembly: An overview of nanostructural pectin modifications assessed by atomic force microscopy. Ann. Bot. 2014, 114, 1375-1383. [CrossRef] [PubMed]

38. Langkilde, A.M.; Champ, M.; Andersson, H. Effects of high-resistant-starch banana flour (RS2) on in vitro fermentation and the small-bowel excretion of energy, nutrients, and sterols: An ileostomy study. Am. J. Clin. Nutr. 2002, 75, 104-111. [CrossRef] [PubMed]

39. Bang, S.-J.; Kim, G.; Young Lim, M.; Song, E.J.; Jung, D.H.; Kum, J.S.; Nam, Y.D.; Park, C.S.; Seo, D.H. The influence of in vitro pectin fermentation on the human fecal microbiome. AMB Expr. 2018, 8, 98. [CrossRef] [PubMed]

40. Chung, W.S.F.; Walker, A.W.; Louis, P.; Parkhill, J.; Vermeiren, J.; Bosscher, D.; Duncan, S.H.; Flint, H.J. Modulation of the human gut microbiota by dietary fibres occurs at the species level. BMC Boil. 2016, 14, 3. [CrossRef] [PubMed]

41. Bianchi, F.; Larsen, N.; de Mello Tieghi, T.; Adorno, M.A.T.; Kot, W.; Saad, S.M.I.; Jespersen, L.; Sivieri, K. Modulation of gut microbiota from obese individuals by in vitro fermentation of citrus pectin in combination with Bifidobacterium longum BB-46. Appl. Microbiol. Biotechnol. 2018, 102, 8827-8840. [CrossRef] [PubMed]

42. Larsen, N.; Cahu, T.B.; Isay Saad, S.M.; Blennow, A.; Jespersen, L. The effects of pectin on survival of probiotic Lactobacillus spp. in gastrointestinal juices is related to their structure and physical properties. Food Microbiol. 2018, 74, 11-20. [CrossRef] [PubMed]

43. Luis, A.S.; Briggs, J.; Zhang, X.; Farnell, B.; Ndeh, D.; Labourwl, A.; Basle, A.; Cartmell, A.; Terrapon, N.; Stott, K.; et al. Dietary pectic glycans are degraded by coordinated enzyme pathways in human colonic Bacteroides. Nat. Microbiol. 2018, 3, 210-219. [CrossRef] [PubMed]

44. Barry, J.-L.; Hoebler, C.; MacFarlane, G.T.; MacFarlane, S.; Mathers, J.C.; Reed, K.A.; Mortensen, P.B.; Nordgaard, I.; Rowland, I.R.; Rumney, C.J. Estimation of the fermentability of dietary fibre in vitro: A European interlaboratory study. Br. J. Nutr. 1995, 74, 303-322. [CrossRef] [PubMed]

45. Condezo-Hoyos, L.; Mohanty, I.P.; Noratto, G.D. Assessing non-digestible compounds in apple cultivars and their potential as modulators of obese faecal microbiota in vitro. Food Chem. 2014, 161, 208-215. [CrossRef] [PubMed]

46. Simpson, H.L.; Campbell, B.J. Review article: Dietary fibre-microbiota interactions. Aliment. Pharmacol. Ther. 2015, 42, 158-179. [CrossRef] [PubMed]

47. Vong, M.H.; Stewart, M.L. In vitro bacterial fermentation of tropical fruit fibres. Benef. Microbes 2013, 4, 291-295. [CrossRef] [PubMed]

48. de Vries, J.; Birkett, A.; Hulshof, T.; Verbeke, K.; Gibes, K. Effects of cereal, fruit and vegetable fibers on human fecal weight and transit time: A comprehensive review of intervention trials. Nutrients 2016, 8, 130. [CrossRef] [PubMed]

49. Koutsos, A.; Lima, M.; Conterno, L.; Gasperotti, M.; Bianchi, M.; Fava, F.; Vrhovsek, U.; Lovegrove, J.A.; Tuohy, K.M. Effects of commercial apple varieties on human gut microbiota composition and metabolic output using an in vitro colonic model. Nutrients 2017, 9, 533. [CrossRef] [PubMed]

50. Mandalari, G.; Chessa, S.; Bisignano, C.; Chan, L.; Carughi, A. The effect of sun-dried raisins (Vitis vinifera L.) on the in vitro composition of the gut microbiota. Food Funct 2016, 7, 4048-4060. [CrossRef] [PubMed]

51. Berding, K.; Holscher, H.D.; Arthur, A.E.; Donovan, S.M. Fecal microbiome composition and stability in 4- to 8-year old children is associated with dietary patterns and nutrient intake. J. Nutr. Biochem. 2018, 56, 165-174. [CrossRef] [PubMed]

52. Shinohara, K.; Ohashi, Y.; Kawasumi, K.; Terada, A.; Fujisawa, T. Effect of apple intake on fecal microbiota and metabolites in humans. Anaerobe 2010, 16, 510-515. [CrossRef] [PubMed]

53. Lever, E.; Scott, M.S.; Louis, P.; Emery, P.W.; Whelan, K. The effect of prunes on stool output, gut transit time and gastrointestinal microbiota: A randomised controlled trial. Clin. Nutr. 2018. [CrossRef] [PubMed]

54. Mitsou, E.K.; Kougia, E.; Normikos, T.; Yannakoulia, M.; Mountzouris, K.C.; Kyriacou, A. Effect of banana consumption on faecal microbiota: A randomized, controlled trial. Anaerobe 2011, 17, 384-387. [CrossRef] [PubMed] 
55. Rabbani, G.H.; Ahmed, S.; Hossain, I.; Islam, R.; Marni, F.; Akhtar, M.; Majid, N. Green banana reduces clinical severity of childhood shigellosis: A double-blind, randomized, controlled clinical trial. Pediatr. Infect. Dis. J. 2009, 28, 420-425. [CrossRef] [PubMed]

56. Rabbani, G.H.; Teka, T.; Zaman, B.; Majid, N.; Khatun, M.; Fuchs, G.J. Clinical studies in persistent diarrhea: Dietary management with green bananas or pectin in Bangladeshi children. Gastroenterology 2001, 121, 554-560. [CrossRef] [PubMed]

57. Emery, E.A.; Ahmad, S.; Koethe, J.D.; Skipper, A.; Perlmutter, S.; Paskin, D.L. Banana flakes control diarrhea in enterally fed patients. Nutr. Clin. Pract. 1997, 12, 72-75. [CrossRef] [PubMed]

58. Alvarez-Acosta, T.; Leon, C.; Acosta-Gonzalez, S.; Parra-Soto, H.; Cluet-Rodriguez, I.; Rossell, M.R.; Colina-Chourio, J.A. Beneficial role of green plantain [Musa paradisiaca] in the management of persistent diarrhea: A prospective randomized trial. J. Am. Coll. Nutr. 2009, 28, 169-176. [CrossRef] [PubMed]

59. Lee, Y.K.; Low, K.Y.; Siah, K.; Drummond, L.M.; Gwee, K.A. Kiwifruit (Actinidia deliciosa) changes intestinal microbial profile. Microb. Ecol. Health Dis. 2012, 23, 18572. [CrossRef] [PubMed]

60. Eid, N.; Osmanova, H.; Natchez, C.; Walton, G.; Costabile, A.; Gibson, G.; Rowland, I.; Spencer, J.P. Impact of palm date consumption on microbiota growth and large intestinal health: A randomised, controlled, cross-over, human intervention study. Br. J. Nutr. 2015, 114, 1226-1236. [CrossRef] [PubMed]

61. Forootan, M.; Bagheri, N.; Darvishi, M. Chronic constipation a review of literature. Medicine 2018, 97, 20. [CrossRef] [PubMed]

62. Xu, L.; Yu, W.; Jiang, J.; Li, N. Clinical benefits after soluble dietary fiber supplementation: A randomized clinical trial in adults with slow-transit constipation. Zhonghua Yi Xue Za Zhi 2014, 94, 3813-3816. [PubMed]

63. Kelsay, J.L.; Behall, K.M.; Prather, E.S. Effect of fiber from fruits and vegetables on metabolic responses of human subjects. Bowel transit time, number of defecations, fecal weight, urinary excretions of energy and nitrogen and apparent digestibilities of energy, nitrogen, and fat. Am. J. Clin. Nutr. 1978, 31, 1149-1153. [CrossRef] [PubMed]

64. Venancio, V.P.; Kim, H.; Sirven, M.A.; Ekwe, C.D.; Honvoh, G.; Talcott, S.T.; Mertens-Talcott, S.U. Polyphenol-rich mango (Mangifera indica L.) ameliorate functional constipation symptoms in humans beyond equivalent amount of fiber. Mol. Nutr. Food Res. 2018, 62, 1701034. [CrossRef] [PubMed]

65. Lever, E.; Cole, J.; Scott, S.M.; Emery, P.W.; Whelan, K. Systematic review: The effect of prunes on gastrointestinal function. Aliment. Pharmacol. Ther. 2014, 40, 750-758. [CrossRef] [PubMed]

66. Attaluri, A.; Donahoe, R.; Valestin, J.; Brown, K.; Rao, S.S. Randomised clinical trial: Dried plums (prunes) vs. psyllium for constipation. Aliment. Pharmacol. Ther. 2011, 33, 822-828. [CrossRef] [PubMed]

67. Rush, E.C.; Patel, M.; Plank, L.D.; Ferguson, L.R. Kiwifruit promotes laxation in the elderly. Asia Pac. J. Clin. Nutr. 2002, 11, 164-168. [CrossRef] [PubMed]

68. Chan, A.O.; Leung, G.; Tong, T.; Wong, N.Y.H. Increasing dietary fiber intake in terms of kiwifruit improves constipation in Chinese patients. World J. Gastroenterol. 2007, 13, 4771-4775. [CrossRef] [PubMed]

69. Salem, A.E.; Singh, R.; Ayoub, Y.K.; Khairy, A.M.; Mullin, G.E. The gut microbiome and irritable bowel syndrome: State of art review. Arab. J. Gastroenterol. 2018. [CrossRef] [PubMed]

70. Pozuelo, M.; Panda, S.; Santiago, A.; Mendez, S.; Accarino, A.; Santos, J.; Guarner, F.; Azpiroz, F.; Manichanh, C. Reduction of butyrate- and methane-producing microorganisms in patient with irritable bowel syndrome. Sci. Rep. 2015, 5, 12693. [CrossRef] [PubMed]

71. El-Salhy, M.; Ystad, S.O.; Mazzawi, T.; Gundersen, D. Dietary fiber in irritable bowel syndrome (review). Int. J. Mol. Med. 2017, 40, 607-613. [CrossRef] [PubMed]

72. Nagarajana, N.; Mordena, A.; Bischof, D.; King, E.A.; Kosztowski, M.; Wick, E.C.; Stein, E.M. The role of fiber supplementation in the treatment of irritable bowel syndrome: A systematic review and meta-analysis. Eur. J. Gastroenterol. Hepatol. 2015, 27, 1002-1010. [CrossRef] [PubMed]

73. Xu, L.; Yu, W.; Jiang, J.; Feng, X.; Li, N. Efficacy of pectin in the treatment of diarrhea predominate irritable bowel syndrome. Zhonghua Wei Chang Wai Ke Za Zhi 2015, 18, 267-271. [PubMed]

74. Chang, C.-C.; Lin, Y.-T.; Lu, Y.-T.; Liu, Y.S.; Liu, J.F. Kiwifruit improves bowel function in patients with irritable bowel syndrome with constipation. Asia Pac. J. Clin. Nutr. 2010, 19, 451-457. [PubMed]

75. Cozma-Petruț, A.; Loghin, F.; Miere, D.; Dumitraşcu, D.L. Diet in irritable bowel syndrome: What to recommend, not what to forbid to patients! World J. Gastroenterol. 2017, 23, 3771-3783. [CrossRef] [PubMed]

76. Haskey, N.; Gibson, D.L. An examination of diet for the maintenance of remission in inflammatory bowel disease. Nutrients 2017, 9, 259. [CrossRef] [PubMed] 
77. Laserna-Mendieta, E.J.; Clooney, A.G.; Carretero-Gomez, J.F.; Moran, C.; Sheehan, D.; Nolan, J.A.; Hill, C.; Gahan, C.G.M.; Joyce, S.A.; Shanahan, F.; et al. Determinants of reduced genetic capacity for butyrate synthesis by the gut microbiome in Crohn's disease and ulcerative colitis. J. Crohn's Colitis 2018, 12, 204-216. [CrossRef] [PubMed]

78. Behzadi, P.; Behzadi, E.; Ranjbar, R. The incidence and prevalence of Crohn's disease in global scale. SOJ Immunol. 2015, 3, 1-6.

79. Li, F.; Liu, X.; Wang, W.; Zhang, D. Consumption of vegetables and fruit and the risk of inflammatory bowel disease: A meta-analysis. Eur. J. Gastroenterol. Hepatol. 2015, 27, 623-630. [CrossRef] [PubMed]

80. Hou, J.K.; Abraham, B.; El-Serag, H. Dietary intake and risk of developing inflammatory bowel disease: A systematic review of the literature. Am. J. Gastroenterol. 2011, 563-573. [CrossRef] [PubMed]

81. Ananthakrishnan, A.N.; Khalili, H.; Konijeti, G.G.; Higuchi, L.M.; de Silva, P.; Korzenik, J.R.; Fuchs, C.S.; Willett, W.C.; Richter, J.M.; Chan, A.T. A prospective study of long-term intake of dietary fiber and risk of Crohn's Disease and ulcerative colitis. Gastroenterology 2013, 145, 970-977. [CrossRef] [PubMed]

82. Amre, D.K.; D’Souza, S.; Morgan, K.; Seidman, G.; Lambrette, P.; Grimard, G.; Israel, D.; Mack, D.; Ghadirian, P.; Deslandres, C.; et al. Imbalances in dietary consumption of fatty acids, vegetables, and fruits are associated with risk for Crohn's disease in children. Am. J. Gastroenterol. 2007, 102, 2016-2025. [CrossRef] [PubMed]

83. Liu, X.; Wu, Y.; Li, F.; Zhang, D. Dietary fiber intake reduces risk of inflammatory bowel disease: Results from a meta-analysis. Nutr. Res. 2015. [CrossRef] [PubMed]

84. Brotherton, C.S.; Martin, C.A.; Long, M.D.; et al. Avoidance of fiber is associated with greater risk of Crohn's Disease flare in a 6-month period. Clin. Gastroenterol. Hepatol. 2016, 14, 1130-1136. [CrossRef] [PubMed]

85. Andersen, V.; Chan, S.; Luben, R.; Khaw, K.T.; Olsen, A.; Tjonneland, A.; Kaaks, R.; Grio, O.; Bergmann, M.M.; Boeing, H.; et al. Fibre intake and the development of inflammatory bowel disease: A European prospective multi-centre cohort study (EPIC-IBD). J. Crohn's Colitis 2018, 129-136. [CrossRef] [PubMed]

86. Carabotti, M.; Annibale, B. Treatment of diverticular disease: An update on latest evidence and clinical implications. Drugs Context 2018, 7, 212526. [CrossRef] [PubMed]

87. Spiller, R.C. Changing views on diverticular disease: Impact of aging, obesity, diet and microbiota. Neurogastroenterol. Motil. 2015, 27, 305-312. [CrossRef] [PubMed]

88. Barbara, G.; Scaioli, E.; Barbaro, M.R.; Biagi, E.; Laghi, L.; Cremon, C.; Marasco, G.; Colecchia, A.; Picone, G.; Salfi, N.; et al. Gut microbiota, metabolome and immune signatures in patients with uncomplicated diverticular disease. Gut 2017, 66, 1252-1261. [CrossRef] [PubMed]

89. Mahmood, M.W.; Abraham-Nordling, M.; Hakansson, N.; Wolk, A.; Hjern, F. High intake of dietary fibre from fruits and vegetables reduces the risk of hospitalization for diverticular disease. Eur. J. Nutr. 2018. [CrossRef] [PubMed]

90. Crowe, F.L.; Balkwill, A.; Cairns, B.J.; Appleby, P.N.; Green, J.; Key, T.J.; Beral, V. Source of dietary fibre and diverticular disease incidence: A prospective study of UK women. Gut 2014, 63, 1450-1456. [CrossRef] [PubMed]

91. Aldoori, W.; Ryan-Harshman, M. Preventing diverticular disease. Review of recent evidence on high-fibre diets. Can. Fam. Physician 2002, 48, 1632-1637. [PubMed]

92. Crowe, F.L.; Appleby, P.N.; Allen, N.E.; Key, T.J. Diet and risk of diverticular disease in Oxford cohort of European Prospective Investigation into Cancer and Nutrition (EPIC): Prospective study of British vegetarians and non-vegetarians. BMJ 2011, 343. [CrossRef] [PubMed]

93. Dahl, C.; Crichton, M.; Jenkins, J.; Nucera, R.; Mahoney, S.; Marx, W.; Marshall, S. Evidence for dietary fibre modification in the recovery and prevention of reoccurrence of acute, uncomplicated diverticulitis: A systematic literature review. Nutrients 2018, 10, 137. [CrossRef] [PubMed]

94. Schwingshackl, L.; Hoffmann, G.; Kalle-Uhlmann, T.; Arregui, M.; Buijsse, B.; Boeing, H. Fruit and vegetable consumption and changes in anthropometric variables in adult populations: A systematic review and meta-analysis of prospective cohort studies. PLOS ONE 2015, 10, e0140846. [CrossRef] [PubMed]

95. Sharma, S.P.; Chung, H.J.; Kim, H.J.; Hong, S.T. Paradoxical effects of fruit on obesity. Nutrients 2016, 8, 633. [CrossRef] [PubMed] 
96. Bertoia, M.L.; Mukamal, K.J.; Cahill, L.E.; Hou, T.; Ludwig, D.S.; Mozaffarian, D.; Willett, W.C.; Hu, F.B.; Rimm, E.B. Changes in intake of fruits and vegetables and weight change in United States men and women followed for up to 24 years: Analysis from three prospective cohort studies. PLoS Med. 2015, 12. [CrossRef] [PubMed]

97. Aljadani, H.M.; Patterson, A.; Sibbritt, D.; Hutchesson, M.J.; Jensen, M.E.; Collins, C.E. Diet quality, measured by fruit and vegetable intake, predicts weight change in young women. J. Obesity 2013, 2013, 525161. [CrossRef] [PubMed]

98. Rautiainen, S.; Wang, L.; Lee, I.M.; Manson, J.E.; Buring, J.E.; Sesso, H.D. Higher intake of fruit, but not vegetables or fiber, at baseline is associated with lower risk of becoming overweight or obese in middle-aged and older women of normal BMI at baseline. J. Nutr. 2015, 145, 960-968. [CrossRef] [PubMed]

99. Yuan, S.; Yu, H.J.; Liu, M.W.; Huang, Y.; Yang, X.H.; Tang, B.W.; Song, Y.; Cao, Z.K.; Wu, H.J.; He, Q.O.; et al. The association of fruit and vegetable consumption with changes in weight and body mass index in Chinese adults: A cohort study. Public Heal 2018, 157, 121-126. [CrossRef] [PubMed]

100. Yu, Z.M.; DeClercq, V.; Cui, Y.; Forbes, C.; Grandy, S.; Keats, M.; Parker, L.; Sweeney, E.; Dummer, T.J.B. Fruit and vegetable intake and body adiposity among populations in Eastern Canada: The Atlantic Partnership for Tomorrow's Health Study. BMJ Open 2018, 8, e018060. [CrossRef] [PubMed]

101. Cavallo, D.N.; Horino, M.; McCarthy, W.J. Adult intake of minimally processed fruits and vegetables: Associated with cardiometabolic disease factors. J. Acad. Nutr. Diet. 2016, 116, 1387-1394. [CrossRef] [PubMed]

102. Auerbach, B.J.; Littman, A.J.; Krieger, J.; Young, B.A.; Larson, J.; Tinker, L.; Neuhouser, M.L. Association of $100 \%$ fruit juice consumption and 3-year weight change among postmenopausal women in the Women's Health Initiative. Prev. Med. 2018, 109, 8-10. [CrossRef] [PubMed]

103. Fogelholm, M.; Anderssen, S.; Gunnarsdottir, I.; Lahti-Koski, M. Dietary macronutrients, and food consumption as determinants of long-term weight change in adult populations: A systematic literature review. Food Nutr. Res. 2012, 56. [CrossRef] [PubMed]

104. Liu, S.; Willett, W.C.; Manson, J.E.; Hu, F.B.; Rosner, B.; Colditz, G. Relation between changes in intakes of dietary fiber nd grain products and changes in weight and development of obesity among middle-aged women. Am. J. Clin. Nutr. 2003, 78, 920-927. [CrossRef] [PubMed]

105. Tucker, L.A.; Thomas, K.S. Increasing total fiber intake reduces risk of weight and fat gains in women. J. Nutr. 2009, 139, 576-581. [CrossRef] [PubMed]

106. Grooms, K.N.; Ommerborn, M.J.; Pham, D.Q.; Djousse, L.; Clark, C.R. Dietary fiber intake and cardiometabolic risk among US adults, NHANES 1999-2010. Am. J. Med. 2013, 126, 1059-1067. [CrossRef] [PubMed]

107. Romaguera, D.; Angquist, L.; Du, H.; Jakobsen, M.U.; Forouhi, N.G.; Halkjaer, J.; Feskens, E.J.; van der A, D.L.; Masala, G.; Steffen, A.; et al. Dietary determinants of changes in waist circumference adjusted for body mass index-A proxy measure of visceral adiposity. PLoS ONE 2010, 5, e11588. [CrossRef] [PubMed]

108. Hairston, K.G.; Vitolins, M.Z.; Norris, J.M.; Anderson, A.M.; Hanley, A.J.; Wagenknecht, L.E. Lifestyle factors and 5-year abdominal fat accumulation in a minority cohort: The IRAS Family Study. Obesity (Silver Spring) 2012, 20. [CrossRef] [PubMed]

109. Othman, F.; Nor, N.S.M.; Appannah, G.; Zaki, N.A.M.; Ambak, R.; Omar, A.; Fazliana, M.; Salleh, R.; Yusof, B.N.M.; Muksan, N.; et al. Prediction of body fat loss in relation to change in nutrient intake among housewives participating in the MyBFF@home study. BMC Women's Heal 2018, 18 (Suppl. 1), 102. [CrossRef] [PubMed]

110. Kaiser, K.A.; Brown, A.W.; Shikany, J.M.; Shikany, J.M.; Mattes, R.D.; Allison, D.B. Increased fruit and vegetable intake has no discernable effect on weight loss: A systematic review and meta-analysis. Am. J. Clin. Nutr. 2014, 100, 567-576. [CrossRef] [PubMed]

111. Mytton, O.T.; Nnoaham, K.; Eyles, H.; Scarborough, P.; Ni Mhurchu, C. Systematic review and meta-analysis of the effect of increased vegetable and fruit consumption on body weight and energy intake. BMC Public 2014, 14, 886. [CrossRef] [PubMed]

112. Sylvetsky, A.C.; Edelstein, S.L.; Walford, G.; Boyko, E.J.; Horton, E.S.; Ibebuogu, U.N.; Knowler, W.C.; Montez, M.G.; Temprosa, M.; Hoskin, M.; et al. A high-carbohydrate, high-fiber, low-fat diet results in weight loss among adults at high risk of type 2 diabetes. J. Nutr. 2017, 147, 2060-2066. [CrossRef] [PubMed] 
113. Champagne, C.M.; Broyles, S.T.; Moran, L.D.; Cash, K.C.; Levy, E.J.; Lin, P.H.; Batch, B.C.; Lien, L.F.; Funk, K.L.; Dalcin, A.; et al. Dietary intakes associated with successful weight loss and maintenance during the Weight Loss Maintenance Trial. J. Am. Diet. Assoc. 2011, 111, 1826-1835. [CrossRef] [PubMed]

114. De Oliveira, M.C.; Sichieri, R.; Venturim Mozzer, R.A. low-energy-dense diet adding fruit reduces weight and energy intake in women. Appetite 2008, 51, 291-295. [CrossRef] [PubMed]

115. Li, Z.; Rasmussen, A.; Woo, S.L.; Yaceczko, S.; Gilbuena, L.V.N.; Thames, G.; Shao, P.; Yang, A.; Henning, S.; Yang, J.; et al. Daily avocado supplementation on weight loss via hypocaloric diet: A prospective randomized trial. Nutrition 2018. American Society for Nutrition Poster 23-062, \#689, Boston, MA, USA, presentation June 10, 2018.

116. Ma, Y.; Olendzki, B.C.; Wang, J.; Persuitte, G.M.; Li, W.; Fang, H.; Merriam, P.A.; Wedick, N.M.; Ockene, I.S.; Culver, A.L.; et al. Single-component versus multi-component dietary goals for the metabolic syndrome: A randomized trial. Ann. Intern. Med. 2015, 162, 248-257. [CrossRef] [PubMed]

117. Pal, S.; Khossousi, A.; Binns, C.; Dhaliwal, S.; Ellis, V. The effect of a fibre supplement compared to a healthy diet on body composition, lipids, glucose, insulin and other metabolic syndrome risk factors in overweight and obese individuals. Br. J. Nutr. 2011, 105, 90-100. [CrossRef] [PubMed]

118. Ferdowsian, H.R.; Barnard, N.D.; Hoover, V.I.; Katcher, H.I.; Levin, S.M.; Green, A.A.; Cohen, J.L. A multi-component intervention reduced body weight and cardiovascular risk at a GEICO corporate site. Am. J. Health Promt. 2010, 24, 384-387. [CrossRef] [PubMed]

119. Lindstrom, J.; Peltonen, M.; Eriksson, J.G.; Louheranta, A.; Fogelholm, M.; Uusitupa, M.; Tuomilehto, J. High-fibre, low-fat diet predicts long-term weight loss and decreased type 2 diabetes risk: The Finnish Diabetes Prevention Study. Diabetologia 2006, 49, 912-920. [CrossRef] [PubMed]

120. Bajerska, J.; Chmurzynska, A.; Muzsik, A.; Krzyzanowska, P.; Madry, E.; Malinowska, A.M.; Walkowiak, J. Weight loss and metabolic health effects from energy-restricted Mediterranean and Central-European diets in postmenopausal women: A randomized controlled trial. Sci. Reps. 2018, 8, 11170. [CrossRef] [PubMed]

121. Davis, H.C. Can the gastrointestinal microbiota be modulated by dietary fibre to treat obesity? Ir. J. Med. Sci. 2018, 187, 393-402. [CrossRef] [PubMed]

122. Fernández-Navarro, T.; Salazar, N.; Gutiérrez-Díaz, I.; de Los Reyes-Gavilan, C.G.; Gueimonde, M.; Gonzalez, S. Different intestinal microbial profile in over-weight and obese subjects consuming a diet with low content of fiber and antioxidants. Nutrients 2017, 9, 551. [CrossRef]

123. Aguirre, M.; Jonkers, D.M.A.E.; Troost, F.J.; Roeselers, G.; Venema, K. In vitro characterization of the impact of different substrates on metabolite production, energy extraction and composition of gut microbiota from lean and obese subjects. PLOS ONE 2014, 9, e113864. [CrossRef] [PubMed]

124. Hjorth, M.F.; Roager, H.M.; Larsen, T.M.; Poulsen, S.K.; Licht, T.R.; Bahl, M.I.; Zohar, Y.; Astrup, A. Pre-treatment microbial Prevotella-to-Bacteroides ratio, determines body fat loss success during a 6-month randomized controlled diet intervention. Int. J. Obes. (Lond.) 2018, 42, 580-583. [CrossRef] [PubMed]

125. Ivan, J.; Major, E.; Sipos, A.; Kovacs, K.; Hovath, D.; Tamas, I.; Bay, P.; Dombradi, V.; Lontay, B. The short-chain fatty acid propionate inhibits adipogenic differentiation of human chorion-derived mesenchymal stem cells through the free fatty acid receptor 2. Stem Cells Dev. 2017, 26, 1724-1733. [CrossRef] [PubMed]

126. Byrne, C.S.; Chambers, E.S.; Alhabeeb, H.; Chhina, N.; Morrison, D.J.; Preston, T.; Tedford, T.; Fitzpatrick, J.; Irani, C.; Busza, A. Increased colonic propionate reduces anticipatory reward responses in the human striatum to high-energy foods. Am. J. Clin. Nutr. 2016, 104, 5-14. [CrossRef] [PubMed]

127. Samuel, B.S.; Shaito, A.; Motoike, T.; Rey, F.E.; Backhed, F.; Manchester, J.K.; Hammer, R.E.; Williams, S.C.; Crowley, J.; Yanagisawa, M.; et al. Effects of the gut microbiota on host adiposity are modulated by the short-chain fatty-acid binding G protein-coupled receptor, Gpr41. Proc. Natl. Acad. Sci. USA 2008, 105, 16767-16772. [CrossRef] [PubMed]

128. Rolls, B.J. Dietary energy density: Applying behavioural science to weight management. Nutr. Bull. 2017, 42, 246-253. [CrossRef] [PubMed]

129. CDC National Center for Chronic Disease Prevention and Health Promotion. Can eating fruits and vegetables help people to manage their weight? Research to Practice Series; No. 1. Available online: https:/ /www.cdc. gov/nccdphp/dnpa/nutrition/pdf/rtp_practitioner_10_07.pdf (accessed on 6 August 2018).

130. Brunstrom, J.M.; Drake, A.C.L.; Forde, C.G.; Rogers, P.J. Undervalued and ignored: Are humans poorly adapted to energy dense foods? Appetite 2018, 120, 589-595. [CrossRef] [PubMed] 
131. Kant, A.K.; Graubard, B.I. Energy density of diets reported by American adults: Association with food group intake, nutrient intake and body weight. Int. J. Obes. (Lond.) 2005, 29, 950-956. [CrossRef] [PubMed]

132. Vernarelli, J.A.; Mitchell, D.C.; Rolls, B.J.; Hartman, T.J. Dietary energy density and obesity: How consumption patterns differ by body weight status. Eur. J. Nutr. 2018, 57, 351-361. [CrossRef] [PubMed]

133. Fernando, N.N.T.; Campbell, K.J.; McNaughton, S.A.; Zheng, M.; Lacy, K.E. Predictors of dietary energy density among preschool aged children. Nutrients 2018, 10, 178. [CrossRef] [PubMed]

134. Raynor, H.A.; Van Walleghen, E.L.; Bachman, J.L. Dietary energy density and successful weight loss maintenance. Eat Behav. 2011, 12, 119-125. [CrossRef] [PubMed]

135. Wanders, A.J.; van den Borne, J.J.; de Graaf, C.; Hulshof, T.; Jonathan, M.C.; Kristensen, M.; Mars, M.; Schols, H.A.; Feskens, E.J. Effects of dietary fibre on subjective appetite, energy intake and body weight: A systematic review of randomized controlled trials. Obes. Rev. 2011, 12, 724-739. [CrossRef] [PubMed]

136. Tiwary, C.M.; Ward, J.A.; Jackson, B.A. Effect of pectin on satiety in healthy US Army adults. J. Am. Coll. Nutr. 1997, 16, 423-428. [CrossRef] [PubMed]

137. Wanders, A.J.; Mars, M.; Borgonjen-van den Berg, K.J.; de Graaf, C.; Feskens, E.J. Satiety and energy intake after single and repeated exposure to gel-forming dietary fiber: Post-ingestive effects. Int. J. Obes. (Lond.) 2014, 38, 794-800. [CrossRef] [PubMed]

138. Dong, H.; Sargent, L.J.; Chatzidiakou, Y.; Saunders, C.; Harkness, L.; Bordenave, N.; Rowland, I.; Spencer, J.P.E.; Lovegrove, J.A. Orange pomace fibre increases a composite scoring of subjective ratings of hunger and fullness in healthy adults. Appetite 2016, 107, 478-485. [CrossRef] [PubMed]

139. Hoffmann Sardá, F.A.; Giuntini, E.B.; Gomez, M.L.P.A.; Lui, M.G.Y.; Negrini, J.A.E.; Tadini, C.C.; Lajolo, F.M.; Menezes, E.W. Impact of resistant starch from unripe banana flour on hunger, satiety, and glucose homeostasis in healthy volunteers. J. Funct. Foods 2016, 24, 63-74. [CrossRef]

140. Rogers, P.J.; Shahrokni, R. A comparison of the satiety effects of a smoothie, its fresh fruit equivalent and other drinks. Nutrients 2018, 10, 431. [CrossRef] [PubMed]

141. Maljaars, P.W.; Peters, H.P.; Mela, D.J.; Masclee, A.A. Ileal brake: A sensible food target for appetite control. A review. Physiol. Behav. 2008, 95, 271-281. [CrossRef] [PubMed]

142. Flood-Obbagy, J.E.; Rolls, B.J. The effect of fruit in different forms on energy intake and satiety at a meal. Appetite 2009, 52, 416-422. [CrossRef] [PubMed]

143. James, L.J.; Funnell, M.P.; Milner, S. An afternoon snack of berries reduces subsequent energy intake compared to an isoenergetic confectionary snack. Appetite 2015, 95, 132-137. [CrossRef] [PubMed]

144. Patel, B.P.; Bellissimo, N.; Luhovyy, B.; Bennett, L.J.; Hurton, E.; Painter, J.E.; Anderson, G.H. An after-school snack of raisins lowers cumulative food intake in young children. J. Food Sci. 2013, 78, A5-A10. [CrossRef] [PubMed]

145. Wien, M.; Haddad, E.; Oda, K.; Sabaté, J. A randomized $3 \times 3$ crossover study to evaluate the effect of Hass avocado intake on post-ingestive satiety, glucose and insulin levels, and subsequent energy intake in overweight adults. Nutr. J. 2013, 12, 155. [CrossRef] [PubMed]

146. Haddad, E.; Wien, M.; Oda, K.; Sabate, J. Postprandial gut hormone responses to Hass avocado meals and their association with visual analog scores in overweight adults; a randomized 3x3 crossover trial. Eat Behav. 2018, 31, 35-40. [CrossRef] [PubMed]

147. Farajian, P.; Katsagani, M.; Zampelas, A. Short-term effects of a snack including dried prunes on energy intake and satiety in normal-weight individuals. Eat Behav. 2010, 11, 201-203. [CrossRef] [PubMed]

148. Miles, C.W. The metabolizable energy of diets differing in dietary fat and fiber measured in humans. J. Nutr. 1992, 122, 306-311. [CrossRef] [PubMed]

149. Miles, C.W.; Kelsay, J.L.; Wong, N.P. Effect of dietary fiber on the metabolizable energy of human diets. J. Nutr. 1988, 118, 1075-1081. [CrossRef] [PubMed]

150. Baer, D.J.; Rumpler, W.V.; Miles, C.W.; Fahey, G.C. Dietary fiber decreases the metabolizable energy content and nutrient digestibility of mixed diets fed to humans. J. Nutr. 1997, 127, 579-586. [CrossRef] [PubMed]

151. Beyer, P.L.; Flynn, M.A. Effects of high- and low-fiber diets on human feces. J. Am. Diet. Assoc. 1978, 72, 271-277. [PubMed]

152. Wisker, E.; Feldheim, W. Metabolizable energy of diets low in dietary fiber from fruits and vegetables when consumed by humans. J. Nutr. 1990, 120, 1331-1337. [CrossRef] [PubMed] 
153. Webb, P.; Annis, J.F. Adaptation to overeating in lean and overweight men and women. Hum. Nutr. Clin. Nutr. 1983, 37, 117-131. [PubMed]

154. Mendis, S.; Puska, P.; Norrving, B. Global Atlas on Cardiovascular Disease Prevention and Control; World Health Organization: Geneva, Switzerland, 2011; Available online: www.who.int/cardiovasculardiseases/ publications/atlascvd/en/ (accessed on 6 August 2018).

155. Pearson-Stuttard, J.; Bandosz, P.; Rehm, C.D.; Penalvo, J.; Whitsel, L.; Gaziano, T.; Conrad, Z.; Wilde, P.; Micha, R.; Lloyd-Williams, F.; et al. Reducing US cardiovascular disease burden and disparities through national and targeted dietary policies: A modelling study. PLoS Med. 2017, 14. [CrossRef] [PubMed]

156. Appiah, D.; Capistrant, B.D. Cardiovascular disease risk assessment in the United States and low- and middle-income countries using predicted heart/vascular age. Sci. Rep. 2017, 7, 16673. [CrossRef] [PubMed]

157. Wu, H.; Dwyer, K.M.; Fan, Z.; Shircore, A.; Fan, J.; Dwyer, J.H. Dietary fiber and progression of atherosclerosis: The Los Angeles Atherosclerosis Study. Am. J. Clin. Nutr. 2003, 78, 1085-1091. [CrossRef] [PubMed]

158. Juonala, M.; Viikari, J.S.A.; Kahonen, M.; Taittonen, L.; Laitinen, T.; Hutri-Kahonen, N.; Lehtimaki, T.; Jula, A.; Pietikainen, M.; Jokinen, E. Life-time risk factors and progression of carotid atherosclerosis in young adults: The Cardiovascular Risk in Young Finns Study. Eur. Hear. J. 2010, 31, 1745-1751. [CrossRef] [PubMed]

159. Buil-Cosiales, P.; Martinez-Gonzalez, M.A.; Ruiz-Canela, M.; Diez-Espino, J.; Garcia-Prellano, A.; Toledo, E. Consumption of fruit and fruit fiber decrease the risk of cardiovascular disease in a Mediterranean young cohort. Nutrients 2017, 9, 295. [CrossRef] [PubMed]

160. Bondonno, N.P.; Lewis, J.R.; Prince, R.L.; Lim, W.H.; Wong, G.; Schousboe, J.T.; Woodman, R.J.; Kiel, D.P.; Bondonno, C.P.; Wars, N.C.; et al. Fruit intake and abdominal aortic calcification in elderly women: A prospective cohort study. Nutrients 2016, 8, 159. [CrossRef] [PubMed]

161. Tian, X.; Du, H.; Li, L.; Bennett, D.; Gao, R.; Li, S.; Wang, S.; Guo, Y.; Bian, Z.; Yang, L.; et al. Fruit consumption and physical activity in relation to all-cause and cardiovascular mortality among 70,000 Chinese adults with pre-existing vascular disease. PLoS ONE 2017, 12. [CrossRef] [PubMed]

162. Lai, H.T.M.; Threapleton, D.E.; Day, A.J.; Williamson, G.; Cade, J.E.; Burley, V.J. Fruit intake and cardiovascular disease mortality in the UK Women's Cohort Study. Eur. J. Epidemiol. 2015, 30, 1035-1048. [CrossRef] [PubMed]

163. Threapleton, D.E.; Greenwood, D.C.; Evans, C.E.L.; Cleghorn, C.L.; Nykjaer, C.; Woodhead, C.; Cade, J.E.; Gale, C.P.; Burley, V.J. Dietary fibre intake and risk of cardiovascular disease: Systematic review and meta-analysis. BMJ 2013, 347. [CrossRef] [PubMed]

164. Najjar, R.S.; Moore, C.E.; Montgomery, B.D. A defined, plant-based diet utilized in an outpatient cardiovascular clinic effectively treats hypercholesterolemia and hypertension and reduces medications. Clin. Cardiol. 2018, 41, 307-313. [CrossRef] [PubMed]

165. Theuwissen, E.; Mensink, R.P. Water-soluble dietary fibers and cardiovascular disease. Physiol. Behav. 2008, 94, 285-292. [CrossRef] [PubMed]

166. Brown, L.; Rosner, B.; Willett, W.W.; Sacks, F.M. Cholesterol lowering effects of dietary fiber. A meta-analysis. Am. J. Clin. Nutr. 1999, 69, 30-42. [CrossRef] [PubMed]

167. Brouns, F.; Theuwissen, E.; Adam, A.; Bell, M.; Berger, A.; Mensink, R.P. Cholesterol-lowering properties of different pectin types in mildly hyper-cholesterolemic men and women. Eur. J. Clin. Nutr. 2012, 66, 591-599. [CrossRef] [PubMed]

168. Ravn-Haren, G.; Dragsted, L.O.; Buch-Andersen, T.; Jensen, E.N.; Jensen, R.I.; Nemeth-Balogh, M.; Paulovicsova, B.; Bergstrom, A.; Wilcks, A.; Licht, T.R.; et al. Intake of whole apples or clear apple juice has contrasting effects on plasma lipids in healthy volunteers. Eur. J. Nutr. 2013, 52, 1875-1889. [CrossRef] [PubMed]

169. Wang, L.; Bordi, P.L.; Fleming, J.A.; Hill, A.M.; Kris-Etherton, P.M. Effects of a moderate fat diet with and without avocados on lipoprotein particle number, size and subclasses in overweight and obese adults: A randomized, controlled trial. J. Am. Heart Assoc. 2015, 4, e001355. [CrossRef] [PubMed]

170. Park, E.; Edirisinghe, I.; Burton-Freeman, B. Avocado fruit on postprandial markers of cardio-metabolic risk: A randomized controlled dose response trial in overweight and obese men and women. Nutrients 2018, 10, 1287. [CrossRef] [PubMed]

171. Peou, S.; Milliard-Hasting, B.; Shah, S. Impact of avocado-enriched diets on plasma lipoproteins: A meta-analysis. J. Clin. Lipidol. 2016, 10, 161-171. [CrossRef] [PubMed] 
172. Mahmassani, H.A.; Avendano, E.E.; Raman, G.; Johnson, E.J. Avocado consumption and risk factors for heart disease: A systematic review and meta-analysis. Am. J. Clin. Nutr. 2018, 107, 523-536. [CrossRef] [PubMed]

173. Tinker, L.F.; Schneeman, B.O.; Davis, P.A.; Gallaher, D.D.; Waggoner, C.R. Consumption of prunes as a source of dietary fiber in men with mild hypercholesterolemia. Am. J. Clin. Nutr. 1991, 53, 1259-1265. [CrossRef] [PubMed]

174. Huang, H.; Chen, G.; Liao, D.; Zhu, Y.; Xue, X. Effects of berries consumption on cardiovascular risk factors: A meta-analysis with trial sequential analysis of randomized controlled trials. Sci. Rep. 2016, 6, 233625. [CrossRef] [PubMed]

175. Borgi, L.; Muraki, I.; Satija, A.; Willett, W.C.; Rimm, E.B.; Forman, J.P. Fruit and vegetable consumption and the incidence of hypertension in three prospective cohort studies. Hypertension 2016, 67, 288-893. [CrossRef] [PubMed]

176. Schwingshackl, L.; Schwedhelm, C.; Hoffmann, G.; Knuppel, S.; Iqbal, K.; Andriolo, V.; Bechthold, A.; Schlesinger, S.; Boeing, H. Food groups and risk of hypertension: A systematic review and dose-response meta-analysis of prospective studies. Adv. Nutr. 2017, 8, 93-803. [CrossRef] [PubMed]

177. Li, B.; Li, F.; Wang, L.; Zhang, D. Fruit and vegetables consumption and risk of hypertension: A meta-analysis. J. Clin. Hypertens. (Greenwich.) 2016, 18, 468-476. [CrossRef] [PubMed]

178. Wu, L.; Sun, D.; He, Y. Fruit and vegetable consumption and incident hypertension: Dose response meta-analysis of prospective cohort studies. J. Hum. Hypertens. 2016, 30, 573-580. [CrossRef] [PubMed]

179. Wang, L.; Manson, J.E.; Gaziano, J.M.; Buring, J.E.; Sesso, H.D. Fruit and vegetable intake and the risk of hypertension in middle-aged and older women. Am. J. Hypertens. 2012, 25, 180-189. [CrossRef] [PubMed]

180. Ascherio, A.; Stampfer, M.J.; Colditz, G.A.; Willet, W.C.; McKinlay, J. Nutrient intake and blood pressure in normotensive males. Int. J. Epidem. 1991, 20, 886-891. [CrossRef]

181. Nunez-Cordoba, J.M.; Alonso, A.; Beunza, J.J.; Palma, S.; Gomez-Gracia, E.; Martinez-Gonzalez, M.A. Role of vegetables and fruits in Mediterranean diets to prevent hypertension. Eur. J. Clin. Nutr. 2009, 63, 605-612. [CrossRef] [PubMed]

182. Kim, J.; Kim, J. Association between fruit and vegetable consumption and risk of hypertension in middle-aged and older Korean adults. J. Acad. Nutr. Diet. 2018, 118, 1438-1449. [CrossRef] [PubMed]

183. Mellendick, K.; Shanahan, L.; Wideman, L.; Calkins, S.; Keane, S.; Lovelady, C. Diets rich in fruits and vegetables are associated with lower cardiovascular disease risk in adolescents. Nutrients 2018, 10, 136. [CrossRef] [PubMed]

184. Aljuraiban, G.S.; Griep, L.M.O.; Chan, Q.; Daviglus, M.L.; Stamler, J.; Van Horn, L.; Elliott, P.; Frost, G.S. Total, insoluble and soluble dietary fibre intake in relation to blood pressure: The INTERMAP Study. Br. J. Nutr. 2015, 114, 1480-1486. [CrossRef] [PubMed]

185. Ascherio, A. A prospective study of nutritional factors and hypertension among US men. Circulation 1992, 86, 1475-1484. [CrossRef] [PubMed]

186. Ascherio, A.; Hennekens, C.; Willett, W.; Sacks, F.; Rosner, B.; Manson, J.; Witteman, J.; Stampfer, M.J. Prospective study of nutritional factors, blood pressure, and hypertension among US women. Hypertension 1996, 27, 1065-1072. [CrossRef] [PubMed]

187. Sun, L.J.; Shi, X.; Wang, T.; Zhang, D. Exploration of the association between dietary fiber intake and hypertension among U.S. adults using 2017 American College of Cardiology/American Heart Association Blood Pressure Guidelines: NHANES 2007-2014. Nutrients 2018, 10, 1091. [CrossRef] [PubMed]

188. Hartley, L.; Igbinedion, E.; Holmes, J.; Flowers, N.; Thorogood, M.; Clarke, A.; Stranges, S.; Hooper, L.; Rees, K. Increased consumption of fruit and vegetables for the primary prevention of cardiovascular diseases. Cochrane Database Syst. Rev. 2013, 6. [CrossRef] [PubMed]

189. Appel, L.J.; Moore, T.J.; Obarzanek, E.; Vollmer, W.M.; Svetkey, L.P; Bray, G.A.; Vogt, T.M.; Culter, J.A.; Windhauser, M.M.; et al. A clinical trial of the effects of dietary patterns on blood pressure. N. Engl. J. Med. 1997, 336, 1117-1124. [CrossRef] [PubMed]

190. McCall, D.O.; McGartland, C.P.; McKinley, M.C.; Patterson, C.C.; Sharpe, P.; McCance, D.R.; Young, I.S.; Woodside, J.V. Dietary intake of fruits and vegetables improves microvascular function in hypertensive subjects in a dose-dependent manner. Circulation 2009, 119, 2153-2160. [CrossRef] [PubMed]

191. John, J.H.; Ziebland, S.; Yudkin, P.; Roe, L.S.; Neil, H.A. Effects of fruit and vegetable consumption on plasma antioxidant concentrations and blood pressure: A randomized controlled trial. Lancet 2002, 359, 1969-1974. [CrossRef] 
192. Krishnan, S.; Adams, S.H.; Allen, L.H.; Laugero, K.D.; Newman, J.W.; Stephensen, C.B.; Burnett, D.J.; Witbracht, M.; Welch, L.C.; Que, E.S.; et al. A randomized controlled-feeding trial based on the Dietary Guidelines for Americans on cardiometabolic health indexes. Am. J. Clin. Nutr. 2018, 108, 266-278. [CrossRef] [PubMed]

193. Siervo, M.; Lara, J.; Chowdhury, S.; Ashor, A.; Oggoni, C.; Mathers, J.C. Effects of the Dietary Approach to Stop Hypertension (DASH) diet on cardiovascular risk factors: A systematic review and meta-analysis. Br. J. Nutr. 2015, 113, 1-15. [CrossRef] [PubMed]

194. Khan, K.; Jovanovski, E.; Ho, H.V.T.; Marques, A.C.R.; Zurbau, A.; Mejia, S.B.; Sievenpiper, J.C.; Vuksan, V. The effect of viscous soluble fiber on blood pressure: A systematic review and meta-analysis of randomized controlled trials. Nutr. Metab. Cardiov. Dis. 2018, 28, 3-13. [CrossRef] [PubMed]

195. Hartley, L.; May, M.D.; Loveman, E.; Colquitt, J.L; Rees, K. Dietary fibre for the primary prevention of cardiovascular disease. Cochrane Database Syst. Rev. 2016, 1, CD011472. [CrossRef] [PubMed]

196. Streppel, M.T.; Arends, L.R.; van't Veer, P.; Grobbee, D.E.; Gelenijnse, J.M. Dietary fiber and blood pressure: A meta-analysis of randomized placebo-controlled trials. Arch. Intern. Med. 2005, 165, 150-156. [CrossRef] [PubMed]

197. Whelton, S.P.; Hyre, A.D.; Pedersen, B.; Yi, Y.; Whelton, P.K.; He, J. Effect of dietary fiber intake on blood pressure: A meta-analysis of randomized, controlled clinical trials. J. Hypertens. 2005, 23, 475-481. [CrossRef] [PubMed]

198. Zhou, M.S.; Schulman, I.H.; Raij, L. Vascular inflammation, insulin resistance, and endothelial dysfunction in salt-sensitive hypertension: Role of nuclear factor kappa B activation. J. Hypertens. 2010, 28, 527-535. [CrossRef] [PubMed]

199. Yang, T.; Santisteban, M.M.; Rodriguez, V.; Li, E.; Ahmari, N.; Carvajal, J.M.; Zadeh, M.; Gong, M.; Qi, Y.; Zubcevic, J.; et al. Gut dysbiosis is linked to hypertension. Hypertension 2015, 65, 1331-1340. [CrossRef] [PubMed]

200. Pluznick, J.L. A novel SCFA receptor, the microbiota, and blood pressure regulation. Gut Microbes 2014, 5, 202-207. [CrossRef] [PubMed]

201. Miyamoto, J.; Kascubuchi, M.; Nakajima, A.; Irie, J.; Itoh, H.; Kimura, I. The role of short-chain fatty acid on blood pressure regulation. Curr. Opin. Nephrol. Hypertens. 2016, 25, 379-383. [CrossRef] [PubMed]

202. Weisman, A.; Fazli, G.S.; Johns, A.; Booth, G.L. Evolving trends in the epidemiology, risk factors, and prevention of type 2 diabetes: A review. Can. J. Cardiol. 2018, 34, 552-564. [CrossRef] [PubMed]

203. Williamson, D.A. Prevention of type 2 diabetes: What is the right target population? Expert Rev. Endocrinol. Metab. 2018, 13. [CrossRef] [PubMed]

204. Ibrahim, M.; Tuomilehto, J.; Aschner, P.; Beseler, L.; Cahn, A.; Eckel, R.H.; Fischl, A.H.; Guthrie, G.; Hill, J.O.; Kumwenda, M.; et al. Global status of diabetes prevention and prospects for action: A consensus statement. Diabetes Metab. Res. Rev. 2018, 34, e3021. [CrossRef] [PubMed]

205. Wang, P.-Y.; Fang, J.-C.; Gao, Z.-H.; Zhang, C.; Xie, S.Y. Higher intake of fruits, vegetables or their fiber reduces the risk of type 2 diabetes: A meta-analysis. J. Diabetes Investig. 2016, 7, 56-69. [CrossRef] [PubMed]

206. Li, S.; Miao, S.; Huang, Y.; Liu, Z.; Tian, H.; Yin, X.; Tang, W.; Steffen, L.; Xi, B. Fruit intake decreases risk of incident type 2 diabetes: An updated meta-analysis. Endocrine 2015, 48, 454-460. [CrossRef] [PubMed]

207. Mursu, J.; Virtanen, J.K.; Tuomainen, T.-P.; Nurmi, T.; Voulainen, S. Intake of fruit, berries, and vegetables and risk of type 2 diabetes in Finnish men: The Kuopio Ischaemic Heart Disease Risk Factor Study. Am. J. Clin. Nutr. 2014, 99, 328-333. [CrossRef] [PubMed]

208. Muraki, I.; Imamura, F.; Manson, J.E.; Hu, F.B.; Willett, W.C.; van Dam, R.M.; Sun, Q. Fruit consumption and risk of type 2 diabetes: Results from three prospective longitudinal cohort studies. BMJ 2013, 347, 5001. [CrossRef] [PubMed]

209. Du, H.; Li, L.; Bennett, D.; Guo, Y.; Turnbull, I.; Yang, L.; Bragg, F.; Bian, Z.; Chen, Y.; Chen, J.; et al. Fresh fruit consumption in relation to incident diabetes and diabetic vascular complications: A 7-y prospective study of 0.5 million Chinese adults. PLoS Med. 2017, 14, e1002279. [CrossRef] [PubMed]

210. Yao, B.; Fang, H.; Xu, W.; Yan, Y.; Xu, H.; Liu, Y.; Mo, M.; Zhang, H.; Zhao, Y. Dietary fiber intake and risk of type 2 diabetes: A dose-response analysis of prospective studies. Eur. J. Epidemiol. 2014, 29, 79-88. [CrossRef] [PubMed]

211. Schulze, M.B.; Schulz, M.; Heidemann, C.; et al. Fiber and magnesium intake and incidence of type 2 diabetes. Arch. Intern. Med. 2007, 167, 956-965. [CrossRef] [PubMed] 
212. Looman, M.; Schoenaker, D.A.J.M.; Soedaman-Muthu, S.S.; Geelen, A.; Feskens, E.J.M.; Mishra, G.D. Pre-pregnancy dietary carbohydrate quantity and quality, and risk of developing gestational diabetes: The Australian Longitudinal Study in Women's Health. Br. J. Nutr. 2018, 120, 435-444. [CrossRef] [PubMed]

213. Sargeant, L.A.; Khaw, K.T.; Bingham, S.; Day, N.E.; Luben, R.N.; Oakes, S.; Welch, A.; Wareham, N.J. Fruit and vegetable intake and population glycosylated haemoglobin levels: The EPIC-Norfolk Study. Eur. J. Clin. Nutr. 2001, 55, 342-348. [CrossRef] [PubMed]

214. Carraro, J.C.; Hermsdorff, H.H.; Mansego, M.L.; Zulet, M.A.; Milagro, F.I.; Bressan, J.; Martinez, J.A. Higher fruit intake is related to TNF- $\alpha$ hypomethylation and better glucose tolerance in healthy subjects. J. Nutr. Nutr. 2016, 9, 95-105. [CrossRef] [PubMed]

215. Tanaka, S.; Yoshimura, Y.; Kawasaki, R.; Kamada, C.; Tanaka, S.; Horikawa, C.; Ohashi, Y.; Araki, A.; Ito, H.; Akanuma, Y.; et al. Fruit intake and incident diabetic retinopathy with type 2 diabetes. Epidemiology 2013, 24, 204-211. [CrossRef] [PubMed]

216. Breneman, C.B.; Tucker, L. Dietary fibre consumption and insulin resistance-The role of body fat and physical activity. Br. J. Nutr. 2013, 110, 375-383. [CrossRef] [PubMed]

217. Morimoto, N.; Kasuga, C.; Tanaka, A.; Kamachi, K.; Ai, M.; Urayama, K.Y.; Tanaka, A. Association between dietary fibre: Carbohydrate intake ratio and insulin resistance in Japanese adults without type 2 diabetes. Br. J. Nutr. 2018, 119, 620-628. [CrossRef] [PubMed]

218. AlEssa, H.B.; Ley, S.H.; Rosner, B.; Malik, U.S.; Willett, W.C.; Campos, H.; Hu, F.B. High fiber and low starch intakes are associated with circulating intermediate biomarkers of type 2 diabetes among women. J. Nutr. 2016, 146, 306-317. [CrossRef] [PubMed]

219. Den Biggelaar, L.J.C.J.; Eussen, S.J.P.M.; Sep, S.J.S.; Mari, A.; Ferranini, E.; van Greevenbroek, M.M.; va der Kallen, C.J.; Schalkwijk, C.G.; Arts, I.C.W.; Stehouwer, C.D.A.; et al. Prospective associations of dietary carbohydrate, fat, and protein intake with $\beta$-cell function in the CODAM study. Eur. J. Nutr. 2018. [CrossRef] [PubMed]

220. AlEssa, H.B.; Bhupathiraju, S.N.; Malik, V.S.; Wedick, N.M.; Campos, H.; Rosen, B.; Willett, W.C.; Hu, F.B. Carbohydrate quality and quantity and risk of type 2 diabetes in US women. Am. J. Clin. Nutr. 2015, 102, 1543-1553. [CrossRef] [PubMed]

221. Haber, G.B.; Heaton, K.W.; Murphy, D. Depletion and disruption of dietary fibre effects on satiety, plasma-glucose, and serum insulin. Lancet 1977, 2, 679-682. [CrossRef]

222. Bolton, R.P.; Heaton, K.W.; Burroughs, L.F. The role of dietary fiber in satiety, glucose and insulin: Studies with fruit and fruit juice. Am. J. Clin. Nutr. 1981, 34, 211-217. [CrossRef] [PubMed]

223. Oliver, C.-Y.; Rasmussen, H.; Kamil, A.; Du, P.; Blumberg, J.B. Orange pomace improves postprandial glycemic responses: An acute, randomized, placebo-controlled, double-blind, crossover trial in overweight men. Nutrients 2017, 9, 130. [CrossRef]

224. Torronen, R.; Kolehmainen, M.; Sarkkinen, E.; Poutanen, K.; Mykkanen, H.; Niskanaen, L. Berries reduce postprandial insulin responses to wheat and rye breads in healthy women. J. Nutr. 2013, 143, 430-436. [CrossRef] [PubMed]

225. De Carvalho, C.; de Paula, T.P.; Viana, L.V.; Machado, V.M.; de Almeida, J.C.; Azevedo, M.J. Plasma glucose and insulin responses after consumption of breakfasts with different sources of soluble fiber in type 2 diabetes patients: A randomized crossover clinical trial. Am. J. Clin. Nutr. 2017, 106, 1238-1245. [CrossRef] [PubMed]

226. Galvao Candido, F.; Silva Ton, W.T.; de Cassia Goncalves Alfenas, R. Addition of dietary fiber sources to shakes reduces postprandial glycemia and alters food intake. Nutr. Hosp. 2015, 31, 299-306. [CrossRef]

227. Esfahani, A.; Lam, J.; Kendall, C.W.C. Acute effects of raisin consumption on glucose and insulin responses in healthy individuals. J. Nutr. Sci. 2014, 3, 1-6. [CrossRef] [PubMed]

228. Jenkins, D.J.; Jenkins, A.L. Dietary fiber and the glycemic response. Proc. Soc. Exp. Biol. Med. 1985, 180, 422-431. [CrossRef] [PubMed]

229. McRorie, J.W. Evidence-based approach to fiber supplement and clinical meaningful health benefits, part 1. Nutr. Today 2015, 50, 82-89. [CrossRef] [PubMed]

230. Boland, B.B.; Rhodes, C.J.; Grimsby, J.S. The dynamic plasticity of insulin production in $\beta$-cells. Mol. Metab. 2017, 6, 958-973. [CrossRef] [PubMed] 
231. Stull, A.J.; Cash, K.C.; Johnson, W.D.; Champagne, C.M.; Cefalu, W.T. Bioactives in blueberries improve insulin sensitivity in obese, insulin-resistant men and women. J. Nutr. 2010, 140, 1764-1768. [CrossRef] [PubMed]

232. Anderson, J.W.; Weiter, K.M.; Christian, A.L.; Ritchey, M.B.; Bays, H.E. Raisins compared with other snack effects on glycemia and blood pressure: A randomized, controlled trial. Post-Grad. Med. 2014, 126, 37-43. [CrossRef] [PubMed]

233. Christensen, A.S.; Viggers, L.; Hasselström, K.; Gregersen, S. Effect of fruit restriction on glycemic control in patients with type 2 diabetes-a randomized trial. Nutr. J. 2013, 12, 29. [CrossRef] [PubMed]

234. Silva, F.M.; Kramer, C.K.; de Almeida, J.C.; Steemburgo, T.; Gross, J.L.; Azevedo, M.J. Fiber intake and glycemic control in patients with type 2 diabetes mellitus: A systematic review with meta-analysis of randomized controlled trials. Nutr. Rev. 2013, 71, 790-801. [CrossRef] [PubMed]

235. Post, R.E.; Mainous, A.G.; King, D.E.; Simpson, K.N. Dietary fiber for the treatment of type 2 diabetes mellitus: A meta-Analysis. J. Am. Board Fam. Med. 2012, 25, 16-23. [CrossRef] [PubMed]

236. Xi, P.; Liu, R.H. Whole food approach for type 2 diabetes prevention. Mol. Nutr. Food Res. 2016, 60, 1819-1836. [CrossRef] [PubMed]

237. Weickert, M.O.; Pfeiffer, A.F.H. Impact of dietary fiber consumption on insulin resistance and the prevention of type 2 diabetes. J. Nutr. 2018, 148, 7-12. [CrossRef] [PubMed]

238. McRorie, J.W. Evidence-based approach to fiber supplements and clinically meaningful health benefits, part 2. Nutr. Today 2015, 50, 90-97. [CrossRef] [PubMed]

239. Zhao, L.; Zhang, F.; Ding, X.; Wu, G.; Lam, Y.Y.; Wang, X.; Fu, H.; Lu, C.; Ma, J.; Yu, L.; et al. Gut bacteria selectively promoted by dietary fiber alleviate type 2 diabetes. Science 2018, 359, 1151-1156. [CrossRef] [PubMed]

240. Weitkunat, K.; Schumann, S.; Nickel, D.; Hornemann, S.; Petzke, K.J.; Schulze, M.B.; Pfeiffer, A.F.; Klaus, S. Odd-chain acids as a biomarker for dietary fiber intake: A novel pathway for endogenous production from propionate. Am. J. Clin. Nutr. 2017, 105, 1544-1551. [CrossRef] [PubMed]

241. Saklayen, M.G. The global epidemic of the metabolic syndrome. Curr. Hypertens. Rep. 2018, 20, 12. [CrossRef] [PubMed]

242. Tian, Y.; Su, L.; Wang, J.; Duan, X.; Jiang, X. Fruit and vegetable consumption and risk of the metabolic syndrome: A meta-analysis. Public Health Nutr. 2018, 21, 756-765. [CrossRef] [PubMed]

243. Zhang, Y.; Zhang, D.-Z. Associations of vegetable and fruit consumption with metabolic syndrome. A meta-analysis of observational studies. Public Health Nutr. 2018, 21, 1693-1703. [CrossRef] [PubMed]

244. Yeo, R.; Yoon, S.R.; Kim, O.Y. The association between food group consumption patterns and early metabolic syndrome risk in non-diabetic healthy people. Clin. Nutr. Res. 2017, 6, 172-182. [CrossRef] [PubMed]

245. Basu, A.; Lyons, T.J. Strawberries, Blueberries, and cranberries in the metabolic syndrome: Clinical perspectives. J. Agric. Food Chem. 2011, 60, 5687-5692. [CrossRef] [PubMed]

246. Vendrame, S.; Bo, D.; Ciappellano, S.; Riso, P.; Zacas, D. Berry fruit consumption and metabolic syndrome. Antioxidants (Basel) 2016, 5, 34. [CrossRef] [PubMed]

247. Fulgoni, V.L., III; Dreher, M.; Davenport, A.J. Avocado consumption is associated with better diet quality and nutrient intake, and lower metabolic syndrome risk in US adults: Results from the National Health and Nutrition Examination Survey (NHANES) 2001-2008. Nutr. J. 2013, 12, 1. [CrossRef] [PubMed]

248. Tabeshpour, J.; Razavi, B.M.; Hosseinzadeh, H. Effects of avocado (Persea americana) on metabolic syndrome; a comprehensive systematic review. Phytother. Res. 2017, 31, 819-837. [CrossRef] [PubMed]

249. Fulgoni, V.L., III; Painter, J.; Carughi, A. Association of raisin consumption with nutrient intake, diet quality, and health risk factors in US adults: National Health and Nutrition Examination Survey 2001-2012. Food Nutr. Res. 2017, 61, 1378567. [CrossRef] [PubMed]

250. Esmaillzadeh, A.; Kimiagar, M.; Mehrabi, Y.; Azadbakht, L.; Hu, F.B.; Willett, W.C. Fruit and vegetable intakes, C-reactive protein, and the metabolic syndrome. Am. J. Clin. Nutr. 2006, 84, 1489-1497. [CrossRef] [PubMed]

251. Wei, B.; Liu, Y.; Lin, X.; Fabg, Y.; Cui, J.; Wan, J. Dietary fiber intake and risk of metabolic syndrome: A meta-analysis of observational studies. Clin. Nutr. 2017. [CrossRef] [PubMed]

252. Hosseinpour-Niazi, S.; Mirmiran, P.; Mirzaei, S.; Azizi, F. Cereal, fruit, and vegetable fibre intake and the risk of the metabolic syndrome: A prospective study in the Tehran Lipid and Glucose Study. J. Hum. Nutr. Diet. 2015, 28, 236-245. [CrossRef] [PubMed] 
253. Garcia-Montalvo, I.A.; Mendez Diaz, S.Y.; Aguirre Guzman, M.A.; Sanchez Medina, M.A.; Matias Perez, D.; Perez Campos, E. Increasing consumption of dietary fiber complementary to the treatment of metabolic syndrome. Nutr. Hosp. 2018, 35, 582-587. [CrossRef] [PubMed]

254. Sekgala, M.D.; Mchiza, Z.J.; Parker, W.; Monyeki, K.D. Dietary fiber intake and metabolic syndrome risk factors among young South African adults. Nutrients 2018, 10, 504. [CrossRef] [PubMed]

255. Chen, J.-P.; Chen, G.-C.; Wang, X.-P.; Qin, L.; Bai, Y. Dietary fiber and metabolic syndrome: A meta-analysis and review of related mechanisms. Nutrients 2018, 10, 24. [CrossRef] [PubMed]

256. Behrens, G.; Gredner, T.; Stock, C.; Leitzmann, M.F.; Brenner, H.; Mons, U. Cancers due to excess weight, low physical activity, and unhealthy diet. Dtsch. Arztebl. Int. 2018, 115, 578-585. [CrossRef] [PubMed]

257. Kushi, L.H.; Doyle, C.; McCullough, M.; Rock, C.L.; Demark-Wahnefried, W.; Bandera, E.V.; Gapstur, S.; Patel, A.V.; Andrews, K.; Gansler, T. American Cancer Society Guidelines on nutrition and physical activity for cancer prevention: Reducing the risk of cancer with healthy food choices and physical activity. CA Cancer J. Clin. 2012, 62, 30-67. [CrossRef] [PubMed]

258. World Cancer Research Fund/American Institute for Cancer Research. Food, Nutrition, Physical Activity, and the Prevention of Colorectal Cancer. Continuous Update Project Report. 2011. Available online: http:/ / www.aicr.org/continuousupdate-project/reports/Colorectal-Cancer-2011-Report.pdf (accessed on 27 July 2018).

259. World Cancer Research Fund/American Institute for Cancer Research expert Report. Food, Nutrition, Physical Activity, and the Prevention of Cancer: A Global Perspective. 2007, pp. 280-288. Available online: www.aicr.org/assets/docs/pdf/reports/Second_Expert_Report.pdf (accessed on 5 August 2018).

260. Aune, D.; Lau, R.; Chan, D.S.M.; Vieira, R.; Greenwood, D.C.; Kampman, E.; Norat, T. Nonlinear reduction in risk for colorectal cancer by fruit and vegetable intake based on meta-analysis of prospective studies. Gastroenterology 2011, 141, 106-118. [CrossRef] [PubMed]

261. Bradbury, K.E.; Appleby, P.N.; Key, T.J. Fruit, vegetable, and fiber intake in relation to cancer risk: Findings from the European Prospective Investigation into Cancer and Nutrition (EPIC). Am. J. Clin. Nutr. 2014, 100 (Suppl. 1), 394S-398S. [CrossRef] [PubMed]

262. Vogtmann, E.; Xiang, Y.-B.; Li, H.-L.; Levitan, E.B.; Yang, G.; Waterbor, J.W.; Gao, J.; Cai, H.; Wu, Q.J.; et al. Fruit and vegetable intake and the risk of colorectal cancer: Results from the Shanghai Men's Health Study. Cancer Causes Control 2013, 24, 1935-1945. [CrossRef] [PubMed]

263. Schwingshackl, L.; Schwedhelm, C.; Hoffmann, G.; Knuppel, S.; Laure Preterre, A.; Iqbal, K.; Bechthold, A.; De Henauw, S.; Michels, N.; Devleeschauwer, B.; et al. Food groups and risk of colorectal cancer. Int. J.Cancer 2018, 142, 1748-1758. [CrossRef] [PubMed]

264. Fabiani, R.; Minelli, L.; Rosignoli, P. Apple intake and cancer risk: A systematic review and meta-analysis of observational studies. Public Health Nutr. 2016, 19, 2603-2617. [CrossRef] [PubMed]

265. Vulcan, A.; Brandstedt, J.; Manjer, J.; Jirdtrom, K.; Ohlsson, B.; Ericson, U. Fibre intake and incident colorectal cancer depending on fibre source, sex, tumour location and tumour, node, metastasis stage. Br. J. Nutr. 2015, 114, 959-969. [CrossRef] [PubMed]

266. Gianfredi, V.; Salvatori, T.; Villarini, M.; Moretti, M.; Nucci, D.; Realdon, S. dietary fibre truly protective against colon cancer? A systematic review and meta-analysis. Int. J. Food Sci. Nutr. 2018,, 1-12. [CrossRef] [PubMed]

267. Ben, Q.; Sun, Y.; Chai, R.; Qian, A.; Xu, B.; Yuan, Y. Dietary fiber intake reduces risk for colorectal adenoma: Meta-analysis. Gastroenterology 2014, 146, 689-699. [CrossRef] [PubMed]

268. Ben, Q.; Zhong, J.; Liu, J.; Wang, L.; Sun, Y.L.; Yuan, Y. Association between consumption of fruits and vegetables and risk of colorectal adenoma A PRISMA-Compliant meta-analysis of observational studies. Medicine 2015, 94, 1-12. [CrossRef] [PubMed]

269. Sansbury, L.B.; Wanke, K.; Albert, P.S.; Kahle, L.; Schatzkin, A.; Lanza, E. The effect of strict adherence to a high-fiber, high-fruit and -vegetable, and low-fat eating pattern on adenoma recurrence. Am. J. Epidem. 2009, 170, 576-584. [CrossRef] [PubMed]

270. Kunzmann, A.T.; Coleman, H.G.; Huang, W.-Y.; Cantwell, M.M.; Kitharn, C.M.; Berndt, S.I. Fruit and vegetable intakes and risk of colorectal cancer and incident and recurrent adenomas in the PLCO cancer screening trial. Int. J. Cancer 2016, 138, 1851-1861. [CrossRef] [PubMed]

271. Song, M.; Wu, K.; Meyerhardt, J.A.; Ogino, S.; Wang, M.; Fuchs, C.S.; Giovannucci, E.L.; Chan, A.T. Fiber intake and survival after colorectal cancer diagnosis. JAMA Oncol. 2018, 4, 71-79. [CrossRef] [PubMed] 
272. Chen, J.; Vitetta, L. Inflammatory-modulating effect of butyrate in the prevention of colon cancer by dietary fiber. Clin. Color. Cancer 2018. [CrossRef] [PubMed]

273. O'Keeffe, L.M.; Taylor, G.; Huxley, R.R.; Mitchell, P.; Woodward, M.; Petters, S.A.E. Smoking as a risk factor for lung cancer in women and men: A systematic review and meta-analysis. BMJ Open 2018, 8, e021611. [CrossRef]

274. Wang, Y.; Li, F.; Wang, Z.; Qiu, T.; Shen, Y.; Wang, M. Fruit and vegetable consumption and risk of lung cancer: Dose response meta-analysis of prospective cohort studies. Lung Cancer 2015, 88, 124-130. [CrossRef] [PubMed]

275. Wang, M.; Qin, S.; Zhang, T.; Song, X.; Zhang, S. The effect of fruit and vegetable intake on the development of lung cancer: A meta-analysis of 32 publications and 20,414 cases. Eur. J. Clin. Nutr. 2015, 69, 1184-1192. [CrossRef] [PubMed]

276. Vieira, A.R.; Abar, L.; Vingeliene, S.; Chan, D.S.; Aune, D.; Navarro-Rosenblatt, D.; Steven, C.; Greenwood, D.; Norat, T. Fruits, vegetables and lung cancer risk: A systematic review and meta-analysis. Ann. Oncol. 2016, 27, 81-96. [CrossRef] [PubMed]

277. Nomura, S.J.O.; Dash, C.; Rosenberg, L.; Palmer, J.; Adams-Campbell, L.L. Fruit and vegetable intake and lung cancer incidence among black women according to cigarette smoking status. Nutr. Cancer 2018. [CrossRef] [PubMed]

278. Milte, C.M.; McNaughton, S.A. Dietary patterns and successful ageing; a systematic review. Eur. J. Nutr. 2016, 55, 423-450. [CrossRef] [PubMed]

279. Assmann, K.E.; Lassale, C.; Andreeva, V.A.; Jeandel, C.; Hercberg, S.; Galan, P.; Kesse-Guyot, E. A healthy dietary pattern at midlife, combined with a regulated energy intake, is related to increased odds for healthy aging. J. Nutr. 2015, 145, 2139-2145. [CrossRef] [PubMed]

280. Myint, P.K.; Welch, A.A.; Bingham, S.A.; Surtees, P.G.; Wainwright, N.W.; Luben, R.N.; Wareham, N.J.; Smith, R.D.; Harvey, I.M.; Day, N.E.; Khaw, K.T. Fruit and vegetable consumption and self-reported functional health in men and women in the European Prospective Investigation into Cancer-Norfolk (EPIC-Norfolk): A population based cross-sectional study. Public Health Nutr. 2007, 10, 34-41. [CrossRef] [PubMed]

281. Hodge, A.M.; O’Dea, K.; English, D.R.; Giles, G.G.; Flicker, L. Dietary patterns as predictors of successful ageing. J. Nutr. Health Aging 2014, 18, 221-227. [CrossRef] [PubMed]

282. Gopinath, B.; Russell, J.; Kifley, A.; Flood, V.M.; Mitchell, P. Adherence to Dietary Guidelines and Successful Aging over 10 Years. J. Gerontol. A Biol. Sci. Med. Sci. 2016, 71, 349-355. [CrossRef] [PubMed]

283. Gopinath, B.; Flood, V.M.; Kifley, A.; Louie, J.C.; Mitchell, P. Association between carbohydrate nutrition and successful aging over 10 years. J. Gerontol. A Biol. Sci. Med. Sci. 2016, 71, 1335-1340. [CrossRef] [PubMed]

284. Hu, D.; Huang, J.; Wang, Y.; Zhang, D.; Qu, Y. Fruits and vegetables consumption and risk of stroke. A meta-analysis of prospective cohort studies. Stroke 2014, 45, 1613-1619. [CrossRef] [PubMed]

285. Aune, D.; Giovannucci, E.; Boffetta, P.; Fadnes, L.T.; Keum, N.; Norat, T.; Greenwood, D.C.; Riboli, E.; Vatten, L.J.; Tonstad, S. Fruit and vegetable intake and the risk of cardiovascular disease, total cancer and all-cause mortality-a systematic review and dose response meta-analysis of prospective studies. Int. J. Epidemiol. 2017, 1-28. [CrossRef] [PubMed]

286. Buil-Cosiales, P.; Zazpe, I.; Toledo, E.; Corella, D.; Salas-Salvado, J.; Diez-Espino, J.; Ros, E.; Fernandez-Creuet Navajas, J.; Santos-Lozano, J.M.; Aros, F. Fiber intake and all-cause mortality in the Prevencion con Dieta Mediterranea (PREDIMED) study. Am. J. Clin. Nutr. 2014, 100, 1498-1507. [CrossRef] [PubMed]

287. Root, M.M.; McGinn, M.C.; Nieman, D.C.; Henson, D.A.; Heinz, S.A.; Shanely, R.A.; Knab, A.M.; Jin, F. Combined fruit and vegetable intake is correlated with improved inflammatory and oxidant status from a cross-sectional study in a community setting. Nutrients 2012, 4, 29-41. [CrossRef] [PubMed]

288. Kim, S.; Rimando, J.; Sandler, D.P. Fruit and vegetable intake and urinary levels of prostaglandin E2 metabolite in postmenopausal women. Nutr. Cancer 2015, 67, 580-586. [CrossRef] [PubMed]

289. Abdullah, M.M.; Gyles, C.L.; Marinangeli, C.P.; Carlberg, J.G.; Jones, P.J. Cost-of-illness analysis reveals potential healthcare savings with reductions in type 2 diabetes and cardiovascular disease following recommended intakes of dietary fiber in Canada. Front. Pharmacol. 2015, 6, 167. [CrossRef] [PubMed]

290. Fellet, M. Increasing Healthspan: Tissue engineering and medicinal chemistry for aging bodies and brains. ACS Chem. Life 2017, 1, 1-33.

291. Tucker, L.A. Dietary fiber and telomere length in 5674 U.S. adults: An NHANES study of biological aging. Nutrients 2018, 10, 400. [CrossRef] [PubMed] 
292. Garcia-Calzon, S.; Gea, A.; Razquin, C.; Corella, D.; Lamuela-Raventos, R.M.; Martinez, J.A.; Martinez-Gonzalez, M.A.; Zalba, G.; Marti, A. Longitudinal association of telomere length and obesity indices in an intervention study with a Mediterranean diet: The PREDIMED-NAVARRA trial. Int. J. Obesity 2014, 38, 177-182. [CrossRef] [PubMed]

293. García-Calzón, S.; Zalba, G.; Ruiz-Canela, M.; Shivappa, N.; Hebert, J.R.; Martinez, J.A.; Fito, M.; Gomez-Gracia, E.; Martinez-Gonzalez, M.A.; Marti, A. Dietary inflammatory index and telomere length in subjects with a high cardiovascular disease risk from the PREDIMED-NAVARRA study: Cross-sectional and longitudinal analyses over 5 y. Am. J. Clin. Nutr. 2015, 102, 897-904. [CrossRef] [PubMed]

294. Nicodemus-Johnson, J.; Sinnott, R.A. Fruit and juice epigenetic signatures are associated with independent immunoregulatory pathways. Nutrients 2017, 9, 752. [CrossRef] [PubMed]

295. Keenan, M.J.; Marco, M.L.; Ingram, D.K.; Martin, R.J. Improving healthspan via changes in gut microbiota and fermentation. Age 2015, 37, 98. [CrossRef] [PubMed]

296. Hosseini, B.; Berthon, B.S.; Wark, P.; Wood, LG. Effects of fruit and vegetable consumption on risk of asthma, wheezing and immune responses: A systematic review and meta-analysis. Nutrients 2017, 9, 41. [CrossRef] [PubMed]

297. Bakolis, I.; Hooper, R.; Bachert, C.; Lange, B.; Haahtela, T.; Keil, T.; Hofmaier, S.; Fokkens, S.; Rymarczyk, B.; Janson, C. Dietary patterns and respiratory health in adults from nine European countries-Evidence from the GA ${ }^{2}$ LEN study. Clin. Exp. Allergy 2018. [CrossRef] [PubMed]

298. Garcia-Larsen, V.; Del Giacco, S.R.; Moreira, A.; Bonini, M.; Charles, D.; Reeves, T.; Carlsen, K.H.; Haahtela, T.; Bonini, S.; Fonseca, J.; et al. Asthma and dietary intake: An overview of systematic reviews. Allergy 2016, 71, 433-442. [CrossRef] [PubMed]

299. Willers, S.M.; Wijga, A.H.; Brunekreef, B.; Scholtens, S.; Postma, D.S.; Kerkhof, M.; de Jongste, J.C.; Smit, H.A. Childhood diet and asthma and atopy at 8 years of age: The PIAMA birth cohort study. Eur. Respir. J. 2011, 37, 1060-1067. [CrossRef] [PubMed]

300. Mendes, A.P.; Zhang, L.; Prietsch, S.O.; Franco, O.S.; Gonzales, K.P.; Fabris, A.G.; Catharino, A. Factors associated with asthma severity in children: A case control study. J. Asthma 2011, 48, 235-240. [CrossRef] [PubMed]

301. Barros, R.; Moreira, A.; Fonseca, J.; de Oliveira, J.F.; Delgado, L.; Castel-Branco, M.G.; Haahtela, T.; Lopes, C.; Moreira, P. Adherence to the Mediterranean diet and fresh fruit intake is associated with improved asthma control. Allergy 2008, 63, 917-923. [CrossRef] [PubMed]

302. Seyedrezazadeh, E.; Moghaddam, M.P.; Ansarin, K.; Vafa, M.R.; Sharma, S.; Kolahdooz, F. Fruit and vegetable intake and risk of wheezing and asthma: A systematic review and meta-analysis. Nutr. Rev. 2014, 72, 411-428. [CrossRef] [PubMed]

303. Ma, J.; Strub, P.; Lv, N.; Xiao, L.; Camargo, C.A; Buist, A.S.; Lavori, P.W.; Wilson, S.R.; Nadeau, K.C.; Rosas, L.G. Pilot randomised trial of a healthy eating behavioural intervention in uncontrolled asthma. Eur. Respir. J. 2016, 47, 122-132. [CrossRef] [PubMed]

304. Cepeda, A.M.; Thawer, S.; Boyle, R.J.; Villalba, S.; Jaller, R.; Tapias, E.; Segura, A.M.; Villegas, R.; Garcia-Larsen, V. Diet and respiratory health in children from 11 Latin American countries: Evidence from ISAAC Phase III. Lung 2017, 195, 683-692. [CrossRef] [PubMed]

305. Hosseini, B.; Berthon, B.S.; Saedisomeolia, A.; Starkey, M.R.; Collison, A.; Wark, P.A.B.; Wood, L.G. Effects of fruit and vegetable consumption on inflammatory biomarkers and immune cell populations: A systematic literature review and meta-analysis. Am. J. Clin. Nutr. 2018, 108, 136-155. [CrossRef] [PubMed]

306. Statovci, D.; Aguilera, M.; MacSharry, J.; Melgar, S. The impact of Western diet and nutrients on the microbiota and immune response at mucosal interfaces. Front. Immunol. 2017, 8, 838. [CrossRef] [PubMed]

307. Berthon, B.S.; Macdonald-Wicks, L.K.; Gibson, P.G.; Wood, L.G. Investigation of the association between dietary intake, disease severity and airway inflammation in asthma. Respirology 2013, 18, 447-454. [CrossRef] [PubMed]

308. Folkerts, J.; Stadhouders, R.; Redegeld, F.A.; Tam, S.Y.; Hendriks, R.W.; Galli, S.J.; Maurer, M. Effect of dietary fiber and metabolites on mast cell activation and mast cell-associated diseases. Front. Immunol. 2018, 9, 1067. [CrossRef] [PubMed] 
309. Cuello-Garcia, C.; Fiocchi, A.; Pawankar, R.; Yepes-Nuez, J.J.; Morgano, G.P.; Zhang, Y.; Agarwal, A.; Gandhi, S.; Terracciano, L.; Schunemann, H.J.; et al. Prebiotics for the prevention of allergies: A systematic review and meta-analysis of randomized controlled trials. Clin. Exp. Allergy 2017, 47, 1468-1477. [CrossRef] [PubMed]

310. Adeloye, D.; Chua, S.; Lee, C.; Basquill, C.; Papana, A.; Theodoratou, E.; Nair, H.; Gasevic, D.; Sridhar, D.; Campbell, H.; et al. Global and reginal estimates of COPD prevalence: Systematic review and meta-analysis. J. Glob. Health 2015, 5, 020415. [CrossRef] [PubMed]

311. Salvi, S. Tobacco smoking and environmental risk factors for chronic obstructive pulmonary disease. Clin. Chest Med. 2014, 35, 17-27. [CrossRef] [PubMed]

312. Steinemann, N.; Grize, L.; Pons, M.; Rothe, T.; Stolz, D.; Turk, A.; Schindler, C.; Brombach, C.; Probst-Hensch, N. Associations between dietary patterns and post-bronchodilation lung function in the SAPALDIA Cohort. Respiration 2018. [CrossRef] [PubMed]

313. Brigham, E.P.; Steffen, L.M.; London, S.J.; Boyce, D.; Diette, G.B.; Hansel, N.N.; Rice, J.; McCormack, M.C. Diet pattern and respiratory morbidity in the Atherosclerosis Risk in Communities Study. Ann. Am. Thorac. Soc. 2018, 15, 675-682. [CrossRef] [PubMed]

314. Kaluza, J.; Larsson, S.C.; Orsini, N.; Linden, A.; Wolk, A. Fruit and vegetable consumption and risk of COPD: A prospective cohort study of men. Thorax 2017, 72, 500-509. [CrossRef] [PubMed]

315. Kaluza, J.; Harris, H.R.; Linden, A.; Wolk, A. Long-term consumption of fruits and vegetables and risk of chronic obstructive pulmonary disease: A prospective cohort study of women. Int. J. Epidemiol. 2018. [CrossRef] [PubMed]

316. Hanson, C.; Lyden, E.; Rennard, S.; Mannino, D.M.; Rutten, E.P.; Hopkins, R.; Young, R. The relationship between dietary fiber intake and lung function in the National Health and Nutrition Examination Surveys. Ann. Am. Thorac. Soc. 2016, 13, 643-650. [CrossRef] [PubMed]

317. Kaluza, J.; Harris, H.; Wallin, A.; Linden, A.; Wolk, A. Dietary fiber intake and risk of chronic obstructive pulmonary disease: A prospective cohort study of men. Epidemiology 2018, 29, 254-260. [CrossRef] [PubMed]

318. Young, R.P.; Hopkins, R.J.; Marsland, B. The gut-liver-lung axis. Modulation of the innate immune response and its possible role in chronic obstruction pulmonary disease. Am. J. Respir. Cell Mol. Biol. 2016, 54, 161-169. [CrossRef] [PubMed]

319. Kim, Y.K.; Shin, C. The microbiota-gut brain axis in neuropsychiatric disorders: Pathophysiological mechanisms and novel treatments. Curr. Neuropharmacol. 2018, 16, 559-573. [CrossRef] [PubMed]

320. Taylor, A.M.; Holscher, H.D. A review of dietary and microbial connections to depression, anxiety, and stress. Nutr. Neurosci. 2018, 9, 1-14. [CrossRef] [PubMed]

321. Nguyen, B.; Ding, D.; Mihrshahi, S. Fruit and vegetable consumption and psychological distress: Cross sectional and longitudinal analyses based on a large Australian sample. BMJ Open 2017, 7, e014201. [CrossRef] [PubMed]

322. Lai, J.S.; Hiles, S.; Bisquera, A.; Hure, A.J.; McEvoy, M.; Attia, J. A systematic review and meta-analysis of dietary patterns and depression in community-dwelling adults. Am. J. Clin. Nutr. 2014, 99, 181-197. [CrossRef] [PubMed]

323. Goyal, M.S.; Iannotti, L.; Raichle, M.E. Brain nutrition: A life span approach. Annu. Rev. Nutr. 2018, 38, 17-19. [CrossRef] [PubMed]

324. Bolduc, F.V.; Lau, A.; Rosenfelt, C.S.; Langer, S.; Wang, N.; Smithson, L.; Letebvre, D.; Alexander, T.; Dickson, C.T.; Li, L.; et al. Cognitive enhancement in infants associated with increased maternal fruit intake during pregnancy: Result from a birth cohort study with validation in an animal model. EBioMedicine 2016, 8, 331-340. [CrossRef] [PubMed]

325. Renzaho, A.M.N.; Kumanyika, S.; Tucker, K.L. Family functioning, parental psychological distress, child behavioural problems, socio-economic disadvantage and fruit and vegetable consumption among 4-12-year-old Victorians, Australia. Health Promot. Int. 2010, 26, 263-275. [CrossRef] [PubMed]

326. Oddy, W.H.; Robinson, M.; Ambrosini, G.L.; O'Sullivan, T.A.; de Klerk, N.H.; Beilin, L.J.; Silburn, S.R.; Zubrick, S.R.; Stanley, F.J. The association between dietary patterns and mental health in early adolescence. Prev. Med. 2009, 49, 39-44. [CrossRef] [PubMed]

327. Meegan, A.P.; Perry, I.J.; Phillips, C.M. The association between dietary quality and dietary guideline adherence with mental health outcomes in adults: A cross-sectional analysis. Nutrients 2017, 9, 238. [CrossRef] [PubMed] 
328. Brookie, K.L.; Best, G.I.; Conner, T.S. Intake of raw fruits and vegetables is associated with better mental health than intake of processed fruits and vegetables. Front. Psychol. 2018, 9, 487. [CrossRef] [PubMed]

329. Mujcic, R.; Oswald, A.J. Evolution of well-being and happiness after increases in consumption of fruit and vegetables. Am. J. Public Heal. 2016, 106, 1504-1510. [CrossRef] [PubMed]

330. Conner, T.S.; Brookie, K.L.; Richardson, A.C.; Polak, M.A. On carrots and curiosity: Eating fruit and vegetables is associated with greater flourishing in daily life. Br. J. Health Psychol. 2015, 20, 413-427. [CrossRef] [PubMed]

331. Conner, T.S.; Thompson, L.M.; Knight, R.L.; Flett, J.A.; Richardson, A.C.; Brookie, K.L. The role of personality traits in young adult fruit and vegetable consumption. Front. Psychol. 2017, 8, 119. [CrossRef] [PubMed]

332. Conner, T.S.; Brookie, K.L.; Carr, A.C.; Mainvil, L.A.; Vissers, M.C. Let them eat fruit! The effect of fruit and vegetable consumption on psychological well-being in young adults: A randomized controlled trial. PLoS ONE 2017, 12, e0171206. [CrossRef] [PubMed]

333. Saghafian, F.; Malmir, H.; Saneei, P.; Keshteli, A.H.; Hosseinzadeh-Attar, M.J.; Afshar, H.; Siassi, F.; Esmaillzadeh, A.; Adubi, P. Consumption of fruit and vegetables in relation with psychological disorders in Iranian adults. Eur. J. Nutr. 2018. [CrossRef] [PubMed]

334. Saghafian, F.; Malmir, H.; Saneei, P.; Milajerdi, A.; Larijani, B. Esmaillzadeh, A. Fruit and vegetable consumption and risk of depression: Accumulative evidence from an updated systematic review and meta-analysis of epidemiological studies. Br. J. Nutr. 2018, 119, 1087-1101. [CrossRef] [PubMed]

335. Kingsbury, M.; Dupuis, G.; Jacka, F.; Roy-Gagnon, M.H.; McMartin, S.E.; Colman, I. Associations between fruit and vegetable consumption and depressive symptoms: Evidence from a national Canadian longitudinal survey. J. Epidemiol. Community Heal. 2016, 70, 155-161. [CrossRef] [PubMed]

336. Miki, T.; Eguchi, M.; Kurotani, K.; Kochi, T.; Kuwahara, K.; Ito, R.; Kimura, Y.; Tsuruoka, H.; Akter, S.; Kashino, I. et al.; et al. Dietary fiber intake and depressive symptoms in Japanese employees: The Furukawa Nutrition and Health Study. Nutrition 2016, 32, 584-589. [CrossRef] [PubMed]

337. Xu, H.; Li, S.; Song, X.; Li, Z.; Zhang, D. Exploration of the association between dietary fiber intake and depressive symptoms in adults. Nutrition 2018, 54, 48-53. [CrossRef] [PubMed]

338. Steptoe, A.; Easterlin, E.; Kirschbaum, C. Conscientious, hair cortisol concentration, and health behaviour in older men and women. Psychoneuroendocrinology 2017, 86, 122-127. [CrossRef] [PubMed]

339. Whisner, C.M.; Castillo, L.F. Prebiotic, bone and mineral metabolism. Calcif. Tissue Int. 2018, 102, $443-479$. [CrossRef] [PubMed]

340. Berger, C.; Langsetmo, L.; Joseph, L.; Hanley, D.A.; Davison, K.S.; Josse, R.; Kreiger, N.; Tenenhouse, A.; Goltzman, D. Change in bone mineral density as a function of age in women and men and association with use of antiresorptive agents. CMAJ 2008, 178, 1660-1668. [CrossRef] [PubMed]

341. Lucas, S.; Omata, Y.; Hofmann, J.; Bottcher, M.; IIjazovic, A.; Starter, K.; Albrecht, O.; Schulz, O.; Krishnacoumar, B.; Kronke, G.; et al. Short-chain fatty acids regulate systemic bone mass and protect from pathological bone loss. Nat. Commun. 2018, 9, 55. [CrossRef] [PubMed]

342. McGartland, C.P.; Robson, P.J.; Murray, L.J.; Cran, G.W.; Savage, M.J.; Watkins, D.C.; Rooney, M.M.; Boreham, C.A. Fruit and vegetable consumption and bone mineral density: The Northern Ireland Young Hearts Project. Am. J. Clin. Nutr. 2004, 80, 1019-1023. [CrossRef] [PubMed]

343. Prynne, C.J.; Mishra, G.D.; O'Connell, M.A.; Muniz, G.; Laskey, M.A.; Yan, L.; Prentice, A.; Ginty, F. Fruit and vegetable intakes and bone mineral status: A cross-sectional study in 5 age and sex cohorts. Am. J. Clin. Nutr. 2006, 83, 1420-1428. [CrossRef] [PubMed]

344. Dai, Z.; Zhang, Y.; Lu, N.; Felson, D.T.; Kiel, D.P.; Sahni, S. J. Association between dietary fiber intake and bone loss in the Framingham Offspring Study. J. Bone Min. Res. 2018, 33, 241-249. [CrossRef] [PubMed]

345. Qiu, R.; Cao, W.-T.; Tian, H.-Y.; He, J.; Chen, G.D.; Ghen, Y.M. Greater intake of fruit and vegetables is associated with greater bone mineral density and lower osteoporosis risk in middle-aged and elderly adults. PLoS ONE 2017, 12, e0168906. [CrossRef] [PubMed]

346. Li, J.-J.; Huang, Z.-W.; Wang, R.-Q.; ma, X.M.; Zhang, Z.Q.; Liu, Z.; Chen, Y.M.; Su, Y.X. Fruit and vegetable intake and bone mass in Chinese adolescents, young and postmenopausal women. Public Health Nutr. 2012, 16, 78-86. [CrossRef] [PubMed]

347. Hooshmand, S.; Chai, S.C.; Saadat, R.L.; Payton, M.E.; Brummel-Smith, K.; Arjmandi, B.H. Comparative effects of dried plum and dried apple on bone in postmenopausal women. Br. J. Nutr. 2011, 106, 923-930. [CrossRef] [PubMed] 
348. Hooshmand, S.; Kern, M.; Metti, D.; Shamloufard, P.; Chai, S.C.; Johnson, S.A.; Payton, M.E.; Arjmandi, B.H. The effect of two doses of dried plum on bone density and bone biomarkers in osteopenic postmenopausal women: A randomized, controlled trial. Osteoporos Int. 2016, 27, 2271-2279. [CrossRef] [PubMed]

349. Sanders, M.G.H.; Pardo, L.M.; Ginger, R.S.; Kiefte-de Jong, K.C; Nijsten, T. Association between diet and seborrheic dermatitis: A cross-sectional study. J. Investig. Dermatol. 2018. [CrossRef] [PubMed]

350. Pascal, M.; Perez-Gordo, M.; Caballero, T.; Escribese, M.M.; Lopez Longo, M.N; Luengo, O.; Manso, L.; Mateu, V.; Seoane, E.; Zamorano, M.; et al. Microbiome and allergic disease. Front. Immunol, 2018, 9, 1584. [CrossRef] [PubMed]

351. Grimaldi, R.; Cela, D.; Swann, J.R.; Vulevic, J.; Gibson, G.R.; Tzortzis, G.; Costabile, A. In vitro fermentation of B-GOS: Impact of faecal bacterial populations and metabolic activity in autistic and non-autistic children. FEMS Microbiol. Ecol. 2017, 93, fiw233. [CrossRef] [PubMed]

352. Sanctuary, M.R.; Kain, J.N.; Angkustsiri, K.; German, J.B. Dietary considerations in autism spectrum disorders: The potential role of protein digestion and microbial putrefaction in the gut-brain axis. Front. Nutr. 2018, 5, 40. [CrossRef] [PubMed]

353. Berding, K.; Donovan, S.M. Diet can impact microbiota composition in children with autism spectrum disorder. Front. Neurosci. 2018. [CrossRef]

354. Sharp, W.G.; Postorino, V.; McCracken, C.E.; Berry, R.C.; Criado, K.K.; Burrell, T.L; Scahill, L. Dietary intake, nutrient status, and growth parameters in children with autism spectrum disorder and severe food sensitivity: An electronic medical record review. J. Acad. Nutr. Diet. 2018, 118, 1943-1950. [CrossRef] [PubMed]

355. Grimaldi, R.; Gibson, G.R.; Vulevic, J.; Giallourou, N.; Castro-Mejia, J.L.; Hansen, L.H.; Leigh Gibson, E.; Nielsen, D.S.; Costabile, A. A prebiotic intervention study in children with autism spectrum disorders (ASDs). Microbiome 2018, 6, 133. [CrossRef] [PubMed]

356. Saavedra, M.J.; Aziz, J.; Cacchiarelli San Roman, N. Scurvy due to restrictive diet in a child with autism spectrum disorder: Case report. Arch. Argent. Pediatr. 2018, 116, e684-e687. [CrossRef] [PubMed]

(C) 2018 by the author. Licensee MDPI, Basel, Switzerland. This article is an open access article distributed under the terms and conditions of the Creative Commons Attribution (CC BY) license (http:// creativecommons.org/licenses/by/4.0/). 